\author{
UNIVERSIDADE DE SÃO PAULO \\ INSTITUTO DE QUÍMICA DE SÃO CARLOS \\ INSTITUTO DE FÍSICA DE SÃO CARLOS \\ ESCOLA DE ENGENHARIA DE SÃO CARLOS
}

GABRIELA BELINATO

ESTUDO DA OXIDAÇÃO DOS ÓLEOS DE SOJA E DENDÊ ADITIVADOS COM ANTIOXIDANTES PARA USO EM TRATAMENTOS TÉRMICOS DE TÊMPERA 
Gabriela Belinato

\section{Estudo da oxidação dos óleos de soja e dendê aditivados com antioxidantes para uso em tratamentos térmicos de têmpera}

Dissertação apresentada ao Programa de Pós-Graduação Interunidades em Ciência e Engenharia de Materiais da Universidade de São Paulo, para obtenção do título de Mestre em Ciência e Engenharia de Materiais.

Área de concentração: Desenvolvimento, Caracterização e Aplicação de Materiais.

Orientador: Profa. Dra. Lauralice de Campos Franceschini Canale. 
AUTORIZO A REPRODUÇÃO E DIVULGAÇÃO TOTAL OU PARCIAL DESTE TRABALHO, POR QUALQUER MEIO CONVENCIONAL OU ELETRÔNICO, PARA FINS DE ESTUDO E PESQUISA, DESDE QUE CITADA A FONTE.

Belinato, Gabriela

Estudo da oxidação dos óleos de soja e dendê aditivados com antioxidantes para uso em tratamentos térmicos de têmpera/ Gabriela Belinato; orientadora Lauralice de Campos Franceschini Canale - São Carlos, 2009.

$119 \mathrm{p}$.

Dissertação (Mestrado - Programa de Pós-Graduação Interunidades em Ciência e Engenharia de Materiais. Área de Concentração: Desenvolvimento, Caracterização e Aplicação de Materiais) - Escola de Engenharia de São Carlos, Instituto de Física de São Carlos, Instituto de Química de São Carlos da Universidade de São Paulo.

1. Óleos vegetais. 2. Tratamento térmico de têmpera. 3. Oxidação. 4. Antioxidantes. I.Título. 


\section{FOLHA DE APROVAÇÃO}

Gabriela Belinato

Dissertação apresentada ao Programa de Pós-Graduação em Ciência e Engenharia de Materiais da Universidade de São Paulo para obtenção do título de Mestre em Ciência e Engenharia de Materiais.

Área de Concentração: Desenvolvimento, Caracterização e Aplicação de Materiais.

Aprovado(a) em: 22/2/2010

\section{Comissão Julgadora}

Prof(a). Dr(a). Lauralice de Campos Franceschini Canale Instituição: EESC/USP Assinatura

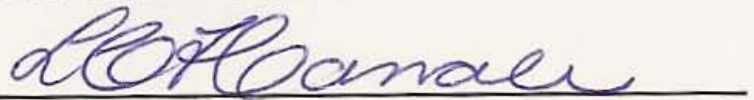

$\operatorname{Prof(a).~} \operatorname{Dr}(a)$. Rafael Agnelli Mesquita

Instituição: UNINOVE/São Paulo

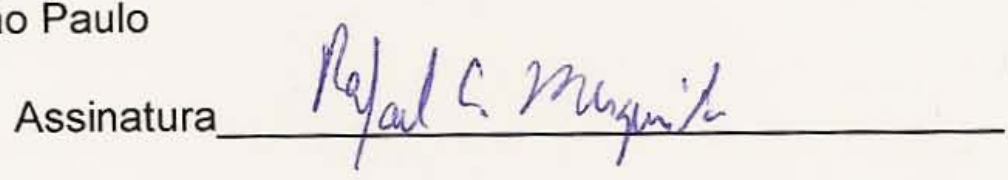

Prof(a). Dr(a). Sylvana Cardoso Miguel Agustinho Instituicão: IQSCIUSP Assinatura bulvawa CM Acuntimbe 



\section{AGRADECIMENTOS}

Em primeiro lugar a Deus, pois sem ele nada seria possível.

A meus pais, Romeu e Maria, que me ajudaram a vencer mais uma batalha: amo vocês.

Ao Gre, meu irmão e amigo.

Ao Bruno que me deu forças quando eu já tinha desistido de lutar: te amo muito.

A Prof. Dra. Lauralice de Campos Franceschini Canale, pela oportunidade e orientação.

Ao Dr. George E. Totten pela grande ajuda durante todo o meu trabalho.

Ao Paulo J. M. Cordeiro, Sylvana C. M. Agustinho, William Capelupi e Renata Leal, pela ajuda nas análises realizadas durante esse trabalho.

Ao Prof. Dr. Sérgio R. Fontes por ceder a infra-estrutura do seu laboratório para as realizações das análises desse trabalho.

As empresas Chemtura e Quimifort por cederem materiais para a realização do trabalho.

Aos funcionários do departamento de Engenharia de Materiais.

Aos colegas do departamento de Engenharia de Materiais.

A CNPq pelo apoio financeiro. 

"O seu caminho tem um coração?"

(Fritjof Capra - O tao da física) 



\section{RESUMO}

BELINATO, Gabriela. Estudo da oxidação dos óleos de soja e dendê aditivados com antioxidantes para uso em tratamentos térmicos de têmpera. 2009, 119 p. Dissertação (Mestrado) - Escola de Engenharia de São Carlos, Instituto de Física de São Carlos, Instituto de Química de São Carlos, Universidade de São Paulo, São Carlos, 2010.

No presente trabalho são relatados os resultados obtidos de ensaios de ressonância magnética nuclear, número de acidez, índice de iodo, índice de saponificação, calorimetria exploratória diferencial com pressão (PDSC), viscosidade e curvas de resfriamento para dois tipos de óleos vegetais, o de soja e o de dendê. Esses ensaios foram efetuados em amostras de óleos "puras" e também em formulações com diferentes antioxidantes em diferentes concentrações em massa. Basicamente duas situações foram avaliadas, a condição "óleo novo" e a condição "óleo oxidado". A condição oxidada foi obtida por meio de ensaios de oxidação acelerada. Uma análise desses resultados permitiu verificar que o óleo de soja foi mais sensível ao envelhecimento (oxidação) e que os aditivos de melhor desempenho foram o Irganox L109 com 5 \% em massa para o óleo de soja e o Galato de Propila com 2 \% em massa para o óleo de dendê.

Palavras chaves: Óleos vegetais. Tratamento térmico de tempera. Oxidação. Antioxidantes. 



\begin{abstract}
BELINATO, Gabriela. Study of the oxidation of soybean and palm oils with different concentrations of anti-oxidant additives for use in the quenchants to heat treatments.119 p. Dissertação (Mestrado) - Escola de Engenharia de São Carlos, Instituto de Física de São Carlos, Instituto de Química de São Carlos, Universidade de São Paulo, São Carlos, 2010.

In the present work are analyzed results from Nuclear Magnetic Resonance, Acid Number, lodine Number, Pressure Differential Scanning Calorimetry, Viscosity and cooling curves obtained from 2 types of vegetable oils: soybean and palm. Such tests were performed in the vegetable oil samples with oxidations inhibitors and without those additives. Basically two conditions were evaluated: as not oxidized (new condition) and as oxidized (used condition). Oxidized condition was made by accelerated oxidized test performed in the different vegetable oil samples. Results show that soybean oil is more sensitive to oxidation than palm oil. Irganox L109 (5 \%) was the better oxidation inhibitor to the soybean oil and Propil Galate (2\%) had better performance as antioxidant to the palm oil.
\end{abstract}

Key-words: Vegetable Oils. Quenchants to heat treatment. Oxidation. Antioxidant. 



\section{LISTA DE FIGURAS}

Figura 1- $\quad$ Evolução da produção de soja no Brasil (6)................................... 26

Figura 2 - $\quad$ Aplicações em potencial do óleo de dendê (adaptado (7)................. 27

Figura 3 - $\quad$ Representação esquemática de um diagrama de transformação isotérmica para um aço SAE 1080 (17)

Figura 4 - Comportamento dos fluidos refrigerantes no processo de têmpera:

a) água, b) óleo

Figura 5 - Curvas de resfriamento (adaptado (9))

Figura 6 - $\quad$ Efeito da temperatura no banho e remoção de calor (9)................... 37

Figura 7 - $\quad$ Etapas do resfriamento com solução salina...................................... 38

Figura 8 - Estruturas dos ácidos graxos que compõem as moléculas de óleos vegetais (30)....

Figura 9 - Processo de oxidação em 3 estágios: iniciação, propagação e terminação.

Figura 10 - Reações de iniciação pela presença de ferro (Fe) e de cobre (Cu) (45)

Figura 11 - Taxa de oxidação relativa devido ao número de duplas ligações nas moléculas (8).....

Figura 12 - Estrutura de hidrocarbonetos aromáticos (52)............................ 50

Figura 13 - Antioxidantes naturais: ácido ascórbico e beta caroteno (52).......... 52

Figura 14 - Antioxidantes sintéticos: a) estrutura molecular do BHA; b) estrutura molecular do ácido cítrico; c) estrutura molecular do BHT; d) estrutura molecular do tercbutil hidroquinona; e) estrutura molecular do galato de propila $(52,59)$.

Figura 15 - Determinação da estabilidade oxidativa (50)................................. 54

Figura 16 - Determinação da capacidade antioxidante (50).............................. 54

Figura 17 - Espectro de RMN de $\mathrm{H}^{1}$ genérico de um óleo vegetal (59).............. 55

Figura 18 - Espectro de RMN de $C^{13}$ genérico de um óleo vegetal (59)............. 56

Figura 19 - Cromatograma do trimethylsilyldiethanolamide polyol, dimetano- 58 amina derivada do óleo de dendê (67) 
Figura 20 - Relação entre superfície de molhamento e ângulo de contato (68)......

Figura 21 - Relação da viscosidade e do ângulo de contato (molhabilidade) na taxa máxima de resfriamento (9)

Figura 22 - Variação da viscosidade de acordo com a temperatura para o óleo de arroz (48).

Figura 23 - Estruturas de: a) Irganox L109, b) Galato de Propila, c) Bisfenol A, d) Difelamina e e) PANA.

Figura 24 - Espectrômetro Bruker, modelo AC-200.

65

Figura 25 - Cromatógrafo a gás GC-17A da marca Shimadzu. 66

Figura 26 - Viscosímetro AVS - 350 da marca Schott-Geräte.

Figura 27 - a) Reômetro Brookifield, b) esquema utilizado para medir a viscosidade das amostras de óleo de dendê: o viscosímetro, banho e software de computador.

Figura 28 - Equipamento de envelhecimento acelerado: a) visto de cima, b) detalhe o agitador, a resistência e o aerador.

Figura 29 - Ilustração do sistema de envelhecimento de óleo (22)........................ 70

Figura 30 - Ilustração da caixa usada no resfriamento do sistema (22)................. 71

Figura 31 - Esquema do equipamento de curvas de resfriamento (adaptado(22)).. 72

Figura 32 - Equipamento para medida de dureza na escala Rockwell C............... 74

Figura 33 - Espectros de RMN H $\mathrm{H}^{1}$ dos óleos de soja e dendê novos e sem aditivos.

Figura 34 - Espectros de RMN $C^{13}$ dos óleos de soja* e dendê novos e sem aditivos.

Figura 35 - Curvas de resfriamento, a $60^{\circ} \mathrm{C}$, relacionando temperatura por tempo para os óleos de soja e dendê, novos e puros.

Figura 36 - Análise de cromatografia gasosa do óleo de dendê.

80

Figura 37 - Viscosidade, a $40{ }^{\circ} \mathrm{C}$, do óleo de soja aditivado com antioxidantes e envelhecido.

Figura 38 - Viscosidade, a $40{ }^{\circ} \mathrm{C}$, do óleo de dendê aditivado com antioxidantes e envelhecido.

Figura 39 - Curvas de resfriamento, a $60^{\circ} \mathrm{C}$, relacionando temperatura por tempo para óleo de soja no estado não oxidado, para todas as formulações.. 
Figura 40 - Curvas de resfriamento, a $60^{\circ} \mathrm{C}$, relacionando temperatura por tempo para óleo de dendê no estado não oxidado, para todas as formulações.

Figura 41 - Curvas de resfriamento, a $60^{\circ} \mathrm{C}$, relacionando temperatura por tempo para o óleo de soja com adição de $1 \%$ de Irganox L109.

Figura 42 - Curvas de resfriamento, a $60{ }^{\circ} \mathrm{C}$, relacionando temperatura por tempo para o óleo de soja com adição de $3 \%$ de Irganox L109.

Figura 43 - Curvas de resfriamento, a $60^{\circ} \mathrm{C}$, relacionando temperatura por tempo para o óleo de soja com adição de $5 \%$ de Irganox L109.

Figura 44 - Curvas de resfriamento, a $60{ }^{\circ} \mathrm{C}$, relacionando temperatura por tempo para o óleo de soja com adição de $1 \%$ de Galato de Propila.

Figura 45 - Curvas de resfriamento, a $60^{\circ} \mathrm{C}$, relacionando temperatura por tempo para o óleo de soja com adição de $2 \%$ de Galato de Propila.

Figura 46 - Curvas de resfriamento, a $60^{\circ} \mathrm{C}$, relacionando temperatura por tempo para o óleo de soja com adição de $3 \%$ de Galato de Propila.

Figura 47 - Curvas de resfriamento, a $60^{\circ} \mathrm{C}$, relacionando temperatura por tempo para o óleo de soja com adição de $1 \%$ de PANA

Figura 48 - Curvas de resfriamento, a $60^{\circ} \mathrm{C}$, relacionando temperatura por tempo para o óleo de soja com adição de $1 \%$ de Bisfenol A

Figura 49 - Curvas de resfriamento, a $60^{\circ} \mathrm{C}$, relacionando temperatura por tempo para o óleo de soja com adição de 1\% de Difenilamina......

Figura 50 - Curvas de resfriamento, a $60{ }^{\circ} \mathrm{C}$, relacionando temperatura por tempo para o óleo de dendê com adição de $1 \%$ de Irganox L109.

Figura 51 - Curvas de resfriamento, a $60{ }^{\circ} \mathrm{C}$, relacionando temperatura por tempo para o óleo de dendê com adição de $3 \%$ de Irganox L109.

Figura 52 - Curvas de resfriamento, a $60{ }^{\circ} \mathrm{C}$, relacionando temperatura por tempo para o óleo de dendê com adição de $5 \%$ de Irganox L109. 
Figura 53 - Curvas de resfriamento, a $60^{\circ} \mathrm{C}$, relacionando temperatura por tempo para o óleo de dendê com adição de $1 \%$ de Galato de Propila.

Figura 54 - Curvas de resfriamento, a $60^{\circ} \mathrm{C}$, relacionando temperatura por tempo para o óleo de dendê com adição de $2 \%$ de Galato de Propila.

Figura 55 - Curvas de resfriamento, a $60{ }^{\circ} \mathrm{C}$, relacionando temperatura por tempo para o óleo de dendê com adição de $3 \%$ de Galato de Propila.

Figura 56 - Curvas de resfriamento, a $60^{\circ} \mathrm{C}$, relacionando temperatura por tempo para os óleos vegetais e minerais utilizados na têmpera

Figura 57 - Dureza Rockwell C, na superfície, centro e superfície, das amostras de aço AISI 1045 com $1 / 2$ ".

Figura 58 - Dureza Rockwell C, na superfície, centro e superfície, das amostras de aço AISI 4140 com 1 "

Figura 59 - Dureza Rockwell C, na superfície, centro e superfície, das amostras de aço AISI4140 com $2 \frac{1}{1 / 2} "$.....

Figura 60 - Micrografia do aço AISI 1045 com 1/2 ", resfriado com óleo de soja $+5 \%$ L109

Figura 61 - Micrografia do aço AISI 1045 com 1/2 ", resfriado com óleo de dendê + 2\% GP.

Figura 62 - Micrografia do aço AISI4140 com 1 " , resfriado com óleo de dendê + 2\% GP.

Figura 63 - Micrografia do aço AISI 4140 com 1 " , resfriado com óleo mineral 2 .

Figura 64 - Micrografia do aço AISI 4140 com 2 1/2 ", resfriado com óleo de soja 5 \% L109.

Figura 65 - Micrografia do aço AISI 4140 com 2 1/2 ", resfriado com óleo de dendê + 2 \% GP. 


\section{LISTA DE TABELAS}

Tabela 1 Produção mundial anual de óleos e gorduras (toneladas/ano) (8)......

Tabela 2 Composição relativa aos ácidos graxos em diferentes óleos vegetais.

Tabela 3 Quantidade biodegradada para diferentes tipos de fluidos.

Tabela 4 Composição e valores teóricos de DI, para as ligas AISI 1045 e AISI 4140 .

Tabela $5 \quad$ RMN de $\mathrm{H}^{1}$ dos óleos vegetais novos e puros................................. 75

Tabela $6 \quad$ RMN de $C^{13}$ dos óleos vegetais novos e puros.............................. 76

Tabela 7 Índices de iodo, acidez e saponificação dos óleos vegetais............... 76

Tabela $8 \quad$ Viscosidade dos óleos vegetais novos e puros a $40^{\circ} \mathrm{C} \ldots \ldots \ldots \ldots \ldots \ldots . . . . . . . . . .77$

Tabela 9 Temperatura de OOT para os óleos de soja e dendê, novos e puros, taxa de aquecimento $10^{\circ} \mathrm{C} / \mathrm{min}$ até $220^{\circ} \mathrm{C}$

Tabela 10 Tempo de oOt para os óleos de soja e dendê, novos e puros, taxa de aquecimento $10^{\circ} \mathrm{C} / \mathrm{min}$ até $220^{\circ} \mathrm{C}$.

Tabela 11 Comparação entre o tempo de resfriamento dos óleos de soja e dendê, novos e puros.

Tabela 12 Porcentagem de ácidos graxos contidos no óleo de dendê.....

Tabela 13 Temperatura de OOT para os óleos de soja aditivados com Irganox L109, sem oxidação, taxa de aquecimento $10^{\circ} \mathrm{C} / \mathrm{min}$ até $220^{\circ} \mathrm{C}$

Tabela 14 Tempo de OOt para os óleos de soja aditivados com Irganox L109, sem oxidação, taxa de aquecimento $10^{\circ} \mathrm{C} / \mathrm{min}$ até $220^{\circ} \mathrm{C}$

Tabela 15 Temperatura de OOT para os óleos de dendê aditivados com Irganox L109, sem oxidação, taxa de aquecimento $10^{\circ} \mathrm{C} / \mathrm{min}$ até 220 ${ }^{\circ} \mathrm{C}$

Tabela 16 Tempo de OOt para os óleos de dendê aditivados com Irganox L109, sem oxidação, taxa de aquecimento $10^{\circ} \mathrm{C} / \mathrm{min}$ até $220^{\circ} \mathrm{C}$ 
Tabela 17 Temperatura de OOT para os óleos de soja aditivados com Galato de Propila, sem oxidação, taxa de aquecimento $10^{\circ} \mathrm{C} / \mathrm{min}$ até $220^{\circ} \mathrm{C}$

Tabela 18 Tempo de OOt para os óleos de soja aditivados com Galato de Propila, sem oxidação, taxa de aquecimento $10^{\circ} \mathrm{C} / \mathrm{min}$ até $220^{\circ} \mathrm{C} \ldots .$.

Tabela 19 Temperatura de OOT para os óleos de dendê aditivados com Galato de Propila, sem oxidação, taxa de aquecimento $10^{\circ} \mathrm{C} / \mathrm{min}$ até $220{ }^{\circ} \mathrm{C}$

Tabela 20 Tempo de OOt para os óleos de dendê aditivados com Galato de Propila, sem oxidação, taxa de aquecimento $10^{\circ} \mathrm{C} / \mathrm{min}$ até 220 ${ }^{\circ} \mathrm{C}$

Tabela 21 Comparação entre o tempo de resfriamento dos óleos de soja puro e com todas as formulações, sem oxidação

Tabela 22 Comparação entre o tempo de resfriamento dos óleos de dendê puro e com todas as formulações, sem oxidação.

Tabela 23 Comparação entre o tempo de resfriamento dos óleos de soja aditivados com 1\% L109 em todos os tempos de envelhecimento....

Tabela 24 Comparação entre o tempo de resfriamento dos óleos de soja aditivados com 3\% L109 em todos os tempos de envelhecimento....

Tabela 25 Comparação entre o tempo de resfriamento dos óleos de soja aditivados com 5\% L109 em todos os tempos de envelhecimento....

Tabela 26 Comparação entre o tempo de resfriamento dos óleos de soja aditivados com 1\% GP em todos os tempos de envelhecimento.......

Tabela 27 Comparação entre o tempo de resfriamento dos óleos de soja aditivados com $2 \%$ GP em todos os tempos de envelhecimento.

Tabela 28 Comparação entre o tempo de resfriamento dos óleos de soja aditivados com $3 \%$ GP em todos os tempos de envelhecimento.......

Tabela 29 Comparação entre o tempo de resfriamento dos óleos de soja aditivados com 1\% PANA em todos os tempos de envelhecimento..

Tabela 30 Comparação entre o tempo de resfriamento dos óleos de soja aditivados com 1\% Bisfenol $\mathrm{A}$ em todos os tempos de envelhecimento.

Tabela 31 Comparação entre o tempo de resfriamento dos óleos de soja aditivados com 1\% Difenilamina em todos os tempos de envelhecimento.

Tabela 32 Comparação entre o tempo de resfriamento dos óleos de dendê aditivados com 1\% L109 em todos os tempos de envelhecimento.... 
Tabela 33 Comparação entre o tempo de resfriamento dos óleos de dendê aditivados com 3\% L109 em todos os tempos de envelhecimento.... 96

Tabela 34 Comparação entre o tempo de resfriamento dos óleos de dendê aditivados com 5\% L109 em todos os tempos de envelhecimento.... 97

Tabela 35 Comparação entre o tempo de resfriamento dos óleos de dendê aditivados com 1\% GP em todos os tempos de envelhecimento....... 97

Tabela 36 Comparação entre o tempo de resfriamento dos óleos de dendê aditivados com 2\% GP em todos os tempos de envelhecimento.

Tabela 37 Comparação entre o tempo de resfriamento dos óleos de dendê aditivados com 3\% GP em todos os tempos de envelhecimento

Tabela 38 Comparação entre o tempo de resfriamento dos óleos vegetais e minerais, utilizados na têmpera.

Tabela 39 Dureza Rockwell C dos aços temperados com os óleos vegetais e óleos minerais 



\section{LISTA DE ABREVIATURAS E SIGLAS}

$\begin{array}{ll}\text { ABNT } & \text { Associação Brasileira de Normas Técnicas } \\ \text { ACR } & \text { Poliacrilato de Sódio } \\ \text { AISI } & \text { American Iron and Steel Institute } \\ \text { BHA } & \text { Butil Hidroxi Anisol } \\ \text { BHT } & \text { Butil Hidroxi Tolueno } \\ \text { C } & \text { Carbono } \\ \text { C }^{13} & \text { Carbono-13 } \\ \text { CO2 } & \text { Dióxido de Carbono } \\ \text { Cu } & \text { Cobre } \\ \text { DI } & \text { Diâmetro Ideal } \\ \text { DSC } & \text { Differential Scanning Calorimetry } \\ \text { ETOX } & \text { Etoxiquina } \\ \text { Fe } & \text { Ferro } \\ \text { Fe }{ }_{3} C & \text { Cementita } \\ \text { FID } & \text { Flame Ionization Detector } \\ \text { GC } & \text { Gas Chromatography } \\ \text { GP } & \text { Galato de Propila } \\ \mathrm{H}^{1} & \text { Hidrogênio-1 } \\ \text { HRC } & \text { Dureza Rockwell C } \\ \text { ISO } & \text { Internationa Organization for Standardization } \\ \text { L109 } & \text { Irganox L109 } \\ \text { 1O } & \text { Oxigênio singleto } \\ \text { OIt } & \text { Oxidation Induction Time } \\ \text { OIT } & \text { Oxidation Induction Temperature } \\ \text { OOt } & \text { Onset Oxidation Time } \\ \text { OOT } & \text { Onset Oxidation Temperature } \\ \text { PAG } & \text { Poli Alquileno Glicol } \\ \text { PAO } & \text { Polialfaolefinas } \\ \text { PDSC } & \text { Pressure Differential Scanning Calorimetry } \\ \text { PIB } & \text { Poliisobutileno } \\ \text { PVA } & \text { Polivinílico } \\ \text { PVP } & \text { Poili Vinil Pirolidone } \\ \text { RMN } & \text { Ressonância Magnética Nuclear } \\ \text { RBOT } & \text { Rotating Bomb Oxidation Test } \\ \text { SAE } & \text { Society of Automotive Engineers } \\ \text { TBHQ } & \text { Terbutil Hidroxi Quinona } \\ \text { TTT } & \text { Tempo Temperatura Transformação } \\ \text { USP } & \text { Universidade de São Paulo } \\ \text { UV } & \text { Ultravioleta } \\ & \end{array}$





\section{SUMÁRIO}

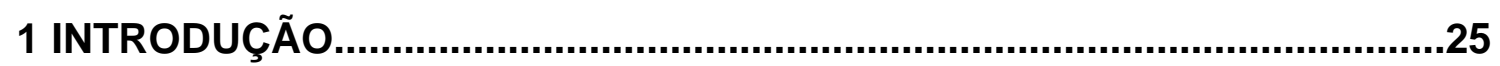

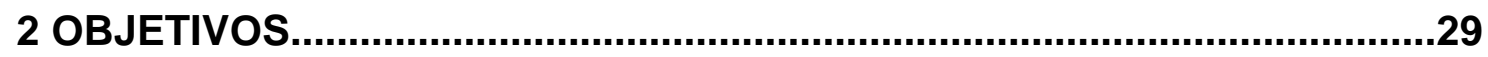

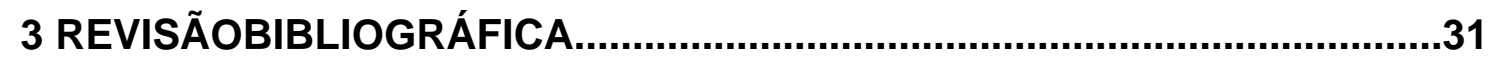

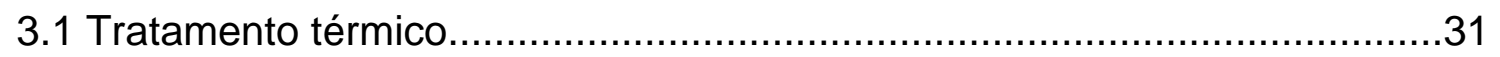

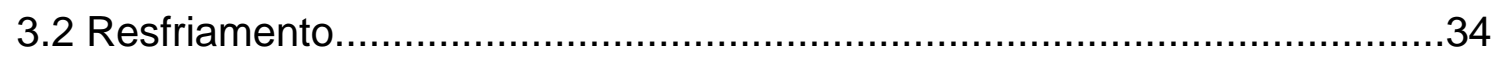

3.2.1 Meios Líquidos de Resfriamento na Têmpera........................................36

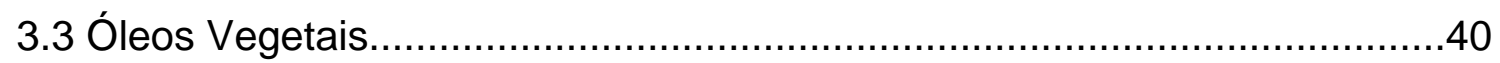

3.3.1 Características dos Óleos Vegetais......................................................

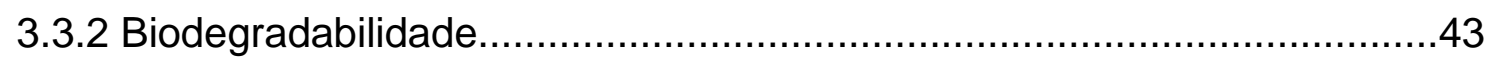

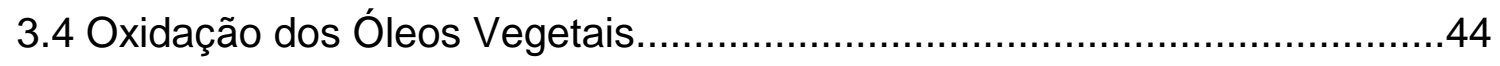

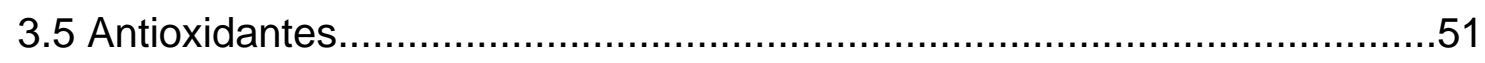

3.6 Ensaios de Caracterização dos Óleos Vegetais........................................55

3.6.1 Ressonância Magnética Nuclear (RMN) ..................................................55

3.6.2 Calorimetria Exploratória Diferencial com Pressão (PDSC).....................57

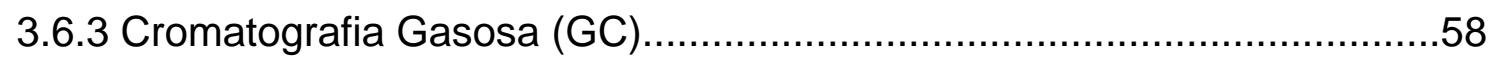

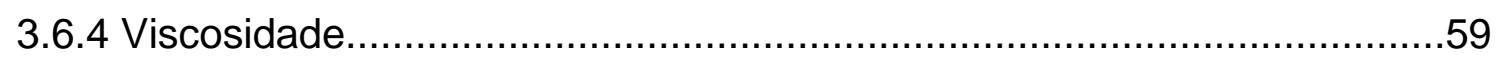

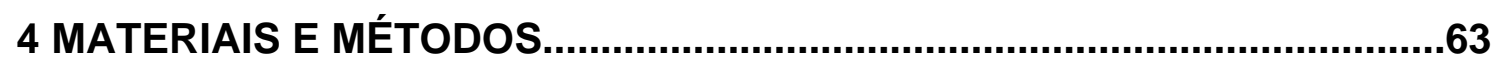

4.1 Amostras dos Óleos e Estruturas dos Antioxidantes.................................63

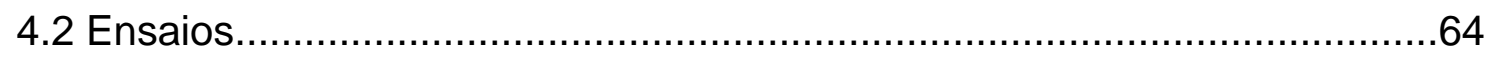

4.2.1 Ressonância Magnética Nuclear.........................................................64

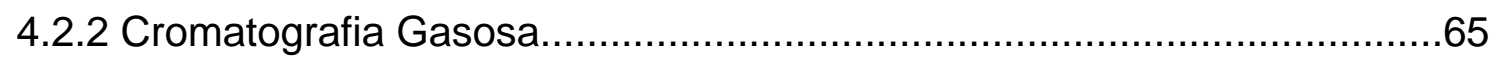

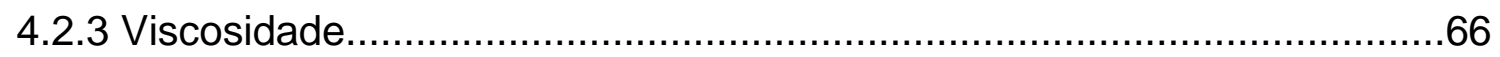

4.2.4 Calorimetria Exploratória Diferencial com Pressão.....................................68 
4.2.5 Ensaio de Envelhecimento Acelerado..........................................69

4.2.6 Curvas de Resfriamento...............................................................

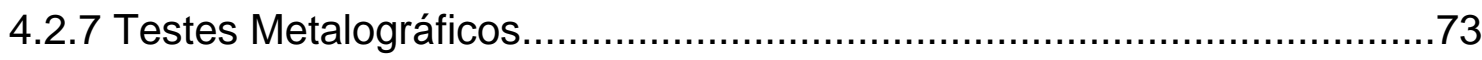

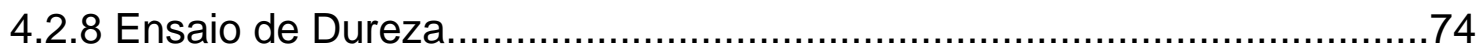

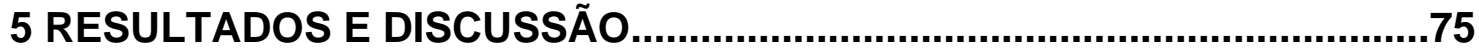

5.1 Análise Físico - Química dos Óleos Vegetais Novos e Puros.....................75

5.2 Análise Físico - Química dos Óleos Vegetais com Antioxidantes...............80

5.3 Comparação entre os Óleos Utilizados na Têmpera...............................99

5.4 Análise da Dureza e Estrutura das Peças Metálicas Temperadas............101

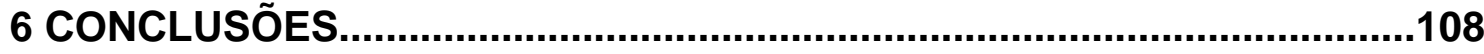

7 SUGESTÕES PARA TRABALHOS FUTUROS......................................110

REFERÊNCIAS...........................................................................................112 


\section{INTRODUÇÃO}

As propriedades dos aços e ligas metálicas podem variar dependendo da sua composição e microestruturas que podem ser modificadas por tratamento térmico. $\mathrm{O}$ tratamento térmico é uma das principais etapas de processo de fabricação, pois permite adequar as propriedades finais específicas na utilização dos materiais metálicos para uma dada aplicação.

Tratamento térmico é o processo de aquecimento de uma peça metálica por um determinado tempo em uma temperatura adequada e por fim um resfriamento em meio conveniente, com o objetivo de modificar a microestrutura e alterar as propriedades mecânicas da peça.

Dentre os diversos tipos de tratamentos térmicos, pode-se citar o tratamento térmico de têmpera que consiste no endurecimento do aço por meio de resfriamento rápido da peça metálica que está no estado austenítico. Para que essa transformação ocorra é necessário que a extração de calor da peça seja feita de maneira rápida. A velocidade de resfriamento é específica para cada aço e depende, também, da capacidade de extração de calor do meio utilizado. É possível também variar a velocidade de resfriamento do meio, modificando-se a temperatura do banho de resfriamento e o grau de agitação.

Entre os meios de resfriamento mais utilizados, o óleo mineral é o que possui as melhores características para a retirada de calor no processo de têmpera, por isso ele é amplamente utilizado como tal fluido, sendo o controle das propriedades e características dos óleos de têmpera uma das grandes preocupações dos fabricantes, pois afetam diretamente as características e propriedades das peças que passaram pelo processo.

Embora tenham sido ao longo dos anos, o meio mais comumente usado como base para formulações de fluidos industriais, ele vem também sendo responsabilizado por parte dos problemas ambientais (1). Além disso, o óleo mineral é uma mistura altamente complexa cujas composições, biodegradabilidade e toxicidade variam de acordo com a fonte do óleo cru (2). Por exemplo, os óleos hidráulicos têm sido identificados como um potencial meio de contaminação da água do subterrâneo (3). Possui, também, a desvantagem de ser derivado de uma fonte 
não renovável. Tais preocupações têm levado a um esforço global para encontrar fluido alternativo com reduzidos impactos ambientais e toxicológicos (4).

Atualmente os óleos vegetais são mundialmente estudados para tal finalidade, principalmente pelas vantagens que os mesmos proporcionam sob o ponto de vista ambiental, por serem biodegradáveis e oriundos de fontes renováveis, sendo o particular interesse dependente da quantidade da produção local de grãos. Por exemplo, o Brasil tem mostrado interesse nos estudos sobre o comportamento do óleo de soja como base para fluidos industriais tanto para resfriamento quanto para a lubrificação, não apenas por ser uma base vegetal biodegradável, vindas de fonte renovável, mas também, pelo fato de ser a soja responsável por 95\% de toda produção de óleo de semente no país. Estudos têm mostrado que esses óleos têm exibido excelente desempenho em várias aplicações comerciais (5). Porém, a sua instabilidade à oxidação e a sua estreita faixa de viscosidade, são os principais obstáculos no uso dos mesmos como meio de tratamento térmico. A Figura 1 mostra que a soja é a principal cultura no Brasil desde a década de 90.

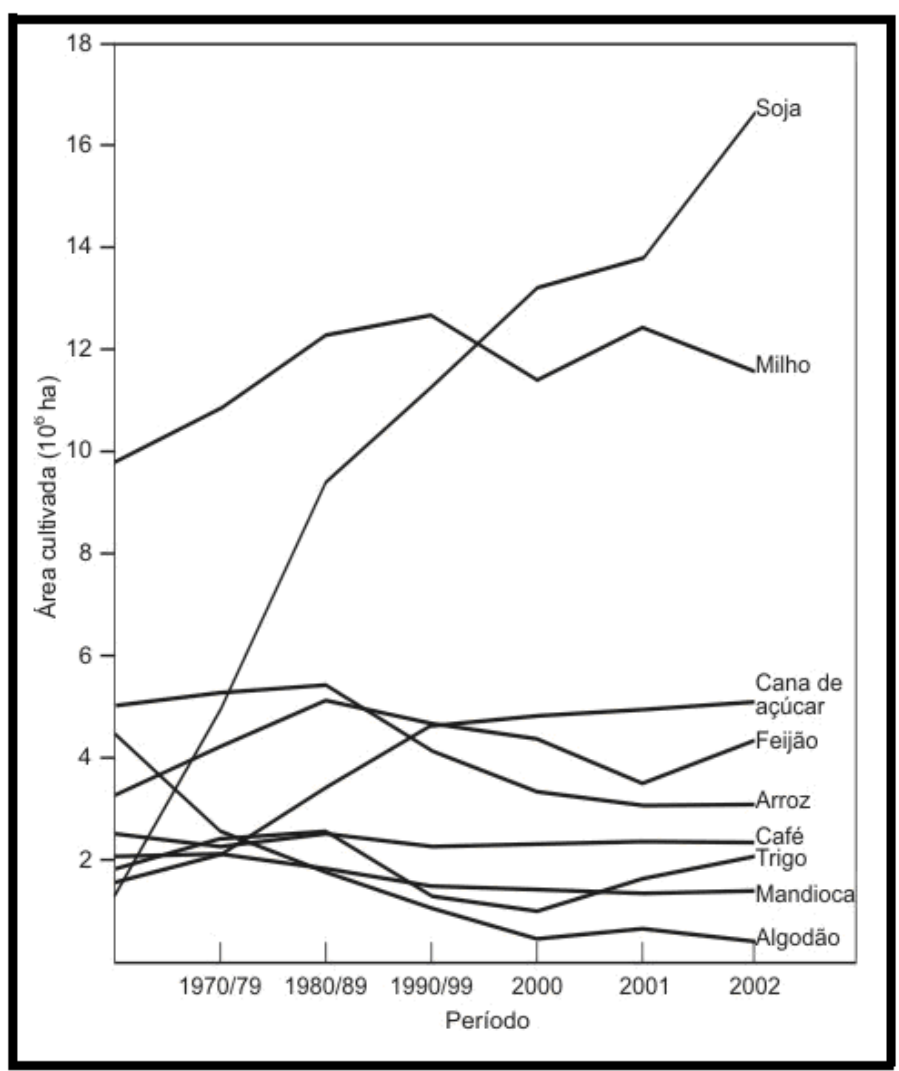

Figura 1 - Evolução da produção de soja no Brasil (6).

O óleo de dendê, ou palma, ocupa uma posição de destaque no mercado mundial. Atualmente é o segundo mais produzido atrás apenas do óleo de soja. Sua 
utilização é principalmente voltada para culinária, mas estudos mostram que o dendê possui grande potencial de aplicação em diversos outros produtos, como mostra a Figura 2.

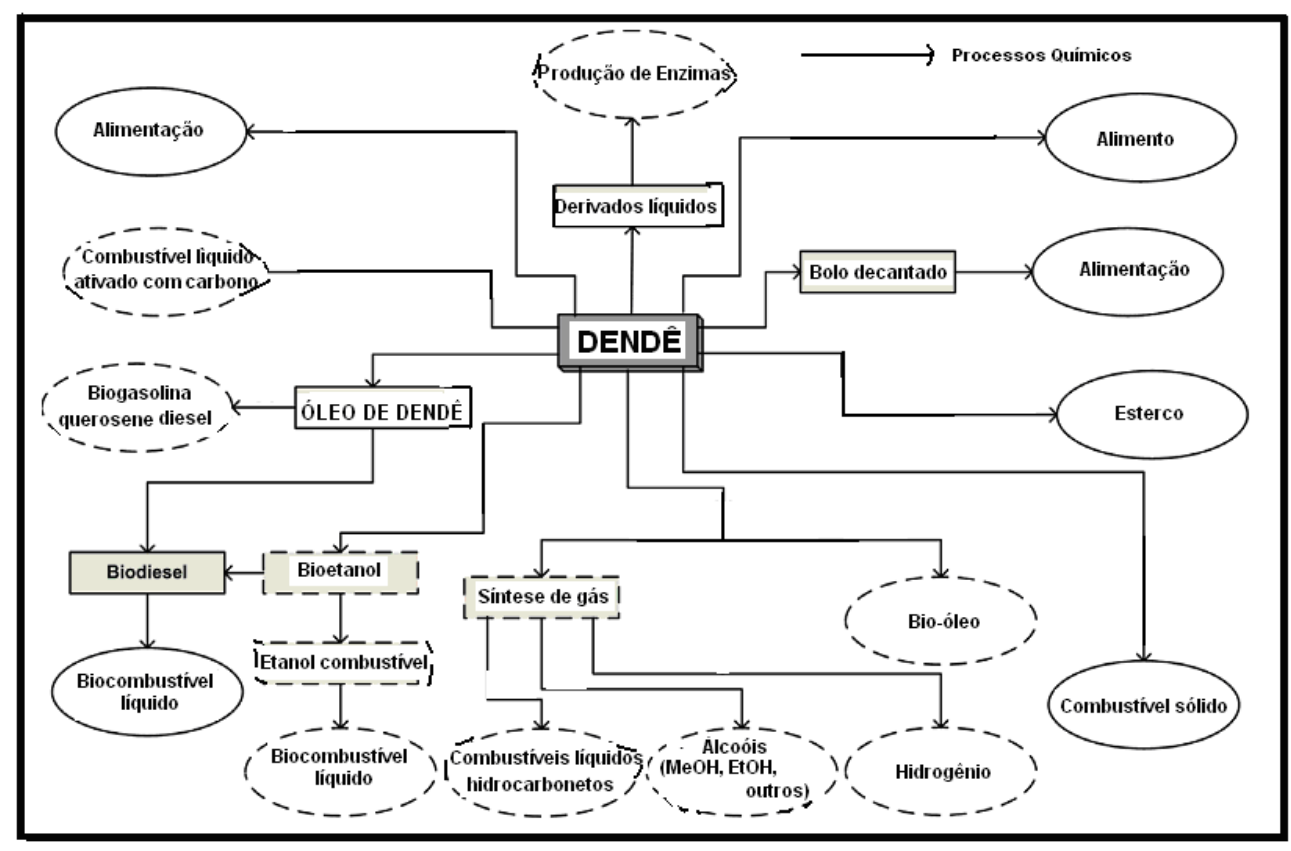

Figura 2 - Aplicações em potencial do óleo de dendê (adaptado (7)).

No Brasil a produção de dendê equivale a 0,1\% da mundial, estimada em 25 milhões de toneladas (6). A Tabela 1 apresenta a produção mundial de óleos e gorduras com estimativa até o ano de 2020.

Tabela 1 - Produção mundial anual de óleos e gorduras (toneladas/ano) (8).

\begin{tabular}{cccc}
\hline Óleo & $1976-1980$ & $1996-2000$ & $2016-2020$ \\
\hline Total mundial & 52,6 & 103,5 & 175,8 \\
Soja & 11,2 & 22,9 & 37,1 \\
Dendê & 4,2 & 20,2 & 45,8 \\
Canola/ Girassol & 7,2 & 21,7 & 38,8 \\
\hline
\end{tabular}

Neste contexto este trabalho é proposto, pretendendo contribuir no fornecimento de informações para a produção de um produto comercial para tratamento térmico, por meio do estudo do comportamento dos antioxidantes nos óleos vegetais. 


\section{OBJETIVOS}

Estudar as características e o comportamento dos óleos de soja e dendê e sua utilização como meios de resfriamento de têmpera. Realizar ensaios para a avaliação do comportamento físico e físico-químico, essenciais na caracterização dos óleos de têmpera.

Estudar o comportamento dos óleos novos e após processo de oxidação acelerado os comparado aos óleos de base mineral.

Estudar os óleos vegetais e a sua aditivação a partir de antioxidantes biodegradáveis de maneira a sugerir uma composição de fluido de resfriamento para uso em tratamento térmico.

Avaliar o desempenho das melhores composições por meios de ensaios mecânicos (dureza) e metalúrgicos (microestruturas). 


\section{REVISÃO BIBLIOGRÁFICA}

\subsection{Tratamento Térmico}

Tratamento térmico é o conjunto de ações como aquecimento e resfriamento, controlados por temperatura, tempo e velocidade de resfriamento, que tem como objetivo alterar as propriedades e características do material.

A têmpera é o tratamento térmico mais utilizado em aços. Trata-se de um processo de aquecimento a uma temperatura tal que a sua estrutura se torne totalmente austenítica, seguido de um resfriamento rápido para que se forme uma nova estrutura, mais frágil, denominada martensita. Após isso o material passa por um revenido para ter suas propriedades de tenacidade melhoradas.

Algumas características dos aços, como o grau de dureza e resistência obtidos após a têmpera dependem de uma outra característica chamada temperabilidade que está relacionada diretamente com a sua facilidade de endurecimento (suscetibilidade de desenvolver estrutura martensítica) e também, com a taxa de resfriamento do meio refrigerante utilizado $(9,10)$.

Os três meios refrigerantes mais utilizados pelas indústrias de tratamentos térmicos de têmpera são: a água, o óleo e o ar (11). Soluções de polímeros também vêm sendo utilizadas como uma alternativa para os óleos e a água, sendo o poli alquileno glicol (PAG), o poli vinil pirolidone (PVP) e o poli acrilato de sódio os mais aplicados na preparação de soluções aquosas utilizadas como meio de têmpera (12). Os óleos apresentam intensidade de resfriamento inferior em relação a certas concentrações de soluções de polímeros, mesmo assim são considerados "insubstituíveis" no tratamento térmico de muitos produtos de engenharia. Uma vantagem é que eles proporcionam menores níveis de distorções na peça temperada, pois diminui o gradiente de temperatura entre a superfície e o centro da peça, o que é importante, principalmente em peças de formato complicado e secções irregulares $(13,14)$. Isso justifica a sua grande utilização como meio de resfriamento, aproximadamente $80 \%$ dos meios de resfriamento utilizados mundialmente (15). 
Os diagramas Tempo - Temperatura - Transformação (TTT) são base para a escolha do meio de resfriamento, pois permitem verificar as estruturas formadas, num determinado ciclo de tempo e transformação e, com isso, as propriedades obtidas. Esses diagramas são construídos através de resfriamentos contínuos ou isotérmicos.

Estes diagramas não fornecem dados quantitativos de temperabilidade, pois são construídos para análise dos constituintes e/ou fases que são produzidos nas temperaturas intermediárias durante o resfriamento (16).

A Figura 3 apresenta o diagrama de resfriamento isotérmico de um aço eutetóide (SAE 1080). A área compreendida entre as curvas vermelha e verde representa a região de transformação para produtos da austenita, que se formam pelo processo difusional, onde ocorre nucleação e crescimento. As linhas horizontais Mi e Mf marcam o início e o fim da região de transformação do constituinte martensita que se forma pelo processo de cisalhamento. Além disso, observa-se na região à direita da curva verde, e também, na região entre as curvas vermelha e verde a presença da estrutura perlita e bainita. A perlita consiste em uma estrutura lamelar composta por ferrita $\alpha$ (solução sólida de carbono em ferro na estrutura cúbica de corpo centrado, estável a temperarura ambiente) e cementita ( $\left.\mathrm{Fe}_{3} \mathrm{C}\right)$. Já a bainita é constituída, também, por ferrita $\alpha$ e cementita $\left(\mathrm{Fe}_{3} \mathrm{C}\right)$, porém pode ser encontrada na forma de agulhas semelhantes às da martensita, sendo encontrada, indistintamente, nas microestruturas resultantes das transformações isotérmicas ou contínuas. 


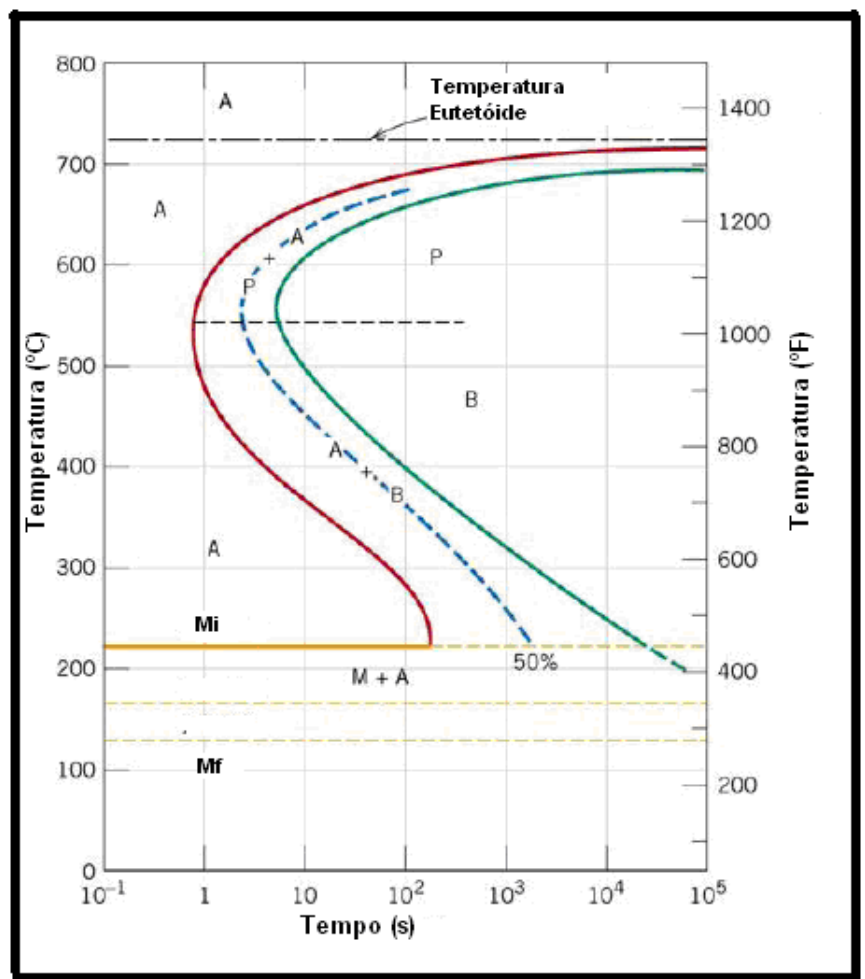

Figura 3 - Representação esquemática de um diagrama de transformação isotérmica para um aço SAE 1080 (17).

Assim, dependendo das condições de resfriamento impostas ao componente de aço, estruturas outras que não a de máxima dureza (martensita), irão se formar.

A dureza final da peça é maior quando a capacidade de extração de calor do meio de resfriamento é alta. Mas, grandes velocidades, proporcionadas por meios com alta capacidade de resfriamento, podem prejudicar as dimensões e formas finais das peças, pois levam ao aparecimento de trincas e distorções dos componentes.

Deve-se então levar em conta, a capacidade de endurecimento do aço, medida pela temperabilidade, para que a dureza final não seja ameaçada, independentemente das formas e dimensões da peça.

Há diversas maneiras de se quantificar a temperabilidade de um aço, sendo o ensaio Jominy a mais utilizada. Esse ensaio é realizado segundo a norma ASTM A 255, (18). Este ensaio também pode ser utilizado para avaliação de meios de resfriamento.

Há também cálculos teóricos para a avaliação da temperabilidade, expressos pelo valor de diâmetro ideal (DI). Esses cálculos são feitos baseados no tamanho de grão e na composição da liga utilizada, (19). O DI é o diâmetro onde, sob condições 
ideais de têmpera, uma barra metálica tem em seu centro $50 \%$ de estrutura martensita e a superfície é temperada numa taxa infinitamente rápida (20).

\subsection{Resfriamento}

A análise da velocidade de resfriamento é um dos parâmetros mais importantes para verificar o desempenho de um fluido de têmpera. Os mecanismos de resfriamento em meios fluidos são facilmente compreendidos através da análise das chamadas "curvas de resfriamento". As curvas de resfriamento mostram os vários mecanismos de resfriamento que ocorrem durante o processo de têmpera (21). O resfriamento ocorre geralmente em três etapas diferentes, cada uma com características distintas, como mostra a figura 4. As características dessas etapas são diferentes para os diversos meios de resfriamento.

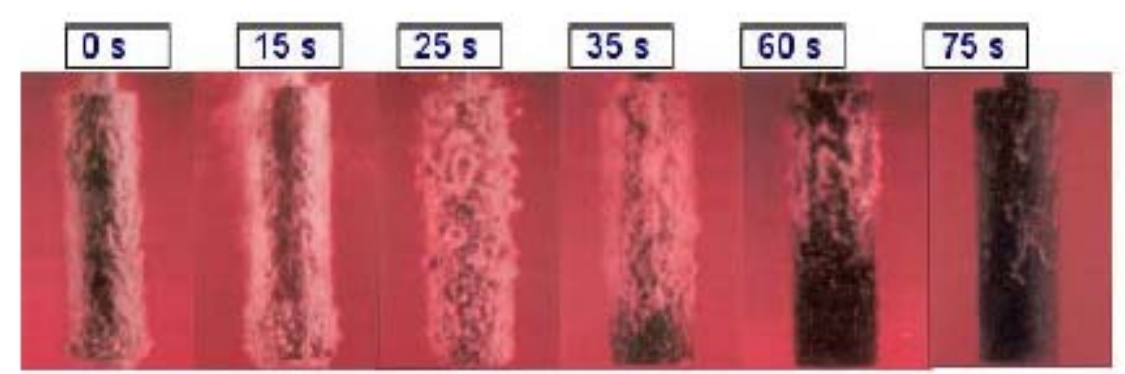

(a) - Evolução da têmpera em água.

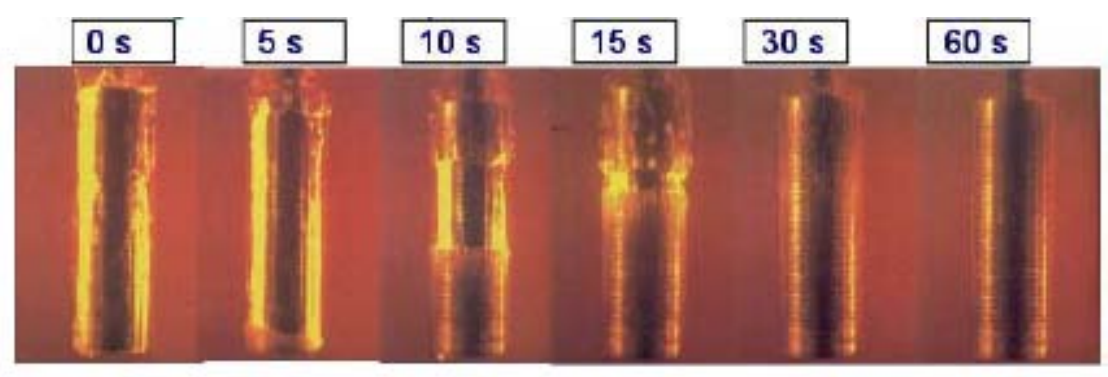

(b) - Evolução da têmpera em óleo.

Figura 4 - Comportamento dos fluidos refrigerantes no processo de têmpera: a) água, b) óleo.

No primeiro estágio forma-se a "camada de vapor", devido o contato do metal aquecido com o meio líquido essa camada de vapor e envolve o metal rapidamente, agindo como isolante térmico. Por isso o resfriamento nesse estagio é lento, e o 
processo de extração de calor pelo meio acontece através de radiação do calor, (22). O primeiro estagio não ocorre quando o meio de resfriamento é uma solução aquosa de solutos não voláteis com $5 \%$ de concentração e, neste caso, as curvas de resfriamento começam no segundo estágio (9).

O segundo estágio é chamado de "nucleação de bolhas" é onde se verifica as maiores velocidades de transferência de calor. A temperatura do metal diminui e o filme de vapor se quebra, gerando uma intensa formação de bolhas, portanto o calor é removido rapidamente do metal $(22,9)$.

O terceiro e último estágio é denominado "resfriamento convectivo". Inicia-se quando a temperatura do metal fica abaixo da temperatura de ebulição do liquido de resfriamento. A ebulição acaba e tem-se um resfriamento lento, por condução e convecção. A taxa de resfriamento neste estágio é menor que a desenvolvida no segundo estágio, $(22,9)$. Esses mecanismos são fortemente influenciados por outros parâmetros do banho como agitação e temperatura. A Figura 5 mostra uma curva de resfriamento típica, contendo os três estágios.

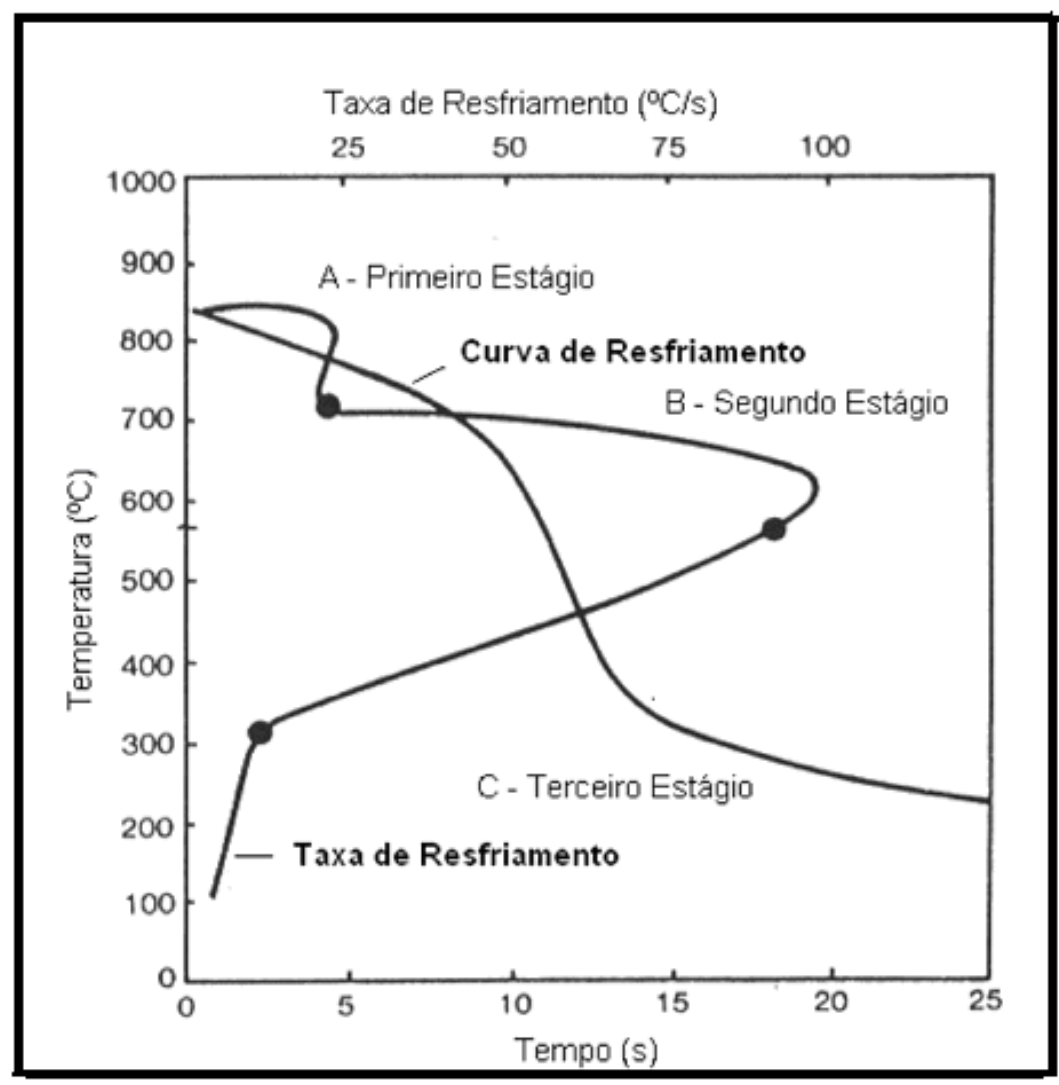

Figura 5 - Curvas de resfriamento (adaptado (9)). 
Os ensaios para a obtenção das curvas de resfriamento são padronizados segundo ASTM D 6200 - 01 (23), para óleos e segundo ASTM D 6482 - 06 para soluções de polímeros.

As propriedades finais do metal são resultados do comportamento desses três estágios durante o processo de resfriamento. Ou seja, as taxas de resfriamento são determinadas pelos meios refrigerantes e também, pelas condições de processo, tais como temperatura do banho, taxa de agitação e no caso de soluções aquosas, da concentração $(13,10)$.

\subsubsection{Meios Líquidos de Resfriamento na Têmpera}

A estrutura desejada ao final do processo de têmpera, é a martensita e é importante que ela seja formada por um endurecimento uniforme através de toda a secção da peça. Portanto o aço deve apresentar suficiente capacidade de endurecimento (endurecibilidade) ou adequada profundidade de endurecimento (temperabilidade).

Os meios de têmpera através do processo de resfriamento influenciam a estrutura final da peça metálica. A escolha do meio de têmpera depende inicialmente de três fatores: dureza final desejada; forma e dimensões das peças e capacidade de endurecimento do aço, (9).

A água, os óleos, as soluções de polímero e as soluções de sais são os meios refrigerantes mais aplicados na têmpera do aço $(9,24)$.

\subsubsection{1 Água}

A água apresenta características desejáveis, (25), tais como baixo custo e abundância, não é inflamável nem tóxica. Devido ao seu alto calor especifico e a baixa viscosidade, a água é um meio de têmpera muito rápido. Isso faz com que seu 
uso seja limitado a peças simples e simétricas, para evitar trincas e distorções. As condições de resfriamento desse meio são melhores na faixa de temperatura que vai de 13 e $24{ }^{\circ} \mathrm{C}$ aproximadamente. O poder de resfriamento da água decresce rapidamente com o aumento da temperatura, como mostra a Figura 6. No entanto, a agitação da água aumenta a velocidade de resfriamento, pela ruptura da camada de vapor que envolve a superfície das peças, permitindo um contato mais íntimo da água fria com essa superfície, (9).

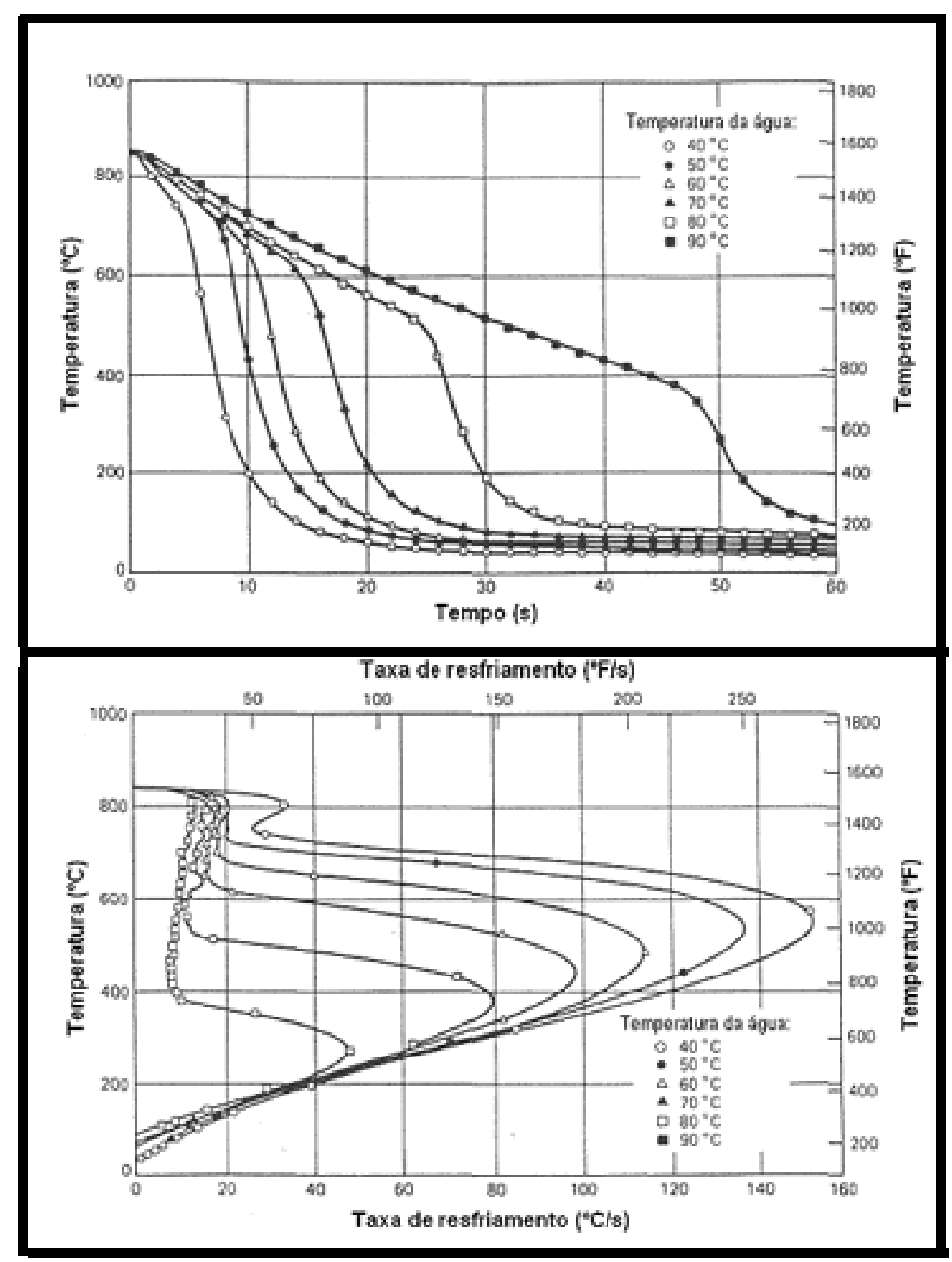

Figura 6 - Efeito da temperatura no banho e remoção de calor (9). 


\subsubsection{Soluções de sais}

As soluções salinas são, em sua maioria, constituídas por concentrações de cloretos, carbonatos, nitritos e nitratos. Essas salmouras são muito utilizadas nos tratamentos térmicos devido à qualidade adquirida na têmpera.

A principal característica dessas soluções é a alta velocidade na taxa de resfriamento, uma vez que o primeiro estágio ocorre rapidamente (estágio de vapor). Isso acontece pela presença de cristais que se incorporam à superfície da peça metálica durante o estado vapor, conforme a Figura 7. A camada de vapor é destruída devido às violentas fragmentações sofridas pelos cristais em alta temperatura, resultando em uma taxa de resfriamento mais elevada.

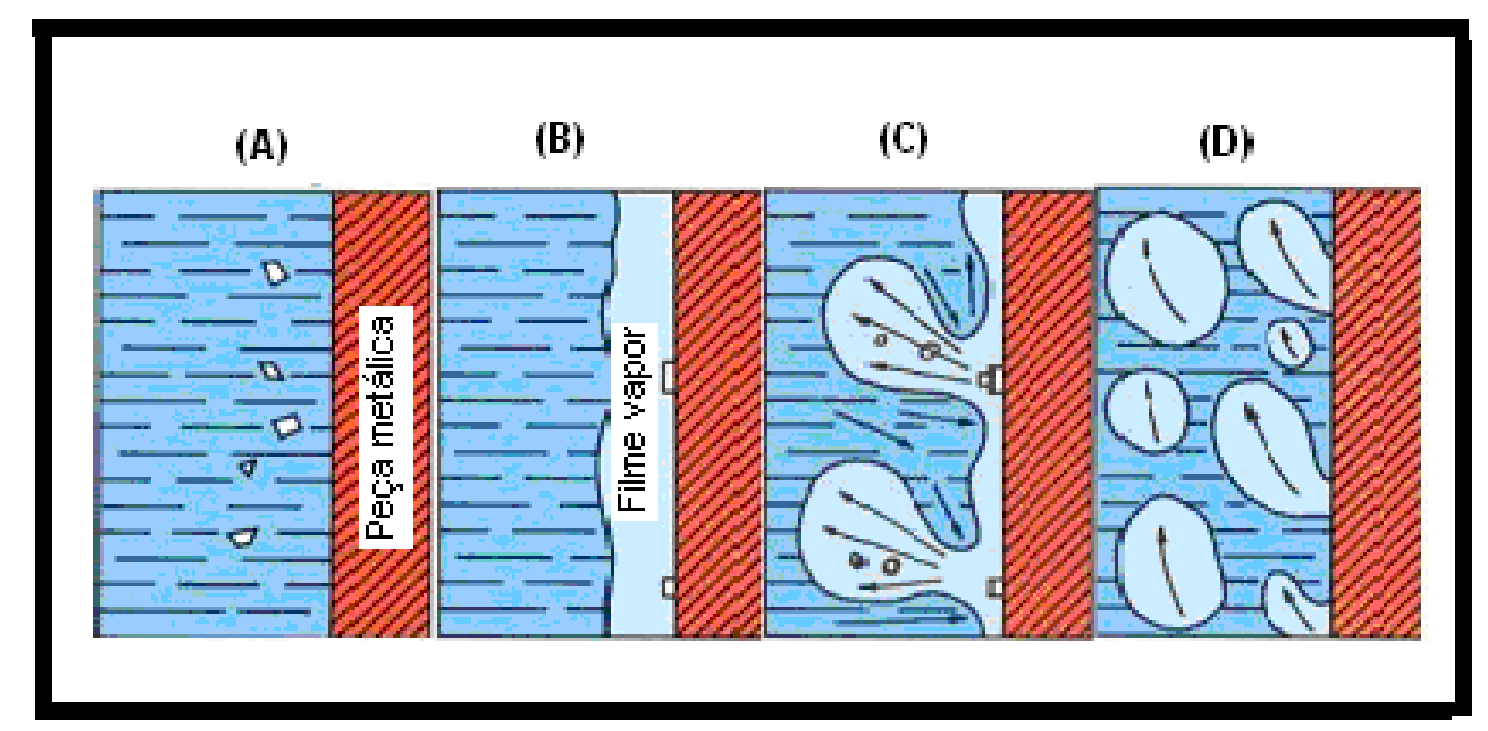

Figura 7 - Etapas do resfriamento com solução salina.

As vantagens da têmpera das soluções salinas sobre a água são (26): alcança a mesma taxa de resfriamento com menor agitação; menor possibilidade de pontos moles na peça metálica, estágio vapor reduzido; resfriamento mais uniforme, com menos distorções nas peças finais temperadas. Apresenta também desvantagens como a corrosão, mas sua utilização se faz necessária quando outros meios não apresentam a mesma eficácia. 


\subsubsection{Soluções de polímeros}

A utilização dos polímeros e desejável não só por fatores ambientais, mas também por apresentar baixo risco de incêndio e um pequeno nível de fumaça, problemas geralmente causados pelo uso de óleos.

Atualmente os polímeros mais utilizados em tratamentos térmicos são: polivinil pirrolidone (PVP); polialquileno glicol (PAG), embora existam ainda o álcool polivinílico (PVA) e o poliacrilato de sódio (ACR) (27).

As soluções são feitas adicionando os polímeros a água numa concentração que varia de 3 a $30 \%$, apresentando propriedades de taxas de resfriamento que se comparam desde a da água até a dos óleos minerais de baixa velocidade. Normalmente são usados na temperatura de $40^{\circ} \mathrm{C}$.

\subsubsection{4 Óleos}

Os óleos começaram a ser utilizados nos processos de têmpera para suprirem as desvantagens da água, já que proporcionam menores gradientes térmicos. Eles produzem menores distorções e tensões residuais na peça de metal, em relação a água. Os óleos podem ter origem animal, vegetal e mineral (petróleo). Isso causa uma grande variedade de características e propriedades que possibilitam seu uso em diversos processos (9).

Atualmente, os óleos mais usados são os derivados do petróleo, embora estejam crescendo os estudos voltados aos óleos vegetais, devido à necessidade de se encontrar um substituto para o óleo mineral que seja renovável e ambientalmente menos prejudicial $(28,29,30)$. Vários tipos de aditivos podem ser adicionados aos óleos, com intuito de modificar suas propriedades como: viscosidade, taxa de resfriamento, molhabilidade, estabilidade à oxidação. 


\section{3 Óleos Vegetais}

Embora os óleos minerais apresentem bom desempenho como meio de resfriamento, características como: ser originário de uma fonte não renovável e sua não degradação fazem com que as indústrias invistam em pesquisas a procura de meios de têmpera alternativos, tendo como principais candidatos, os óleos vegetais (28).

A utilização dos óleos vegetais como fluido de tempera é relativamente recente, embora como combustível ou como meio de transferência de energia, ou seja, como fluido hidráulico, já venha sendo utilizado há mais tempo. Esse interesse atual na utilização em algumas aplicações industriais é impulsionado pela preocupação ambiental, que procura minimizar os efeitos negativos causados no ambiente devido ao descarte, vazamento, derramamento, etc.

Os óleos vegetais apresentam algumas vantagens quando comparados aos óleos minerais, como $(31,32)$ : possui fonte renovável, baixo risco toxicológico, alto ponto de ebulição e é biodegradável. Porém apresentam também algumas desvantagens como instabilidade à oxidação e faixa de viscosidade reduzida.

\subsubsection{Características dos Óleos Vegetais}

As estruturas químicas dos óleos vegetais são diferentes quando comparadas com as de outros óleos base utilizadas como fluidos industriais. São constituídos de fragmentos de ácidos graxos, unidos por ligações de ésteres com glicerol, denominadas como triglicérides (33). Os óleos vegetais crus possuem diversos componentes tais como: fosfolipídeos (máx. 8\%), glicolipídeos (máx. 5\%), mono ou diglicerídeos e ácidos graxos livres (cerca de 2\%), ceras e outros hidrocarbonetos (máx. 1\%), pigmentos, compostos de odor ativo e outros constituintes menores. Estes pigmentos são normalmente removidos durante o processamento, que envolve despolimerização, refinamento alcalino e branqueamento. 
A composição química dos óleos vegetais refinados é uniforme e possui abundancia de ácidos graxos, sendo classificada da seguinte forma: saturados (sem dupla ligação - ácidos palmítico e esteárico), mono insaturados (uma ligação dupla ácido oléico), poli insaturados (várias ligações duplas - ácidos linoleico e linolênico) e especiais (contêm grupos funcionais como hidroxila (em ácidos ricinoleico e lesquerolico) e epóxi (ácido vernólico)) (33). A Figura 8 mostra a estrutura dos principais ácidos graxos presentes nos óleos vegetais.

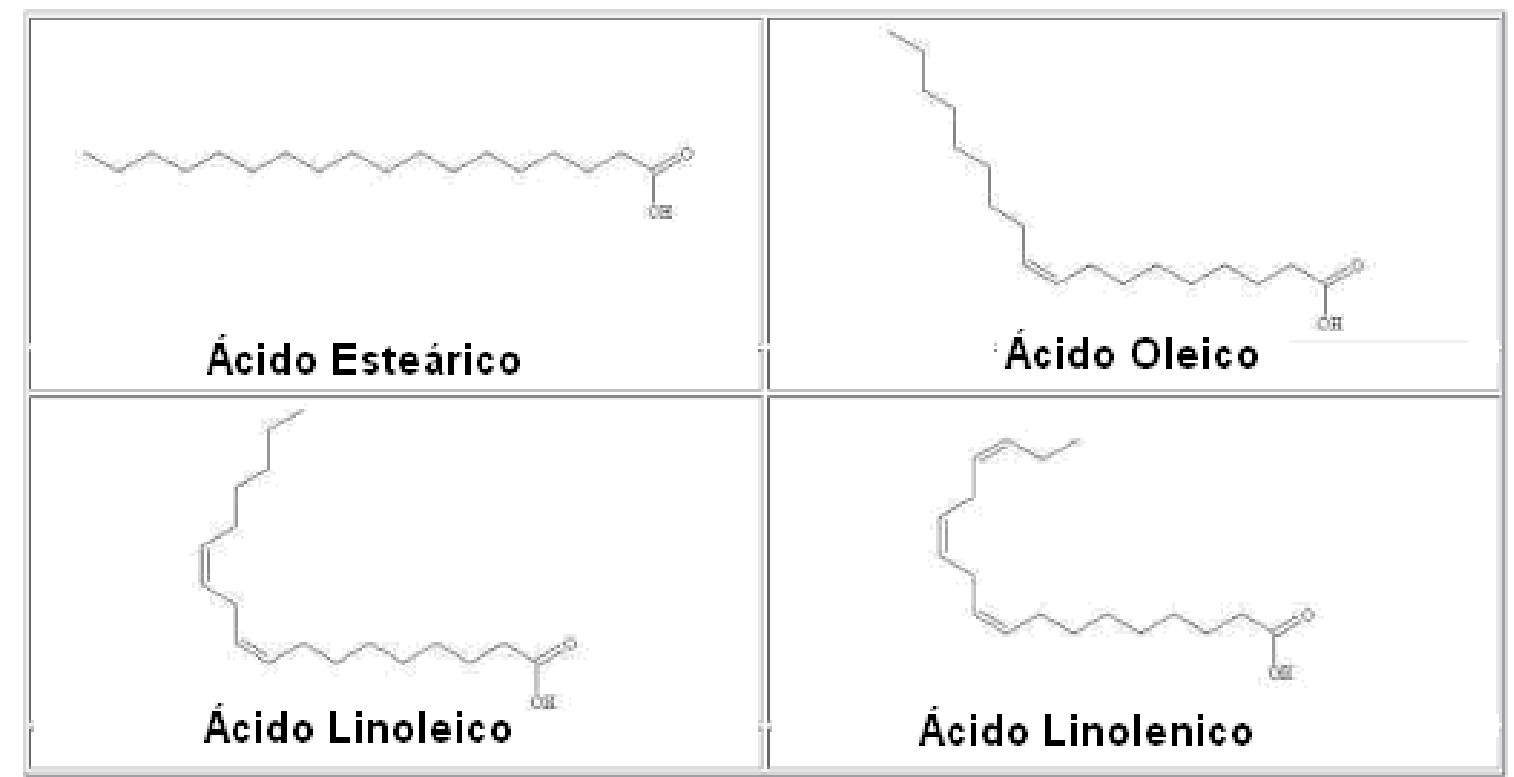

Figura 8 - Estruturas dos ácidos graxos que compõem as moléculas de óleos vegetais (30).

Os óleos e gorduras apresentam como componentes substâncias que podem ser reunidas em duas grandes categorias: glicerídios e não-glicerídios.

Glicerídios: São definidos como produtos da esterificação de uma molécula de glicerol com até três moléculas de ácidos graxos. Os ácidos graxos são ácidos carboxílicos de cadeia longa, livres ou esterificados, constituindo os óleos e gorduras, segundo (34). Quando saturados possuem apenas ligações simples entre os carbonos e possuem pouca reatividade química. Já os ácidos graxos insaturados, contêm uma ou mais ligações duplas no seu esqueleto carbônico; são mais reativos e mais suscetíveis à termo-oxidação, (35).

Não-glicerídios: Em todos os óleos e gorduras, pequenas quantidades de componentes não-glicerídios são encontradas, (36). Os óleos vegetais brutos possuem menos de $5 \%$ e os óleos refinados menos de $2 \%$. No refino, alguns desses componentes são removidos completamente, enquanto outros, parcialmente. 
Aqueles que ainda permanecem no óleo refinado, embora que em traços, podem afetar as características dos óleos devido a alguma propriedade peculiar, como apresentar ação pró ou anti-oxidante, ser fortemente odorífero, ter sabor acentuado ou ser altamente colorido (34). Alguns exemplos de grupos não-glicerídios são os fosfatídeos (lecitinas, cefalinas, fosfatidil inositol); esteróis (estigmasterol); ceras (palmitado de cetila); hidrocarbonetos insolúveis (esqualeno); carotenóides; clorofila; tocoferóis (vitamina E); lactonas e metilcetonas (37).

Em sua maioria os óleos vegetais são mono ou poli insaturados. Isso significa que apresentam menor estabilidade à oxidação quando comparados aos óleos minerais. A adição de antioxidantes específicos se faz necessária, pois eles inibem a degradação pela oxidação.

A Tabela 2 mostra as composições de ácidos graxos e de seus componentes em diferentes tipos de óleo vegetal (29).

Tabela 2 - Composição relativa aos ácidos graxos em diferentes óleos vegetais

\begin{tabular}{|c|c|c|c|c|c|c|}
\hline \multicolumn{7}{|c|}{ Ácidos Graxos (\%) } \\
\hline \multirow[t]{2}{*}{ óleos } & \multicolumn{2}{|c|}{ Saturados } & \multicolumn{2}{|c|}{ Mono insaturados } & \multicolumn{2}{|c|}{ Poli insaturados } \\
\hline & Palmítico & Esteárico & Oléico & Linoléico & Linolênico & Outros \\
\hline Canola & 3 & - & 60 & 30 & 7 & $<1$ \\
\hline Colza & $2-4$ & $1-2$ & $60-65$ & 20 & 8 & - \\
\hline Girassol & $4-19$ & $3-6$ & $14-35$ & $50-75$ & $0,1-4$ & $<1$ \\
\hline Linhaça & $6-7$ & $3-5$ & $20-26$ & $14-20$ & $51-54$ & - \\
\hline Mamona & $1-3$ & 1 & $3-4$ & $4-4,2$ & $0-0,3$ & $89-89,5$ \\
\hline Milho & $9-19$ & $1-3$ & $26-47$ & $40-55$ & $1-4$ & - \\
\hline Oliva & $7-16$ & $1-3$ & $60,7-86$ & $4-15$ & $0,5-1$ & 5,5 \\
\hline Soja & $7-16$ & $3-5$ & $18,9-35$ & $42,3-55$ & $5,5-11$ & $0-2,4$ \\
\hline
\end{tabular}
Fonte: $(38,29)$.

Os óleos vegetais mais estáveis à oxidação são os com alto teor oléico se comparado aos óleos vegetais convencionais, por apresentarem altos níveis de mono insaturação e baixos níveis de poli insaturação, porém, ainda são menos estáveis que os óleos minerais $(33,39)$. 


\subsubsection{Biodegradabilidade}

Os óleos de base mineral são de difícil biodegradação e podem ocasionar sérios problemas ambientais quando não manuseados adequadamente, segundo Domingues e Bidoia, 2007 (40). O descarte indevido desses fluidos prejudica o meio ambiente, pois formam uma fina camada sobre a superfície da água, que bloqueia a passagem de ar e luz atrapalhando a fotossíntese de algas e plantas o que impede a respiração dos animais aquáticos. Pode causar também algumas disfunções em animais marinhos.

A Tabela 3 mostra os valores do teste de biodegradabilidade para óleos comuns.

Tabela 3 - Quantidade biodegradada para diferentes tipos de fluidos.

\begin{tabular}{lc}
\hline Tipo de óleo & Quantidade biodegradada (\%) \\
\hline Óleo mineral & $15-35$ \\
Óleo altamente refinado (base mineral) & $25-45$ \\
Óleo vegetal natural & $70-100$ \\
Polialfaolefinas (PAO) & $5-30$ \\
Poli éter & $0-25$ \\
Poliisobutileno (PIB) & $0-25$ \\
Ftalato e éster trimeliato & $5-80$ \\
Polióis e diésteres & $55-100$ \\
\hline
\end{tabular}

Fonte: (41).

Nas últimas décadas houve uma preocupação com o uso dos produtos de base mineral e seu impacto no ambiente, gerando assim uma busca por fluídos ambientalmente aceitáveis, ou seja, biodegradáveis. Os benefícios dos fluidos ambientalmente aceitáveis incluem: menor poluição (ar, água e solo), menor toxidade e maior facilidade de eliminação devido a sua fácil biodegradabilidade (8). Além disso, os fluidos derivados das sementes de plantas são oriundos de uma fonte renovável, reduzindo, assim, a dependência do petróleo. 


\subsection{Oxidação dos óleos vegetais}

Óleos e gorduras se deterioram quando expostos ou armazenados em atmosfera de oxigênio. As alterações desses produtos podem ser classificadas como:

- auto-oxidação: ocorre a temperaturas abaixo de $100^{\circ} \mathrm{C}$;

- polimerização térmica: ocorre a temperaturas que variam entre 200 e $300^{\circ} \mathrm{C}$, na ausência de oxigênio;

- oxidação térmica: ocorre na presença de oxigênio e altas temperaturas (oxipolimerização);

- modificações físicas: modificações nas propriedades físicas;

- modificações nutricionais: modificações nos aspectos fisiológicos e nutricionais dos óleos;

- hidrólise dos triglicerídios: resulta na liberação de ácidos graxos, glicerina, mono e diglicerídio;

- modificações químicas (42).

Os óleos vegetais se degradam pelo mesmo mecanismo que os óleos minerais, porém com uma velocidade maior, ou seja, reagem muito mais rápido com o oxigênio. Isso acontece pelo fato de os óleos vegetais serem compostos por cadeias de triglicerídeos (ésteres) que possuem insaturações, sendo, este, o fator da maior velocidade de oxidação dos óleos vegetais em relação aos óleos minerais, que são basicamente uma mistura de hidrocarbonetos parafínicos e naftênicos.

A oxidação dos óleos vegetais ocorre através do mecanismo do radical livre, devido à decomposição de hidroperóxidos e peróxidos nos ácidos e aldeídos de baixa massa molecular (43), sendo esse processo acelerado na presença de altas temperaturas, gerando mudanças físico-químicas indesejáveis, nesse caso, na textura do óleo.

A manipulação inadequada dos óleos e gorduras pode causar a sua deterioração, que pode ocorrer de três formas: a hidrólise, a oxidação e a polimerização, sendo a oxidação a principal reação de decomposição. A oxidação é comum e freqüentemente causa mudanças químicas indesejáveis nos óleos. As gorduras oxidadas podem interagir com as proteínas e os hidratos de carbono que 
causam mudanças na textura (em alguns casos). A rancidez oxidativa e a rancidez hidrolítica são os dois tipos de oxidação de maior interesse (44).

A rancidez hidrolítica resulta na formação dos ácidos graxos livres e, é causada pela reação do lipídio e pela água na presença de um catalizador ou pela ação de enzimas lipases, ocorrendo geralmente durante o armazenamento dos óleos.

A rancidez oxidativa resulta de processos mais complexos da oxidação do lipídio. A oxidação de óleos resulta de uma reação em cadeia. Os processos ocorrem, geralmente, em três fases: iniciação, propagação e terminação, conforme mostra a Figura 9.

\begin{tabular}{|c|c|c|c|}
\hline Iniciação & $\begin{array}{l}\mathrm{RH} \\
\mathrm{R}^{*}+\mathrm{O}_{2} \\
\end{array}$ & $\begin{array}{l}\mathrm{R}^{*} \\
\mathrm{RO}_{2}{ }^{*}\end{array}$ & $\begin{array}{l}\text { (a) } \\
\text { (b) }\end{array}$ \\
\hline Propagação & $\begin{array}{l}\mathrm{RO}_{2}^{+}+\mathrm{RH} \\
\mathrm{R}^{*}+\mathrm{O}_{2}\end{array}$ & $\begin{array}{l}\mathrm{RO}_{2} \mathrm{H}+\mathrm{R}^{*} \\
\mathrm{RO}_{2}{ }^{*}\end{array}$ & $\begin{array}{l}\text { (c) } \\
\text { (d) }\end{array}$ \\
\hline Terminação & $\begin{array}{l}\mathrm{RO}_{2} \mathrm{H} \\
\mathrm{RO}^{*}+\mathrm{RH}+\mathrm{O}_{2} \\
\cdot \mathrm{OH}+\mathrm{RH}+\mathrm{O}_{2}\end{array}$ & $\begin{array}{l}\mathrm{RO}^{+}+{ }^{\circ} \mathrm{OH} \\
\mathrm{ROH}+\mathrm{RO}_{2}^{*} \\
\mathrm{H}_{2} \mathrm{O}+\mathrm{RO}_{2}{ }^{*}\end{array}$ & $\begin{array}{l}\text { (c) } \\
\text { (f) } \\
\text { (g) }\end{array}$ \\
\hline
\end{tabular}

Figura 9 - Processo de oxidação em 3 estágios: iniciação, propagação e terminação.

O oxigênio presente no óleo é a fonte dessa reação. O calor e a presença de metais aceleram um processo de quebra. No estágio de iniciação um radical é formado (a) por aquecimento, luz UV ou alguma substância do óleo, como por exemplo, um composto de nitrogênio. Esse radical vai reagir muito rápido (b) com o oxigênio, formando um radical peróxido. No próximo estágio, propagação, o radical peróxido deve reagir com uma nova molécula de óleo (c) formando um hidroperóxido e um radical alquil. Esse novo radical também reagirá com o oxigênio e formará um radical peróxido. No estágio de terminação o hidroperóxido formado em (c) vai se separar (e) em dois novos radicais, onde ambos irão reagir com novas moléculas de óleo na presença de oxigênio. Essas reações resultam em novos radicais peróxidos e a reação de oxidação continua. Os radicais também podem reagir entre si, formando produtos finais da oxidação, como ácidos e longas cadeias de 
hidrocarbonetos. Os compostos relativamente não reativos formados são hidrocarbonetos, aldeídos, e cetonas.

Em sistemas complexos o produto de cada fase aumentará ou diminuirá com o tempo, sendo difícil quantificar a oxidação do lipídio. Na iniciação, o oxigênio da molécula se combina com ácidos graxos insaturados para produzir os hidroperóxidos e os radicais livres.

Estas reações normalmente são muito lentas a temperatura ambiente, mas acima de $100^{\circ} \mathrm{C}$ se tornam mais rápidas. Para atingir uma taxa significativa é necessário que algum tipo de iniciador oxidativo esteja presente, como componentes químicos oxidados, metais de transição (ferro ou cobre), ou enzimas (lipoxigenases). A Figura 10 mostra as reações de iniciação pela presença de metais de transição.

$$
\begin{aligned}
& \mathrm{Fe}^{3+}+\mathrm{ROOH} \rightarrow \mathrm{Fe}^{2+}+\mathrm{ROO} \cdot+\mathrm{H}^{+} \\
& \mathrm{Fe}^{2+}+\mathrm{ROOH} \rightarrow \mathrm{Fe}^{3+}+\mathrm{RO} \cdot+\mathrm{HO}^{-} \\
& \mathrm{Cu}^{2+}+\mathrm{ROOH} \rightarrow \mathrm{Cu}^{+}+\mathrm{ROO} \cdot+\mathrm{H}^{+} \\
& \mathrm{Cu}^{+}+\mathrm{ROOH} \rightarrow \mathrm{Cu}^{2+}+\mathrm{RO} \cdot+\mathrm{HO}^{-}
\end{aligned}
$$

Figura 10 - Reações de iniciação pela presença de ferro (Fe) e de cobre (Cu) (45).

Os óleos vegetais oxidam pela reação da oxidação do radical livre que é comum a todos os hidrocarbonetos. O que diferencia essa reação é o fato de que as cadeias dos triglicerídios possuem alguns locais altamente reativos, geralmente em carbonos junto às duplas ligações (insaturados). Quanto mais ligações duplas possuir, mais rápido reagirão com o oxigênio e oxidarão. A Figura 11 mostra a taxa de oxidação relativa devido ao número de duplas ligações em moléculas dos principais ácidos graxos que compõem os óleos vegetais. 


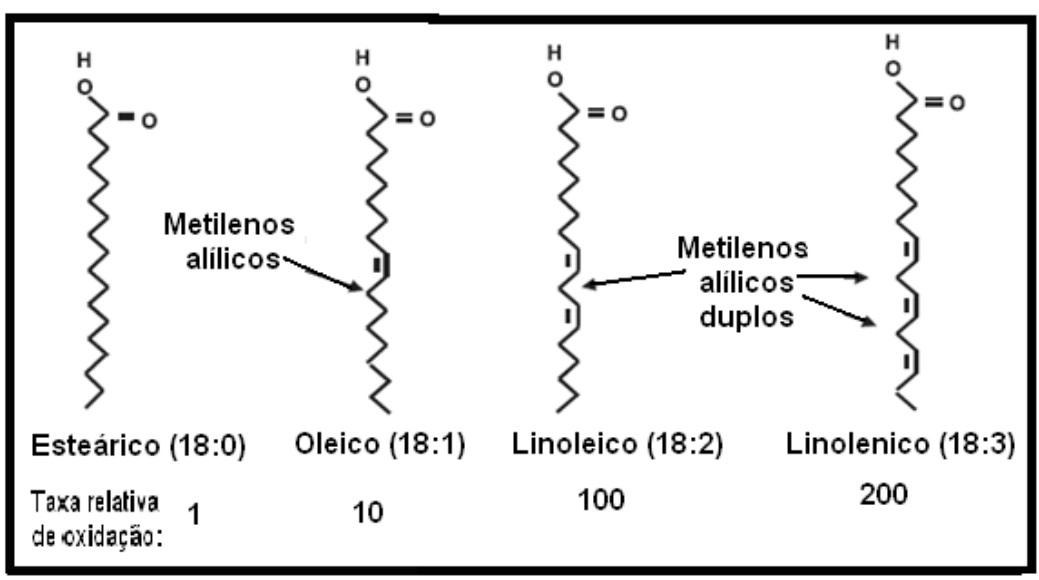

Figura 11 - Taxa de oxidação relativa devido ao número de duplas ligações nas moléculas (8).

A reação à degradação oxidativa dos ésteres esteárico, oléico, linoleico, linolenico nas estruturas triglicérides é de 1, 10, 100, 200 respectivamente (8).

Os fatores mais comuns que influenciam a taxa da oxidação do lipídio em um produto são:

- Qualidade do óleo ou gordura utilizado na fabricação do produto;

- Condições usadas na fabricação do produto;

- Condições de armazenamento (calor, luz, empacotamento);

- Área de superfície exposta ao oxigênio da atmosfera;

- Presença de metais de transição;

- Concentração de lipoxigenases ativas;

- Aplicação de aditivos apropriados sintéticos ou naturais e

- Presença de componentes químicos oxidados.

$\mathrm{Na}$ primeira fase do processo de oxidação dos lipídios, os produtos predominantes da reação são os peróxidos e os hidroperóxidos. Os produtos da oxidação são tóxicos e se formam a partir da ligação dos peróxidos formados a um grande número de produtos instáveis (46).

Estes produtos da reação continuam a aumentar até que ocorram mudanças nas condições de armazenamento; um ou mais iniciadores é esgotado ou todo o oxigênio disponível é consumido.

O estado da matéria prima, dos produtos finais e a eficiência dos antioxidantes podem ser analisados através da avaliação da rancidez oxidativa.

Os óleos vegetais são estabilizados pelos mesmos tipos de aditivos que os óleos minerais, porém em maior quantidade (47). Para conseguir uma estabilidade oxidativa máxima para os óleos vegetais, um destes itens deve ser otimizado: 
- Antioxidante de amina,

- Antioxidante de fenol,

- Relação amina-fenol e

- Concentrações dos estabilizadores.

A decomposição térmica dos óleos ocorre em três etapas, devido à decomposição dos ácidos graxos polinsaturados, monoinsaturados e saturados, respectivamente. Muitas metodologias foram propostas para avaliar a qualidade do óleo comercial, sendo que a maioria submete uma amostra às circunstâncias que acelerem o processo de oxidação normal. A degradação é avaliada pelo ganho de massa e por medidas organolépticas (48). A complexidade da oxidação do óleo vegetal é primeiramente devido à participação de parâmetros estruturais diferentes na cadeia do ácido graxo. Diferentes parâmetros participam em estágios diferentes na reação da oxidação. Assim, consequentemente não é conveniente medir a extensão da degradação oxidativa em termos de um único parâmetro, tais como índice de iodo, índice de peróxido, viscosidade, entre outros (38). Existem três tipos de mecanismos de oxidação: auto-oxidação (já comentado), fotoxidação e oxidação enzimática, sendo os dois primeiros mais comuns. O produto desses mecanismos são os hidroperóxidos, produtos primários completamente instáveis, e responsáveis pela rancidez oxidativa (49).

Auto-oxidação: é um processo dinâmico que evolui ao longo do tempo (50). Trata-se de um fenômeno puramente químico e bastante complexo, envolvendo reações entre radicais capazes de se auto-propagar, e que dependem do tipo de ação catalítica (temperatura, íons metálicos, radicais livres, pH). No decurso da seqüência reacional, classicamente dividida em iniciação, propagação e terminação, é possível distinguir três etapas de evolução oxidativa:

1 - desaparecimento dos substratos de oxidação (oxigênio, lipídio insaturado);

2 - aparecimento dos produtos primários de oxidação (peróxidos e hidroperóxidos), cuja estrutura depende da natureza dos ácidos graxos presentes;

3 - aparecimento dos produtos secundários de oxidação, obtidos por cisão e rearranjo dos peróxidos (epóxidos, compostos voláteis e não voláteis), cuja natureza e proporção dependem de diversos parâmetros.

A auto-oxidação de ácidos graxos insaturados produz uma redução na estabilidade térmica dos óleos vegetais, causando uma diminuição no tempo de 
indução oxidativa (43). Fatores tais como a mudança na cor, aumento da viscosidade e o odor desagradável são observados no processo da degradação destes óleos.

Fotoxidação: é promovido essencialmente pela radiação ultravioleta (UV) em presença de sensibilizadores como a clorofila e a mioglobina, e envolve a participação do oxigênio singlete $\left({ }^{1} \mathrm{O}_{2}\right)$ como intermediário reativo. O resultado desse processo é a formação de hidroperóxidos diferentes dos que se observam na ausência da luz e de sensibilizadores, e que por degradação posterior originam aldeídos, álcoois e hidrocarbonetos. A velocidade da reação é inibida pelos carotenos (50).

Oxidação enzimática: ocorre por catálise enzimática, por ação da lipoxigenase. Esta enzima atua sobre os ácidos graxos polinsaturados (ácidos linoleíco e linolênico, e seus ésteres), catalisando a adição de oxigênio à cadeia hidrocarbonada polinsaturada. Resulta na formação de peróxidos e hidroperóxidos com duplas ligações conjugadas, os quais podem envolver-se em diferentes reações degradativas, semelhantes às observadas para os processos de autoxidação, originando diversos produtos. O processo de catálise enzimática decorre com maior especificidade, em termos de substrato e de produtos finais, do que o processo de autoxidação. Um aspecto importante da atuação da lipoxigenase é o que se relaciona com a sua capacidade para co-oxidar substratos (carotenóides, tocoferóis, clorofila, proteínas, etc.), sendo responsável pela iniciação de novos processos oxidativos (50).

Segundo Lemar, 1967 (51) propriedades como: boa estabilidade térmica, boa lubrificação e boa relação viscosidade-temperatura, são importantes em trabalhos envolvendo altas temperaturas. A dificuldade de obter estas propriedades em um fluido base está no fato da estrutura molecular influenciar estas propriedades.

Por exemplo, os grupos aromáticos (compostos caracterizados por apresentar como cadeia principal um ou vários anéis benzênicos) presentes nos óleos vegetais, geralmente aumentam a estabilidade térmica de uma molécula fluida, mas diminuem as propriedades da viscosidade-temperatura do fluido. A Figura 12 apresenta a estrutura de três hidrocarbonetos aromáticos. 


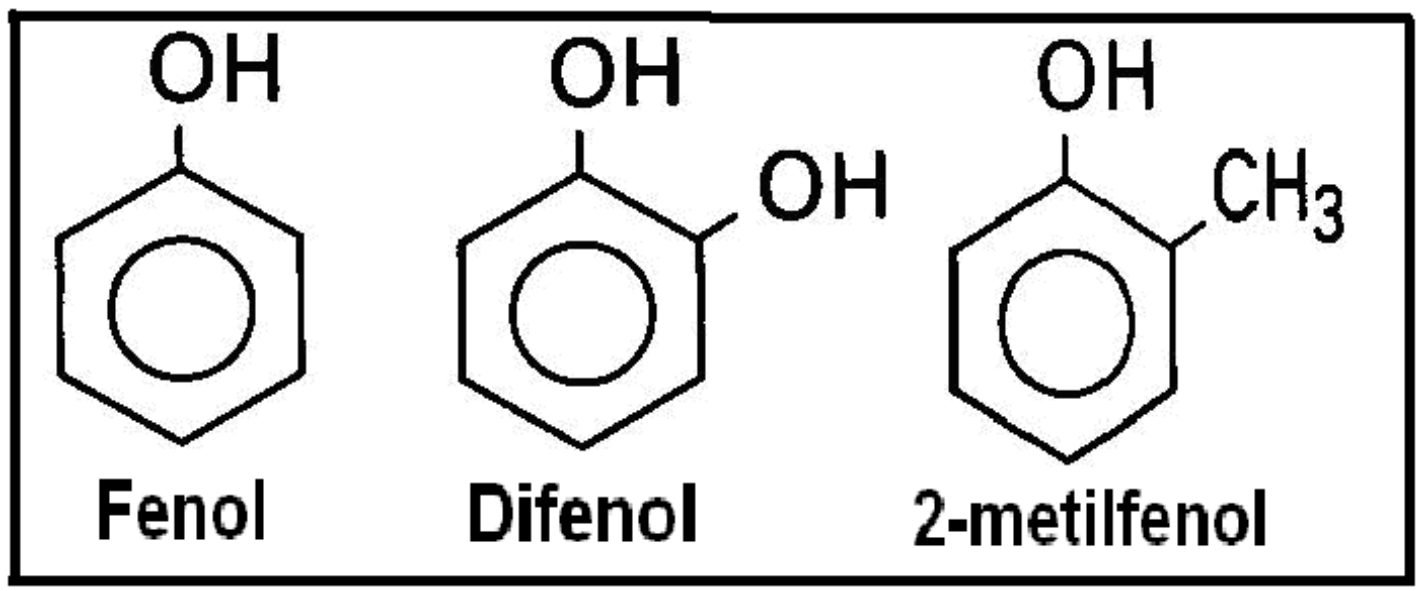

Figura 12 - Estrutura de hidrocarbonetos aromáticos (52).

Outros tipos de fluidos tais como polisiloxanes podem mostrar boas propriedades de estabilidade térmica e de viscosidade-temperatura, mas possuem pobre propriedade anti-desgaste, o que é preocupante para fluidos industriais que trabalharão como lubrificantes. Grande parte dos estudos de oxidação em óleos vegetais são desenvolvidos em fluidos hidráulicos, sendo essa, atualmente, uma das mais importantes aplicações de óleos vegetais.

Os fluidos hidráulicos usados para aplicações não estacionárias estão sujeitos a temperaturas mais elevadas. Consequentemente, a estabilidade oxidativa é particularmente importante. A estabilidade oxidativa de fluidos de base vegetal está relacionada diretamente ao índice de ácido oléico. Aumentar o índice de ácido oléico, relativos aos ácidos di e tri insaturados, fornece aumentos correspondentes na estabilidade oxidativa $(53,54,5)$. Entretanto, a estabilidade oxidativa para fluidos com alto índice de ácido oléico é quase sempre insuficiente e, consequentemente, somente uns poucos podem ser usados com limitações. Em alguns casos, é recomendado o uso de temperaturas entre 60 e $80^{\circ} \mathrm{C}(55,56)$.

A estabilidade oxidativa de fluidos biodegradáveis foi estudada usando o Teste da Oxidação da Bomba Giratória (RBOT) de acordo com ASTM D 2272. Neste estudo, mostrou-se que a estabilidade oxidativa, é minimamente afetada pela contaminação com água, mas é significativamente afetada pela presença de alguns metais tais como o cobre (57).

Desde que a instabilidade hidrolítica não pode ser controlada, a contaminação da água deve, ou ser eliminada ou ser removida antes que o hidrolise ocorra. Entretanto, em aplicações da hidráulica, é difícil excluir a possibilidade de contaminação com a umidade (água) (58). 
Os óleos vegetais contêm uma variedade de antioxidantes e de estabilizadores naturais tais como os tocoferóis e os esteróis que tem um papel importante na inibição da degradação do lipídio. Alguns óleos vegetais têm composições de ácidos graxos melhores do que outros.

Entre outros compostos, as gorduras naturais possuem igualmente esteróis (colesterol e sitosterol), que não intervêm de forma significativa na sua estabilidade oxidativa (50).

Os lipídios podem estar dispersos na matriz formada pelos polissacarídios e pelas proteínas, encontrando-se facilmente expostos à oxidação. No entanto, a existência de interações hidrofóbicas entre as cadeias de ácidos graxos e as hélices de amilase, ou o encapsulamento dos lipídios pelas proteínas, podem conduzir ao retardamento dos processos oxidativos. Freqüentemente, a estabilidade e a conservação, em condições normais, de alguns alimentos com elevado teor em lipídios deve-se à forma compartimentada ou descontínua de como alguns dos seus constituintes (lipoxigenase, água e oxigênio) se distribuem no seio da matriz. A relação entre a fração oxidável e a fração estável dos lipídios num mesmo alimento pode ser modificada pela formulação e pelas condições de processamento (50).

\subsection{Antioxidantes}

Antioxidantes podem ser definidos como substâncias que, numa concentração consideravelmente menor que a do substrato oxidável, retardam a oxidação, diminuindo a velocidade da reação ou prolongando o seu período de indução (50). Os antioxidantes têm como objetivo neutralizar quimicamente a ação dos radicais livres, que podem atuar no início do processo da rancidez oxidativa. Eles apresentam em sua estrutura, o citrato fosfato que se liga aos radicais livres, fazendo a quelação dos metais, que são grandes formadores de oxidação (46).

Em geral, os antioxidantes são substâncias que impedem ou diminuem a formação de compostos como peróxidos, aldeídos, cetonas, dímeros e polímeros, produtos formados por termo-oxidação de óleos e gorduras, impedindo a etapa inicial de auto-oxidação, a formação de radicais livres, removendo-os do meio (46). 
Os antioxidantes são divididos em naturais (encontrados principalmente no reino vegetal) e sintéticos. Os antioxidantes naturais mais utilizados são tocoferol (vitamina E), ácido ascórbico (vitamina C), beta caroteno (vitamina A) e flavonóides. Os antioxidantes sintéticos amplamente utilizados na indústria são: butil hidroxi anisol (BHA), butil hidroxi tolueno (BHT), etoxiquina (ETOX), terbutil hidroxi quinona (TBHQ), galato de propila e dodecil galato. Existem diversas formas desses produtos no mercado, e, muitas vezes, quando usados mesclados, apresentam excelentes resultados. A Figura 13 apresenta a estrutura molecular de alguns antioxidantes naturais e a Figura 14 apresenta a estrutura molecular de alguns antioxidantes sintéticos.
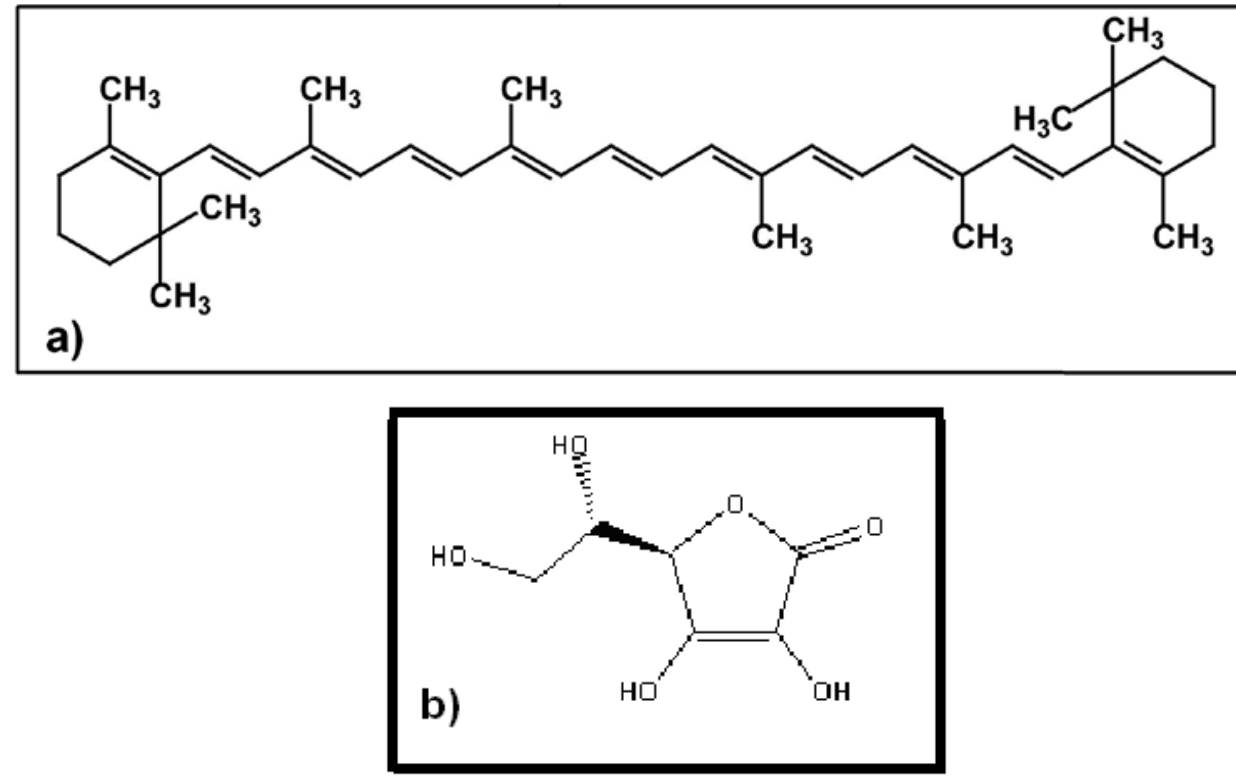

Figura 13 - Antioxidantes naturais: ácido ascórbico e beta caroteno (52). 
a)

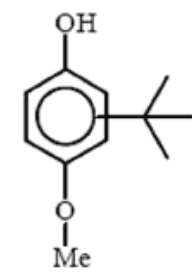

d)

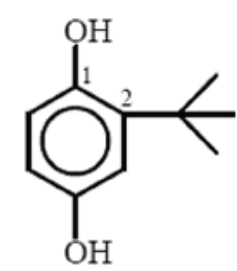

b)

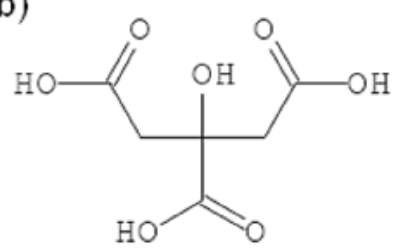

c)<smiles>Cc1cc(C)c(O)c(C(C)(C)C)c1</smiles>

e)<smiles>CCCOC(=O)c1cc(O)c(O)c(O)c1</smiles>

Figura 14 - Antioxidantes sintéticos: a) estrutura molecular do BHA; b) estrutura molecular do ácido cítrico; c) estrutura molecular do BHT; d) estrutura molecular do tercbutil hidroquinona; e) estrutura molecular do galato de propila $(52,59)$.

A quebra da cadeia reacional da oxidação lipídica pelos antioxidantes não ocorre segundo um mecanismo simples e, certos aspectos, relativos às interações entre constituintes de meios complexos, não estão completamente esclarecidos. O emprego de antioxidantes em formulações é muitas vezes empírico, de tal modo que a garantia da sua eficácia nem sempre existe. A atividade antioxidante varia de acordo com o tipo de composto e sua concentração (50).

Uma das dificuldades para avaliar o grau de oxidação reside na escolha do momento mais adequado para efetuar essa determinação. De um modo geral, procura-se avaliar, em condições padronizadas e selecionando um determinado parâmetro indicador, o período de indução da reação, ou seja, o tempo necessário para se atingir um ponto crítico de oxidação (por exemplo, alteração de gosto, aceleração brusca da velocidade do processo oxidativo), como mostra a Figura 15. A determinação não deve ser pontual, isto é, restrita a um determinado momento, mas deve-se efetuar ao longo do tempo, de forma a ser representativa da duração de vida do produto. 


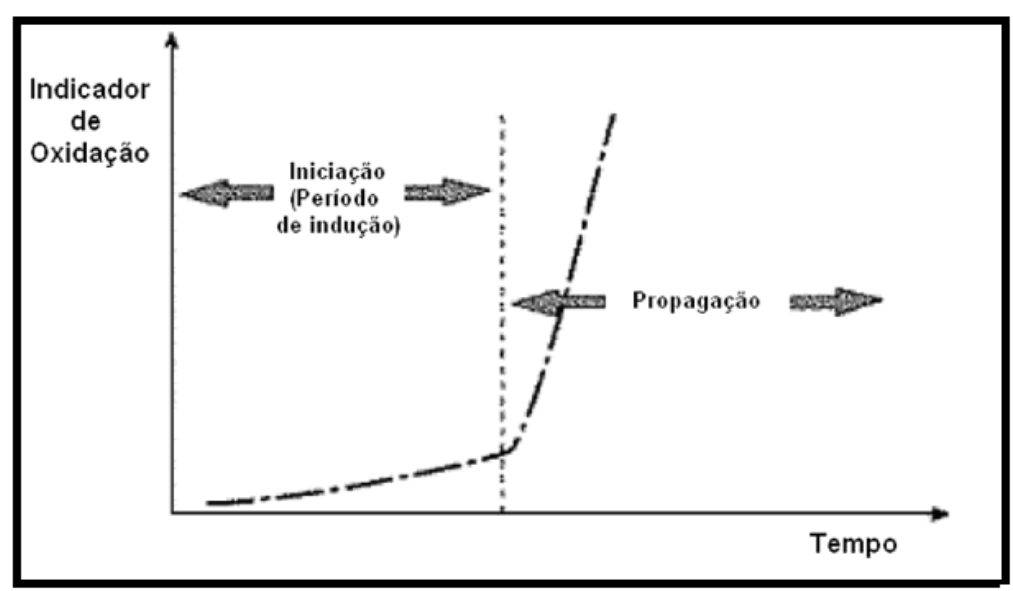

Figura 15 - Determinação da estabilidade oxidativa (50).

A determinação da eficácia de um antioxidante corresponde freqüentemente à medida do alargamento do período de indução resultante da sua adição. Esse alargamento é por vezes expresso como um índice antioxidante ou fator de proteção, a Figura 16 mostra a capacidade antioxidante.

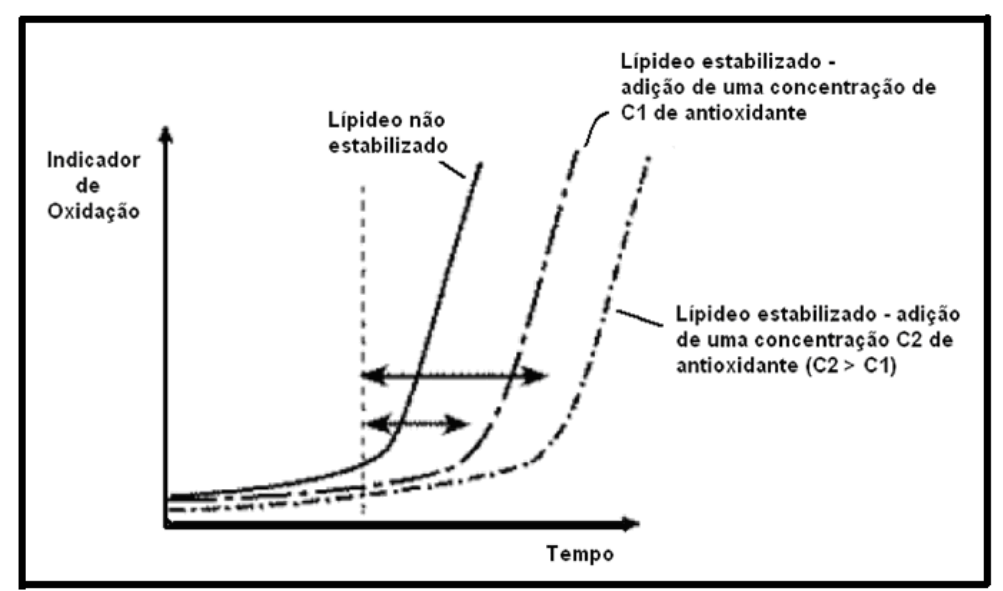

Figura 16 - Determinação da capacidade antioxidante (50).

Fluidos industriais a base de mineral normalmente contém aditivos. Os aditivos são usados para melhorar as propriedades fluidas, que incluem a estabilidade oxidativa, reduzida formação de espuma entre outras. A presença de aditivos afeta também a biodegradação do fluido e as propriedades toxicológicas. Em muitos casos, os aditivos usados na formulação de fluidos à base de óleos vegetais são derivados do petróleo, os quais não são apropriados, sendo indicado os aditivos desenvolvidos com base biodegradável. Consequentemente, a seleção do aditivo afeta a biodegradabilidade, segundo Totten, 1999 (29). 


\subsection{Ensaios de Caracterização dos Óleos Vegetais}

\subsubsection{Ressonância Magnética Nuclear (RMN)}

A Figura 17 mostra o espectro de $\mathrm{RMN}$ de $\mathrm{H}^{1}$ genérico de um óleo vegetal para análise.

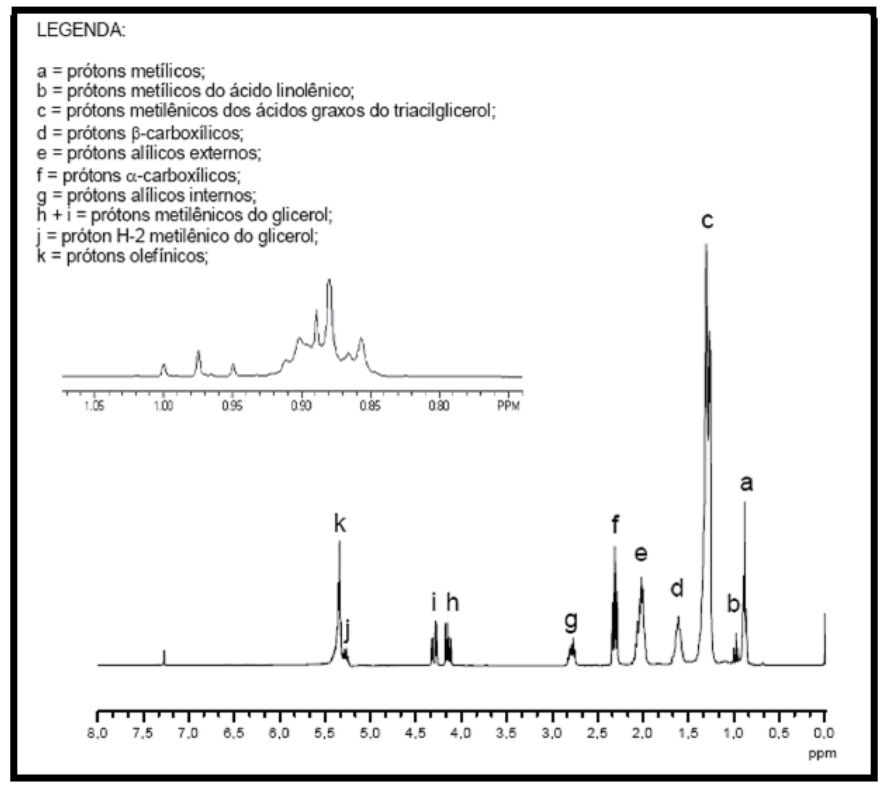

Figura 17 - Espectro de $\mathrm{RMN}$ de $\mathrm{H}^{1}$ genérico de um óleo vegetal (59).

Do espectro de $\mathrm{RMN}$ de $\mathrm{H}^{1}$ integrado, obtem-se a medida direta do grau de insaturação de modo preciso. Todos os hidrogênios olefínicos (aqueles conectados diretamente nos carbonos das ligações duplas carbono-carbono) mostram deslocamento químico entre 5,40-5,26 ppm (k). Todos os hidrogênios metílicos parte saturada da molécula - mostram deslocamento químico entre 0,80 e 1,00 ppm $(\mathrm{a}+\mathrm{b})$. Portanto o número total de insaturação, em moles, é a medida direta da área dos picos normalizados e integrados, dos hidrogênios que geraram aqueles sinais, naquelas regiões do espectro de $\mathrm{RMN}$ de $\mathrm{H}^{1}(60)$.

A RMN de $\mathrm{H}^{1}$ é uma técnica extremamente sensível à densidade eletrônica e a população de hidrogênios que gerou o sinal. Hidrogênios em ambientes eletrônicos diferentes mostram diferentes deslocamentos químicos, e a intensidade 
do sinal é estritamente proporcional à quantidade de hidrogênios que o gerou. $O$ espectro de $\mathrm{RMN}$ de $\mathrm{H}^{1}$ dos triglicerídios é bem resolvido, observando-se sinais distintos, característicos, para os prótons olefínicos, do glicerol e alquílicos, que mostram absorção em regiões diferentes do espectro.

$\mathrm{Na}$ Figura 18, é mostrado o espectro de $\mathrm{RMN}$ de $\mathrm{C}^{13}$ genérico de um óleo vegetal.

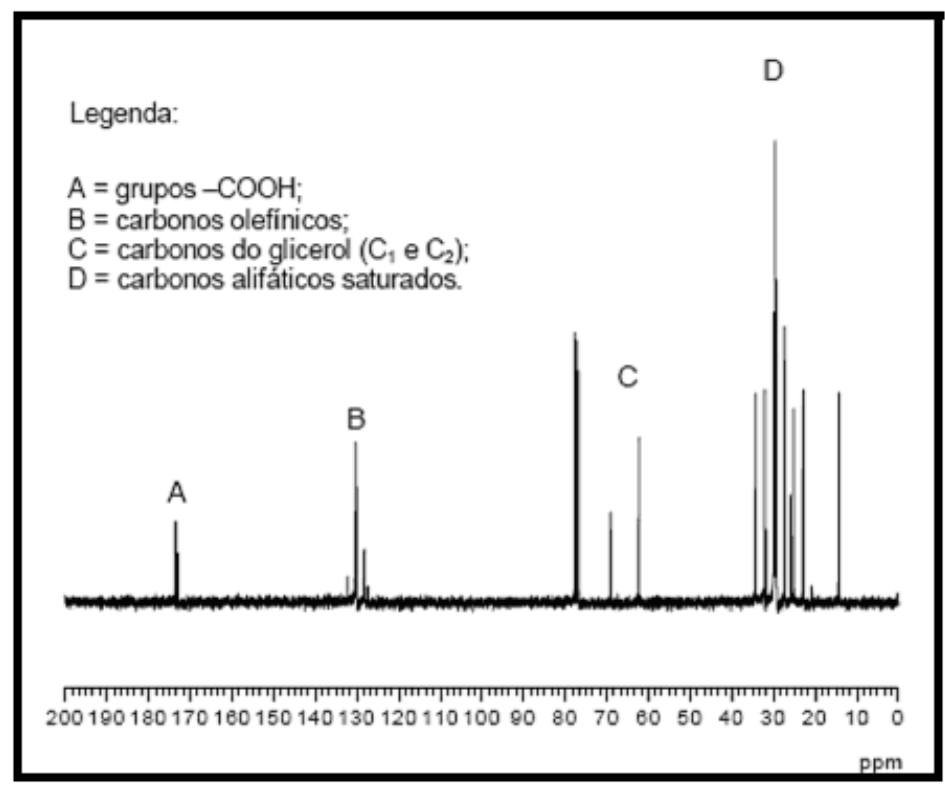

Figura 18 - Espectro de RMN de $C^{13}$ genérico de um óleo vegetal (59).

$\mathrm{Na}$ análise especifica de um óleo vegetal por $\mathrm{RMN}^{13}$, quatro regiões bem distintas no espectro podem ser descritas: 173,3-172,8 ppm (A) região dos carbonos dos grupos carboxilas; 132,0-127,1 ppm (B), região dos carbonos olefínicos; 69,161,6 ppm, região dos carbonos do glicerol (C: C1 e C2); e 34 ppm (D), onde estão presentes os carbonos alifáticos saturados. Quando se analisa a região dos grupos carboxílicos, os substituintes nas posições 1 e 2 do glicerol podem ser distinguidos, porque mostram intensidades diferentes. Óleos deteriorados termicamente, mostram redução do número de carbonos olefínicos; 34 ppm correspondem aos grupos ametilênicos em relação à carboxila; os grupos $\mathrm{CH}_{2}$ saturados encontram-se em 30,028,5 ppm; os $\mathrm{CH}_{2}$ alílicos externos à $\mathrm{C}=\mathrm{C}$, estão em 27,5 ppm; os $\mathrm{CH}_{2}$ olefínicos internos, são observados em 26,0-25,0 ppm; os carbonos b-carbonílicos são observados em 25,0 ppm e as metilas podem ser observadas em 14,0 ppm.

Os métodos instrumentais apresentam grande vantagem sobre os tradicionais (volumétricos) pela sua capacidade em necessitar apenas de quantidades mínimas 
de amostra e terem uma extrema sensibilidade e reprodutibilidade nas análises, além de serem mais precisos e exatos (59). Muitos outros métodos são utilizados para avaliar a qualidade da gordura e do óleo, alguns com muito sucesso em indústrias específicas. Devido à complexidade da oxidação do lipídio, nenhum método é suficiente, sendo necessário utilizar mais de um método para chegar a conclusões (44).

\subsubsection{Calorimetria Exploratória Diferencial com Pressão (PDSC)}

A análise de PDSC é uma análise de calorimetria exploratória diferencial (DSC) conduzida sob leve pressão, de até 500 psi. A PDSC apresenta duas vantagens sobre a DSC: diminuição das reações sensíveis à pressão (incluindo a volatilização), e, com o aumento da pressão parcial nas amostras, as reações de

oxidação atmosférica são aceleradas, porque a evaporação da amostra é minimizada $(61,62)$.

A análise de PDSC tem como objetivo determinar a estabilidade oxidativa de óleos lubrificantes. Nos estudos de degradação oxidativa o PDSC inclui a adição da amostra a ser testada em um cadinho de alumínio apropriado e, em seguida, a colocação do cadinho na célula de PDSC pré-equilibrada na temperatura de teste desejada. O momento em que o cadinho com a amostra é introduzido na célula é considerado como sendo $t=0$. O cadinho e a amostra são equilibrados em um período de tempo de 30 segundos e a célula é pressurizada por 60 segundos (63).

A termo-estabilidade oxidativa de diferentes lubrificantes biodegradáveis foi avaliada por (64) utilizando a oxidation induction temperature (OIT) e oxidation induction time (OOt) obtidos por PDSC para fazer uma diferenciação entre a estabilidade oxidativa de fluidos à base de óleos vegetais.

Em algumas situações, uma técnica isotérmica de PDSC pode não ser a melhor escolha para a determinação da estabilidade de oxidação de um óleo básico. Nestas situações, melhores resultados são obtidos através de um teste nãoisotérmico que produz valores designados onset oxidation temperature (OOT) e onset oxidation time (OOt). A OOT é a temperatura extrapolada de onset em que a 
amostra começa a oxidar (65). Normalmente a OOT e OOt são usadas para classificar diferenças relativamente grandes na estabilidade dos materiais e a OIT e Oit são testes mais sensíveis.

\subsubsection{Cromatografia Gasosa (GC)}

A GC é a técnica mais utilizada na avaliação de óleos e derivados de petróleo ultimamente, pois consiste em separar uma amostra em seus componentes individuais, baseado em suas propriedades físicas.

A análise de cromatografia gasosa depende essencialmente de três componentes: uma entrada onde a amostra é introduzida na coluna; a coluna, que contem um líquido estacionário e por onde o gás passa continuamente e um detector, que mede a quantidade dos compostos presentes na amostra, $(66,18)$, esses componentes devem ser escolhidos de acordo com o produto a ser analisado.

A Figura 19 apresenta um cromatograma de derivados do trimethylsilyldiethanolamide polyol uma dietano-amina que tem como base o óleo de dendê.

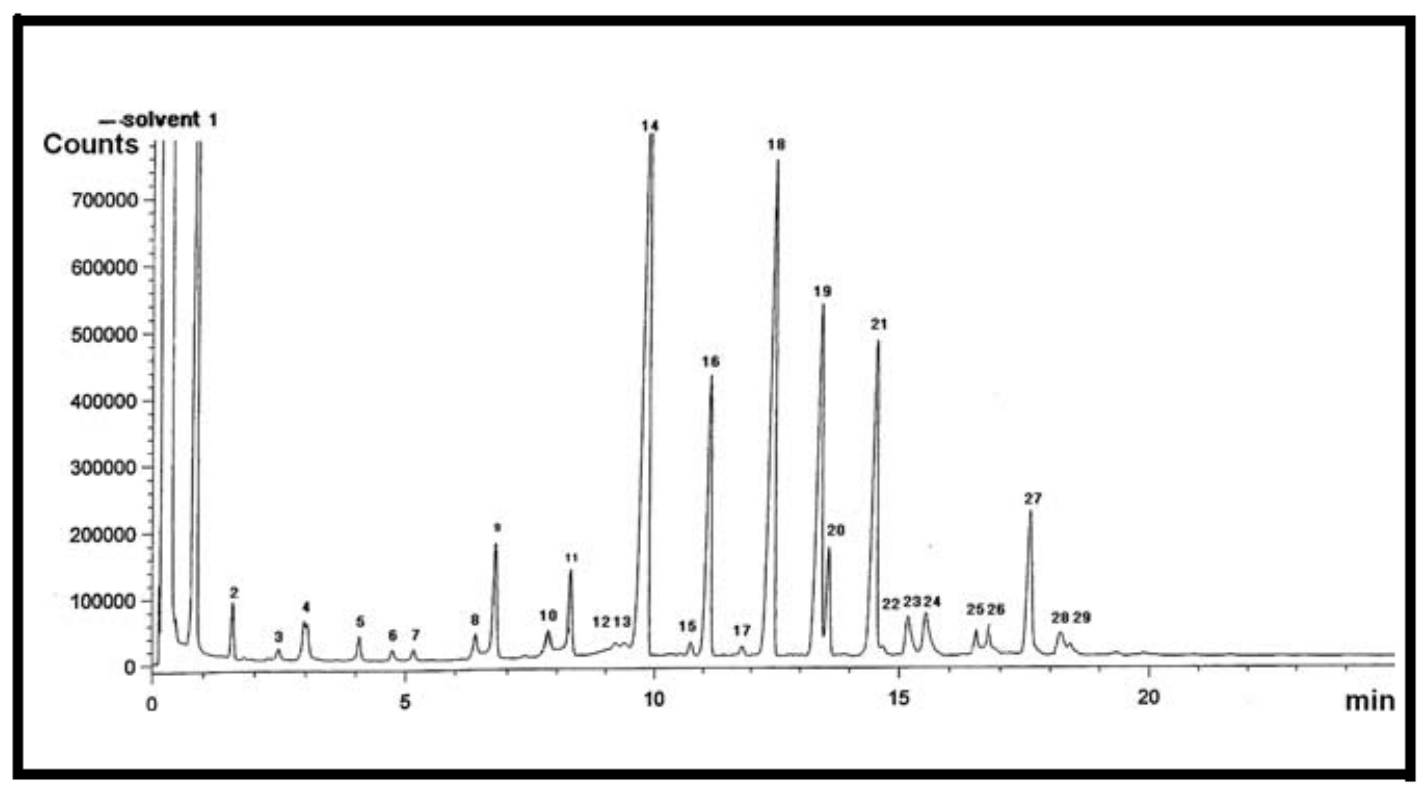

Figura 19 - Cromatograma do trimethylsilyldiethanolamide polyol, dimetano-amina derivada do óleo de dendê (67). 
Os picos representam os compostos presentes na amostra, aminas ácidos graxos, gliceróis e algumas substâncias desconhecidas. Os picos que correspondem aos ácidos graxos do óleo de dendê são os de números 12, 14 e 16, (67).

\subsubsection{Viscosidade}

A viscosidade de um óleo tem grande influência no desempenho desse óleo como fluido de têmpera, pois a têmpera está intimamente relacionada à capacidade de molhamento do fluido e, consequentemente, na sua capacidade de extração de calor. Uma melhor circulação do óleo e uma maior turbulência do mesmo é consequência de uma baixa viscosidade, pois facilita a dissipação do calor através da peça e favorece a quebra da camada de vapor no primeiro estágio, aumentando a taxa de resfriamento no estágio de nucleação de bolhas (25).

A facilidade de molhamento de um meio de resfriamento na superfície do metal é uma das características mais importantes desse meio $(10,68,69)$. A viscosidade do meio está diretamente relacionada com esse molhamento, ou seja, uma diminuição da viscosidade diminui a tensão superficial do meio e consequentemente melhora a molhabilidade. A Figura 20 ilustra a relação entre a superfície de molhamento e o ângulo de contato.

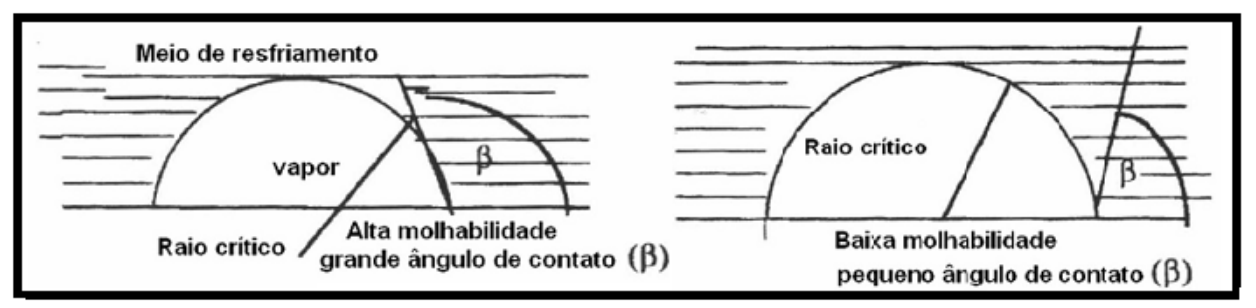

Figura 20 - Relação entre a superfície de molhamento e o ângulo de contato (68).

Nota-se, na Figura 21, que o meio que exibe o maior ângulo de contato possui um maior contato líquido com a superfície do metal. Totten et al.,1993 relacionam a viscosidade com o ângulo de contato, que é uma medida quantitativa de habilidade do óleo para molhar a superfície do aço. Assim, um aumento da viscosidade produz uma diminuição do ângulo de contato e, consequentemente, 
diminuição da taxa máxima de resfriamento. A Figura 21 mostra a relação da viscosidade e o ângulo de contato na taxa máxima de resfriamento.

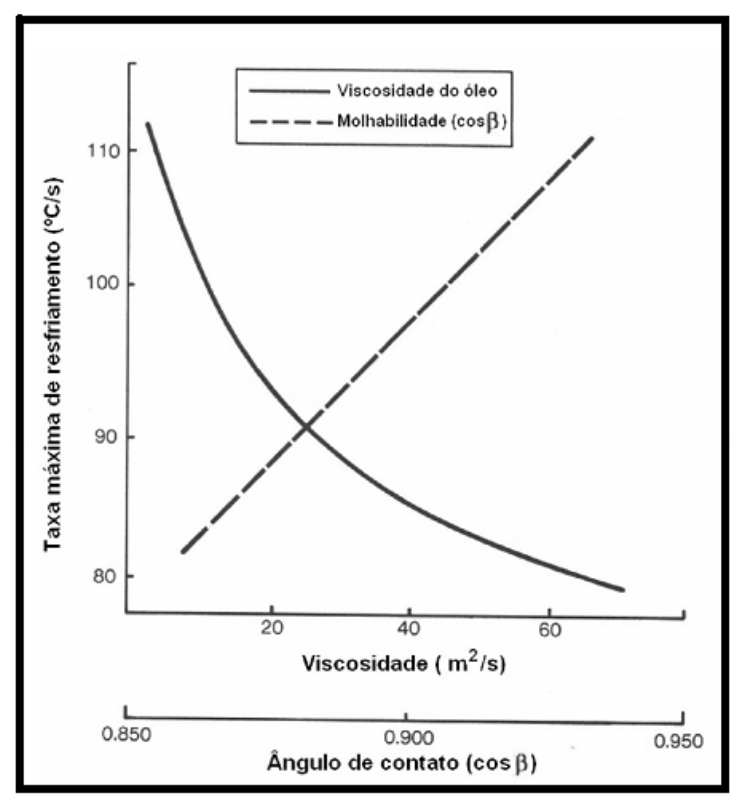

Figura 21 - Relação da viscosidade e do ângulo de contato (molhabilidade) na taxa máxima de resfriamento (9).

Em geral, a viscosidade aumenta à medida que o óleo se degrada, resultando em mudanças na característica de resfriamento do óleo. Mudanças na viscosidade de um óleo de têmpera podem indicar oxidação e degradação térmica ou a presença de contaminantes (70).

A viscosidade dos óleos vegetais é influenciada por um número de fatores, que inclui as propriedades físicas e químicas, tais como densidade, peso molecular, ponto de fusão e grau de insaturação. Um fator que afeta extremamente a viscosidade dos óleos é a temperatura (71). A Figura 22 mostra a variação da viscosidade com o aumento da temperatura para o óleo de arroz (48). 


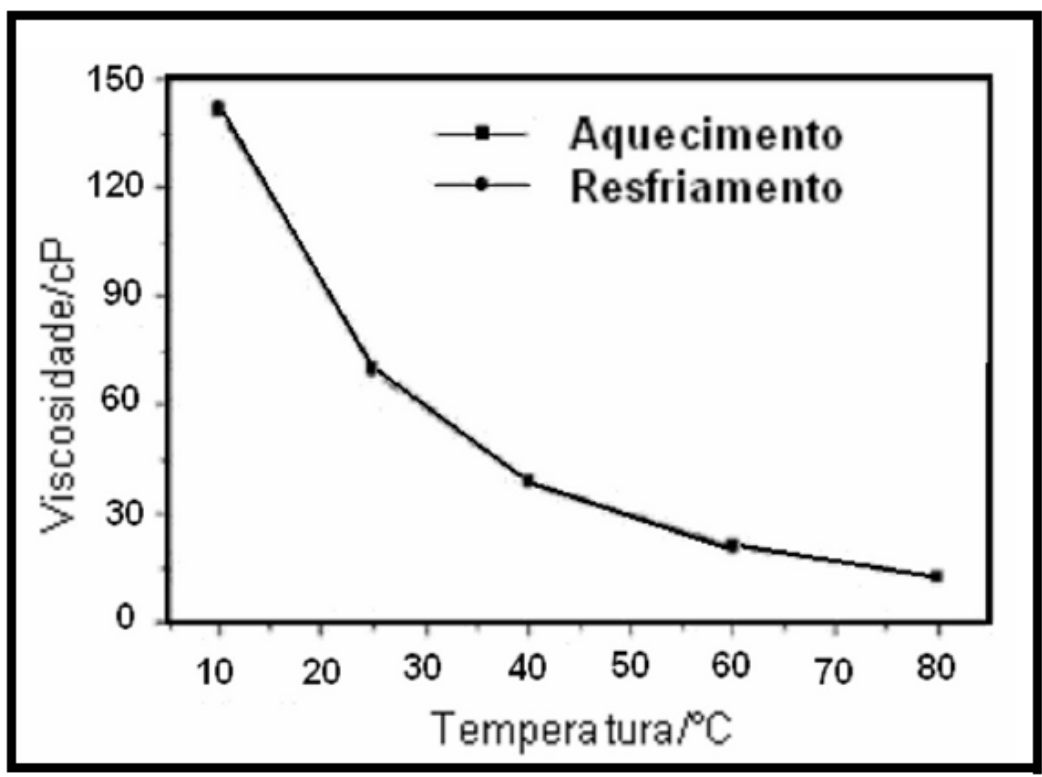

Figura 22 - Variação da viscosidade de acordo com a temperatura para o óleo de arroz, (48).

Essa diminuição da viscosidade se dá devido ao maior movimento térmico das moléculas, além da redução da força de ligação intermolecular, que faz com que o fluxo entre as ligações seja mais fácil. As propriedades termoanalíticas e cinéticas dos óleos vegetais comestíveis dependem da composição e são mudadas com a presença de antioxidantes artificiais.

As aplicações industriais dos óleos vegetais em que há variações de temperatura são boas, de acordo com Igwe, 2004 (71). Um exemplo de tal aplicação é a produção das resinas alkyd, que são sinterizadas industrialmente em temperaturas entre 200 e $265^{\circ} \mathrm{C}$. Para tais aplicações, torna-se importante o estudo da viscosidade da solução básica dos óleos vegetais.

Nesse contexto insere-se esse trabalho sobre óleos vegetais para uso em têmpera, que pretende analisar diversas amostras de óleos vegetais, com e sem a aditivação de antioxidantes. 


\section{MATERIAIS E MÉTODOS}

Abaixo serão apresentados os materiais usados e equipamentos utilizados e os ensaios e procedimentos realizados neste trabalho.

\subsection{Amostras dos Óleos e Estruturas dos Antioxidantes}

Foram utilizados 30 litros de óleo de soja * , comprados em supermercado em vasilhames de $900 \mathrm{~mL}$, e 18 litros de óleo de dendê comercializados por A. Azevedo ind. e comércio de óleos Ltda.

Os aditivos antioxidantes utilizados foram o Irganox L 109 e o Galato de Propila, que foram selecionados por já terem sidos estudados e por descreveram os melhores desempenhos nos trabalhos desenvolvidos anteriormente por Souza, 2007 (72). Esses antioxidantes foram adicionados aos óleos de soja e dendê em proporções de massa de no máximo 5\%, como listados a seguir.

1\% Irganox L109;

3\% Irganox L109;

5\% Irganox L109;

1\% Galato de Propila;

2\% Galato de Propila;

3\% Galato de Propila.

Além dessas amostras também foram testados mais três antioxidantes, somente no óleo de soja e na proporção de 1\% em massa, são eles:

Fenil-a-Nafitilamina (PANA ${ }^{* *}$ );

Bisfenol A;

Difenilamina.

A homogeneização desses antioxidantes no óleo ocorreu com agitação constante e aquecimento a $40^{\circ} \mathrm{C}$ por $20 \mathrm{~min}$.

As estruturas dos antioxidantes são apresentadas na Fig 23.

\footnotetext{
* Antioxidante PANA foi gentilmente cedido pela empresa Chemtura.

** Óleo de soja da marca Soya.
} 


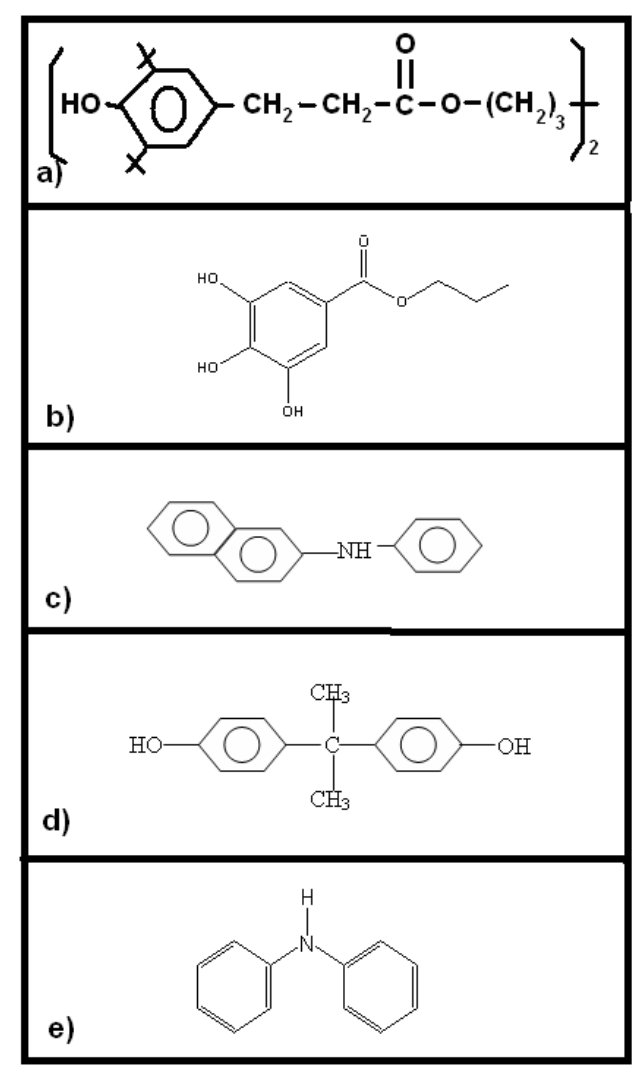

Figura 23 - Estruturas de: a) Irganox L109, b) Galato de Propila, c) Bisfenol A, d) Difelamina e e) PANA.

\subsection{Ensaios}

\subsubsection{Ressonância Magnética Nuclear}

Os espectros de RMN de $\mathrm{H}^{1}$ foram obtidos usando um espectrômetro Varain Unity Inova $400 \mathrm{MHz}$ (freqüência de observação para o núcleo de $\mathrm{H}^{1}$ de 399,9 MHz). Os de RMN de $\mathrm{C}^{13}$ foram obtidos usando em um espectrômetro Bruker AC - 200 (freqüência de observação para o núcleo de $\mathrm{C}^{13}$ de $50,32 \mathrm{MHz}$ ). As amostras foram preparadas dissolvendo-se $20 \mathrm{mg}$ de óleo em $0,7 \mathrm{~mL}$ de clorofórmio deuterado $\left(\mathrm{CDCl}_{3} 99,8 \%\right)$ em tubos de $5 \mathrm{~mm}$. 
Para o RMN de $\mathrm{H}^{1}$ foram utilizados os seguintes parâmetros de aquisição: pulso $=45^{\circ}$; tempo de aquisição $=3,14 \mathrm{~s}$; tempo de espera $=3 \mathrm{~s}$ e número de varreduras $=16$.

Para as medidas quantitativas de RMN de $\mathrm{C}^{13}$, foi utilizado um espectrômetro Bruker, modelo AC-200, Figura 24, operando no modo FT à temperatura ambiente, o programa INVGATE (inverse gated decoupling) e os seguintes parâmetros de aquisição: pulso $=90$; tempo se espera $=40 \mathrm{~s}$, tempo de aquisição $=1,4 \mathrm{~s}$, e número de varreduras $=2000$.

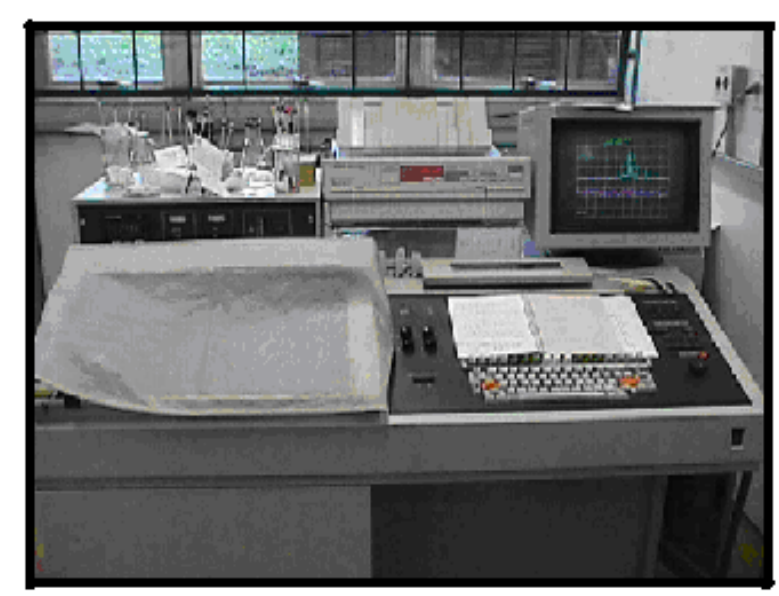

Figura 24 - Espectrômetro Bruker, modelo AC-200.

Os sinais através do espectro foram adquiridos de acordo com Adhvaryu et al., 2000 (38).

\subsubsection{Cromatografia Gasosa}

As análises de cromatografia gasosa foram realizadas em um cromatógrafo a gás GC-17A da marca Shimadzu, Figura 25. Utilizou-se $\mathrm{N}_{2}$ como gás de arraste a uma velocidade linear média de $35 \mathrm{~cm} / \mathrm{s}$, e um sistema de injeção no modo splitless de 1:30, para um volume de $1 \mu \mathrm{L}$. As temperaturas do injetor e da interfase foram ambas $300{ }^{\circ} \mathrm{C}$. Realizou-se estas análises com uma coluna capilar de sílica fundida LM-100 (Carbowax 50M, polietileno glicol) com dimensões de $50 \mathrm{~m} \times 0,25 \mathrm{~mm} \times$ 0,32 $\mu \mathrm{m}$. A temperatura inicial do forno foi de $100{ }^{\circ} \mathrm{C}$, mantendo-se esta temperatura por 
10 min, aquecendo-se até $300{ }^{\circ} \mathrm{C}$ numa taxa de $10{ }^{\circ} \mathrm{Cl}$ min, manteve-se a temperatura final isotérmica por 20 minutos. O detector utilizado foi um flame ionization detector (FID), ou seja, detector por ionização de chama.

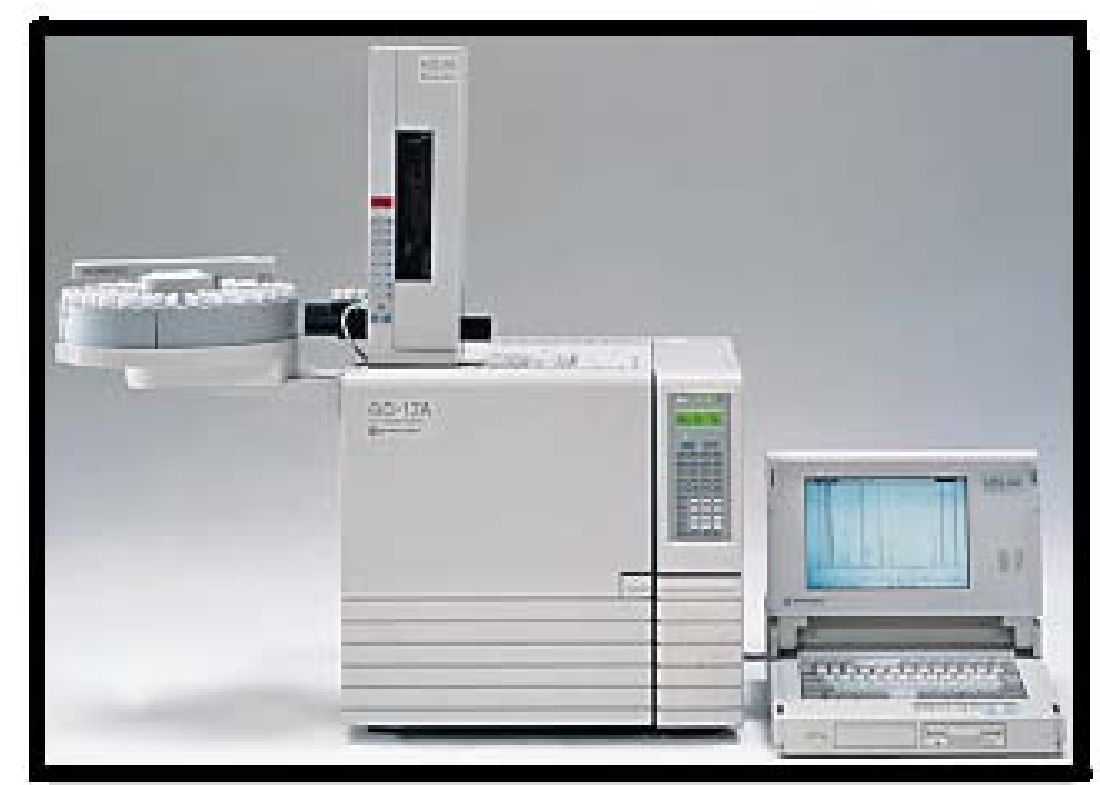

Figura 25 - Cromatógrafo a gás GC-17A da marca Shimadzu.

Fez-se a quantificação dos ésteres metílicos de ácidos graxos através da normalização das áreas dos picos.

\subsubsection{Viscosidade}

As medidas de viscosidade das amostras de óleo de soja foram realizadas em um viscosímetro AVS - 350 da marca Schott-Geräte, Figura 26, utilizando-se um capilar de vidro (do tipo Ubbelohde, tubo $2 \mathrm{C}$ ), seguindo a norma técnica ABNT NBR 10441 - 10/02 (73). 


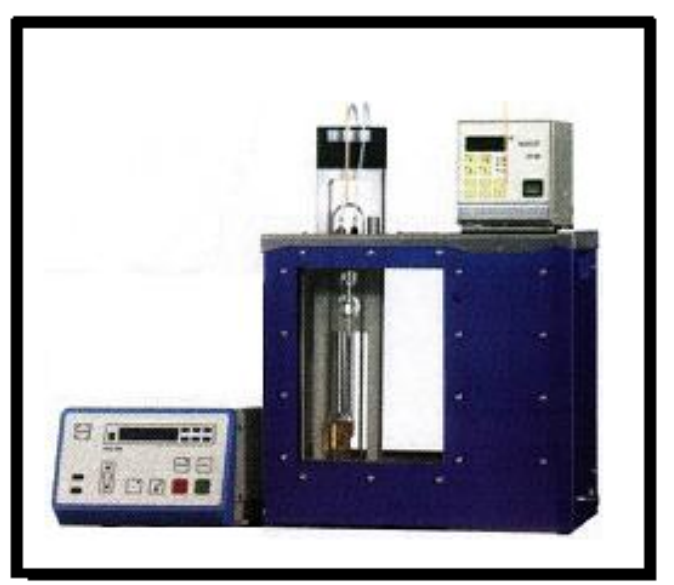

Figura 26- Viscosímetro AVS - 350 da marca Schott-Geräte.

A medida consiste em se conectar uma mangueira de sucção ao capilar de vidro para que a amostra, de volume de $15 \mathrm{~mL}$, se eleve dentro do mesmo. Esse capilar é inserido dentro de um banho de água a $40{ }^{\circ} \mathrm{C}$ onde ficará até final da medição. Antes que o teste se inicie, a amostra fica por 5 minutos em repouso no banho para estabilizar a temperatura. Passado os 5 minutos, o teste é iniciado: a mangueira de sucção eleva o volume de óleo e ao soltá-lo começa a escorrer. O capilar possui dois sensores e quando o óleo passa pelo primeiro um contador de tempo é ativado e só desligado quando todo o volume passa pelo segundo sensor. A viscosidade é calculada de acordo com o intervalo de tempo que a amostra leva para percorrer a distância entre os dois sensores do capilar. Esse intervalo de tempo é registrado num computador e a medida é repetida mais duas vezes, depois é feita uma média e a viscosidade é calculada a partir dessa média e de uma constante própria do capilar. Dessa forma quanto mais viscosa for a amostra, mais tempo ela levará para percorrer esse caminho. Terminada a medida, o capilar de vidro é lavado com álcool etílico e água destilada, abundantemente e, por fim, é passada acetona para secar.

As amostras de óleo de dendê são mais viscosas em comparação com as de óleo de soja, portanto necessitaram de um outro método de medição. Foi utilizado um reômetro Brookfield DV-III Ultra e spindle 51. Ao reômetro é acoplado um banho térmico que mantém a temperatura em $40{ }^{\circ} \mathrm{C}$. As medidas foram realizadas duas vezes e registradas no computador pelo software Rheocalc V3.1, que faz o cálculo da viscosidade dinâmica a partir da velocidade do spindle e do torque exercido na amostra. A figura 27 mostra o equipamento utilizado. Após esse procedimento mediu-se o volume em um picnômetro, a massa em uma balança e calculada a 
densidade. Por fim foi feito o cálculo da viscosidade cinemática, que é dada pela razão entre a viscosidade dinâmica e a densidade.

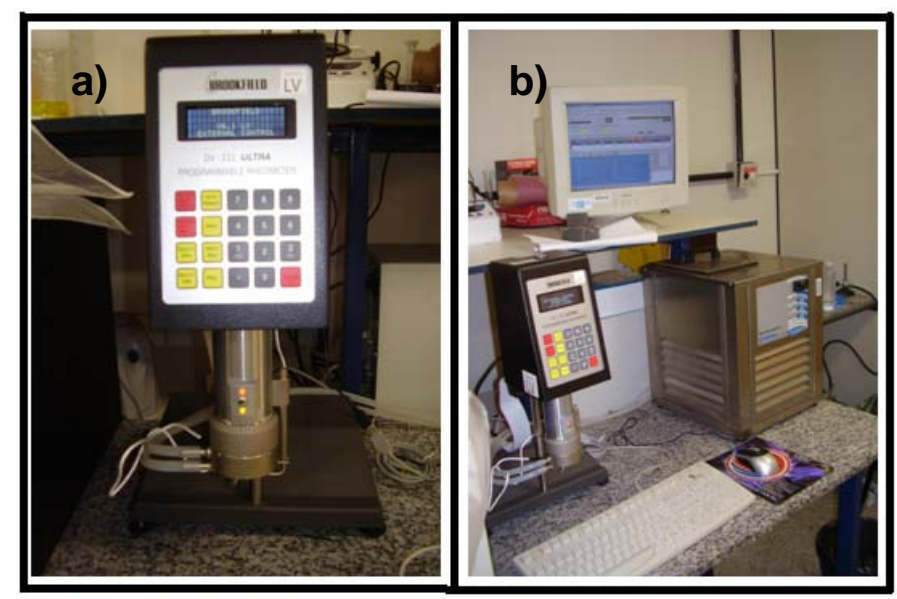

Figura 27 - a) Reômetro Brookifield, b) esquema utilizado para medir a viscosidade das amostras de óleo de dendê: o viscosímetro, banho e software de computador.

\subsubsection{Calorimetria Exploratória Diferencial com Pressão}

Foram preparados três cadinhos com aproximadamente 2,0 mg de amostra, pesadas como auxílio de uma micro seringa, de cada um dos óleos nas seguintes condições: puros e adicionados de anti-oxidantes e sem envelhecer. As amostras foram preparadas de maneira individual, poucos instantes antes do início da análise, para evitar que possíveis perdas por evaporação ocorressem e para que não houvesse chances de contaminação ou troca de cadinhos. O cadinho (já com a amostra) e um cadinho de referência foram então colocados no interior da célula de pressão, que teve sua tampa devidamente fechada.

Após o fechamento, o sistema foi então pressurizado com oxigênio ultrapuro até atingir a pressão de 3500 psi. Quando a pressão foi alcançada e estabilizada, deu-se início a análise. Foram feitos, ao todo, oito lotes de análises via PDSC.

Um lote pelo método isotérmico e os demais pelo método dinâmico. $\mathrm{Na}$ análise isotérmica, o intuito foi verificar o tempo de início de oxidação e na análise dinâmica, verificar a temperatura e o tempo inicial 
de oxidação. Para a análise isotérmica, o programa de aquecimento foi organizado da seguinte forma:

- $\quad$ Equilibrar a $80^{\circ} \mathrm{C}$;

- $\quad$ Rampa de $10^{\circ} \mathrm{C} \cdot \mathrm{min}^{-1}$ até $140^{\circ} \mathrm{C}$;

- Temperatura constante por 30 minutos.

E para as análises dinâmicas, o programa de aquecimento foi organizado da seguinte maneira:

- $\quad$ Equilibrar a $80^{\circ} \mathrm{C}$;

- $\quad$ Rampa de $10^{\circ} \mathrm{C} \cdot \mathrm{min}^{-1}$ até $220^{\circ} \mathrm{C}$;

- $\quad$ Temperatura constante por 1 minuto.

\subsubsection{Ensaio de Envelhecimento Acelerado}

O equipamento de envelhecimento acelerado foi construído para induzir o processo de oxidação em óleos vegetais estudados por Farah, 2002 (22), sofrendo algumas modificações até então. Ele foi projetado e construído dentro do Departamento de Materiais, Aeronáutica e Automobilística da Universidade de São Paulo, USP, campus de São Carlos. Foi baseado no equipamento proposto por Bashford e Mills, 1984 (25).

O princípio de funcionamento do equipamento consiste em acelerar o processo de oxidação dos óleos de têmpera através de choques térmicos contínuos provocados pelo aquecimento de uma resistência elétrica, seguido de um resfriamento por um sistema de fluxo de água.

O sistema de aquecimento do óleo é comandado por um Controlador de Temperatura Microprocessado CNT 120, onde uma resistência elétrica de 3000 W é aquecida sob agitação mecânica e aeração até que a temperatura do óleo atinja 150 ${ }^{\circ} \mathrm{C}$, essa temperatura é mantida por certo tempo, para depois dar início ao processo de resfriamento e choque térmico.

A temperatura do óleo é controlada por um termopar tipo J, a agitação mecânica é proporcionada por uma hélice acoplada a um motor com controle de velocidade e a aeração é feita por um fluxo de ar comprimido que também é 
controlado. A função do controlador microprocessado é regular a temperatura do óleo em $150^{\circ} \mathrm{C} \mathrm{e}$, depois de aproximadamente $15 \mathrm{~min}$, para $120^{\circ} \mathrm{C}$.

As Figuras 28 e 29 mostram a foto e um esquema do equipamento de envelhecimento acelerado, respectivamente.

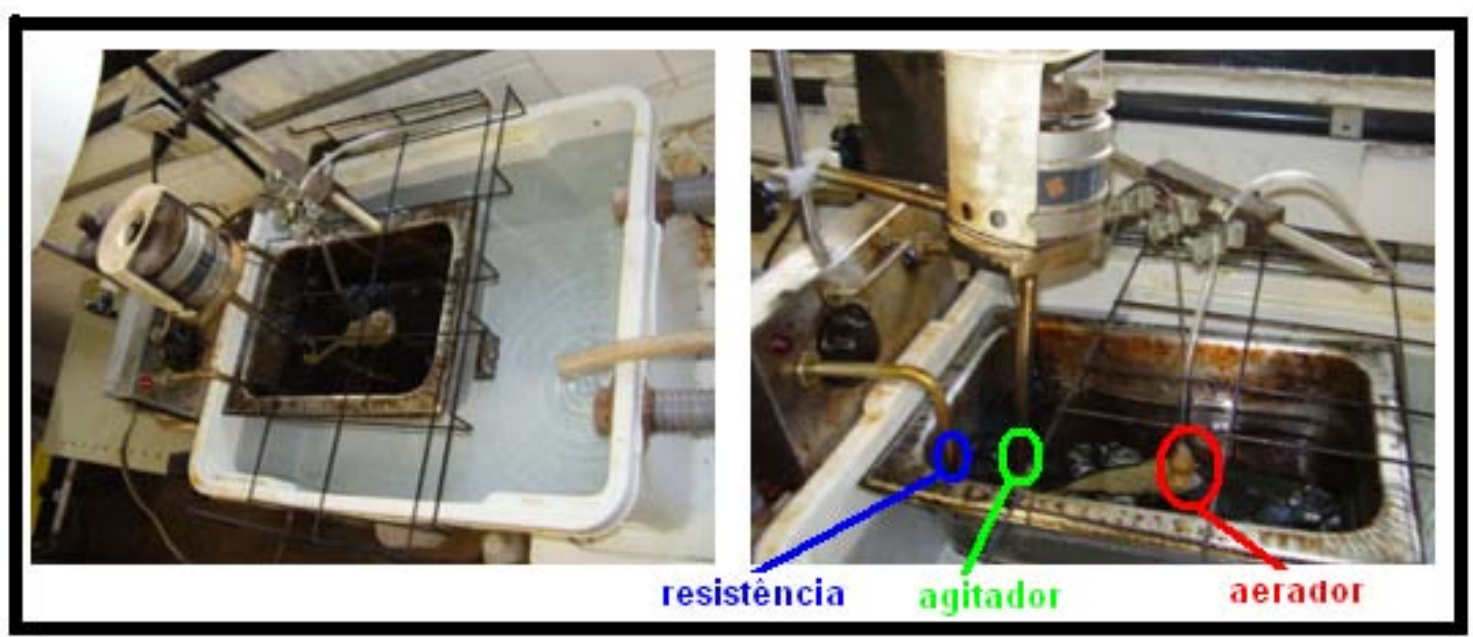

Figura 28 - Equipamento de envelhecimento acelerado: a) visto de cima, b) detalhe o agitador, a resistência e o aerador.

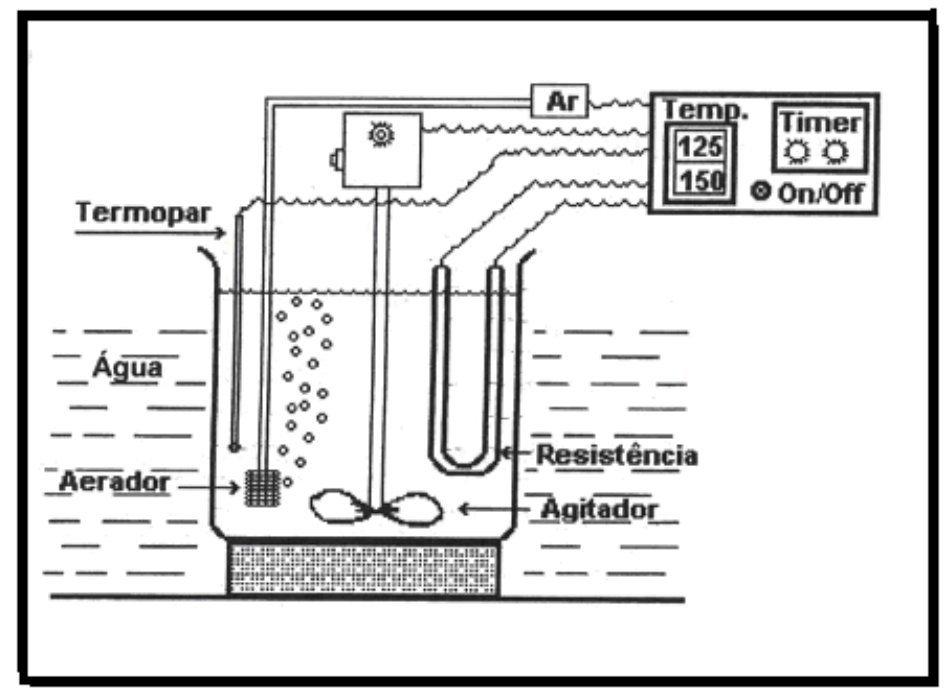

Figura 29 - Ilustração do sistema de envelhecimento de óleo (22).

Para o sistema de resfriamento do sistema é utilizada uma caixa de plástico com as seguintes dimensões: $650 \mathrm{~mm}$ comprimento, $450 \mathrm{~mm}$ de largura e $200 \mathrm{~mm}$ de altura. A caixa possui duas saídas para água e uma entrada que é controlada por uma válvula. O resfriamento se dá pela entrada de água fria no sistema pela válvula e pelo contato dessa água com o recipiente onde está o óleo. Um esquema da caixa pode ser visto na Figura 30. 


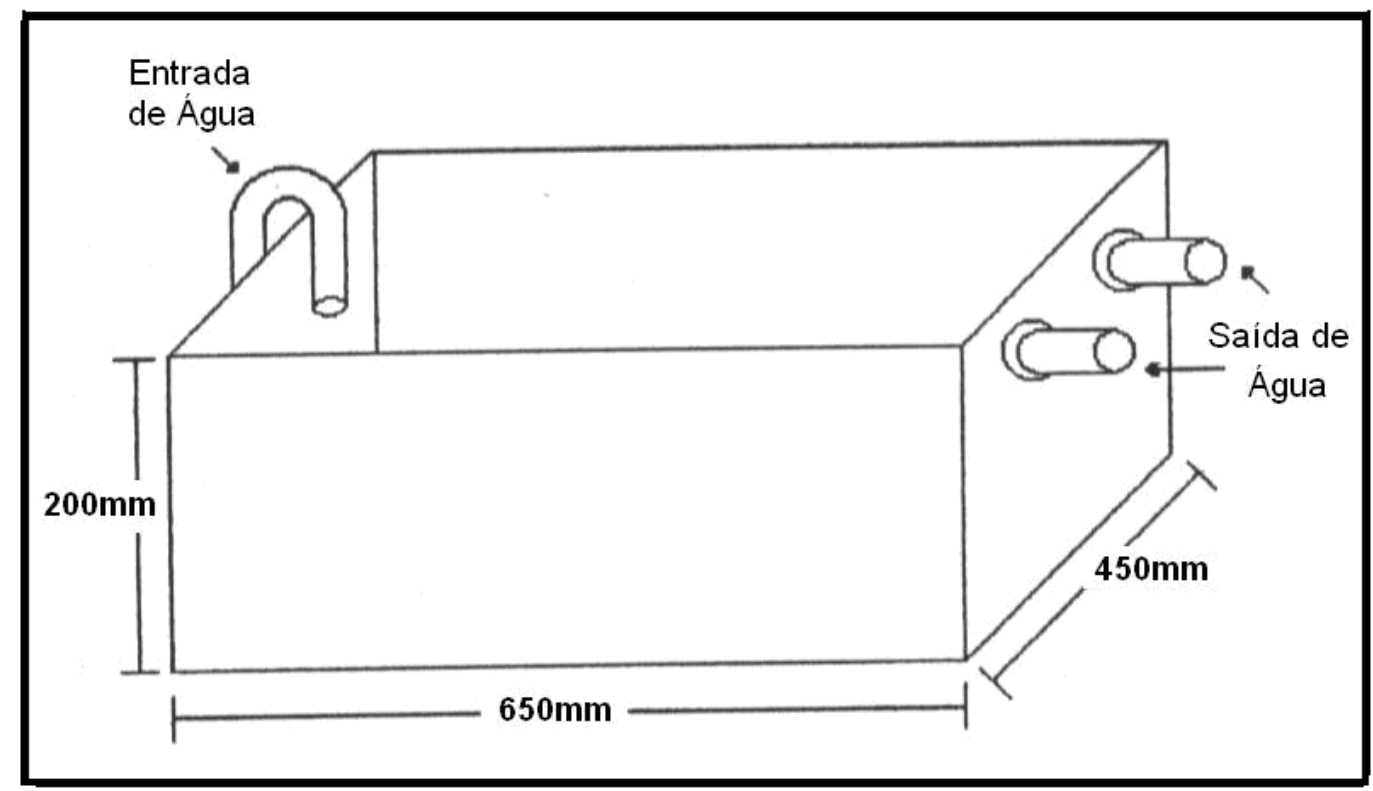

Figura 30 - llustração da caixa usada no resfriamento do sistema (22).

Para esse ensaio utiliza-se inicialmente um volume aproximado de 2,7 L de amostra de óleo que é colocado numa bacia de metal dentro da caixa com água. Feito isso, a resistência do sistema eleva a temperatura do óleo da temperatura ambiente até a $150^{\circ} \mathrm{C}$, tendo uma variação de $\pm 3^{\circ} \mathrm{C}$, sendo mantida durante aproximadamente 15 minutos sob agitação e aeração. A aeração é feita por um fluxo de $\operatorname{ar}$ de $4 \mathrm{~L}$ por hora, havendo uma diminuição do mesmo durante o processo de envelhecimento do óleo, devido à mudança na sua viscosidade. Sua função é introduzir ar no sistema para que o processo de oxidação seja mais acelerado. Já a agitação proporciona uma melhor homogeneização do meio em relação à temperatura e quantidade de ar soprado dentro do sistema.

Passado esse tempo de 15 minutos a resistência é desligada. Nesse momento a válvula é acionada pelo controlador microprocessado, liberando um fluxo de água que faz com que a amostra de óleo seja resfriada até $120^{\circ} \mathrm{C}$. Atingindo essa temperatura, o óleo é novamente aquecido até $150^{\circ} \mathrm{C}$ e o processo é repetido. Isso é feito durante 48 horas, interrompidas a cada 12 horas para a realização das curvas de resfriamento e retorno ao sistema de envelhecimento sem mais adição de óleo. 


\subsubsection{Curvas de Resfriamento}

As curvas de resfriamento foram obtidas através de um sistema de aquisição de dados desenvolvido especialmente para esta finalidade. O equipamento conta com uma sonda normalizada tipo Wolfson, (ISO 9950) semelhante à desenvolvida por Bodin e Segerberg, 1993 (74), com um termopar do tipo K (NiCr/NiAl) no seu centro geométrico, para a captação de mudança de temperatura durante 0 resfriamento do fluido. A sonda padrão é cilíndrica feita de inconel 600 com dimensões de 12,5 mm de diâmetro por $60 \mathrm{~mm}$ de comprimento, a qual é aquecida até a $850{ }^{\circ} \mathrm{C}$ e resfriada imediatamente no fluido analisado. Utiliza-se aproximadamente neste ensaio $2 \mathrm{~L}$ de fluido. Esse procedimento foi feito de acordo com a norma ASTM D6200-01. A Figura 31 mostra uma ilustração do esquema do equipamento de curvas de resfriamento.

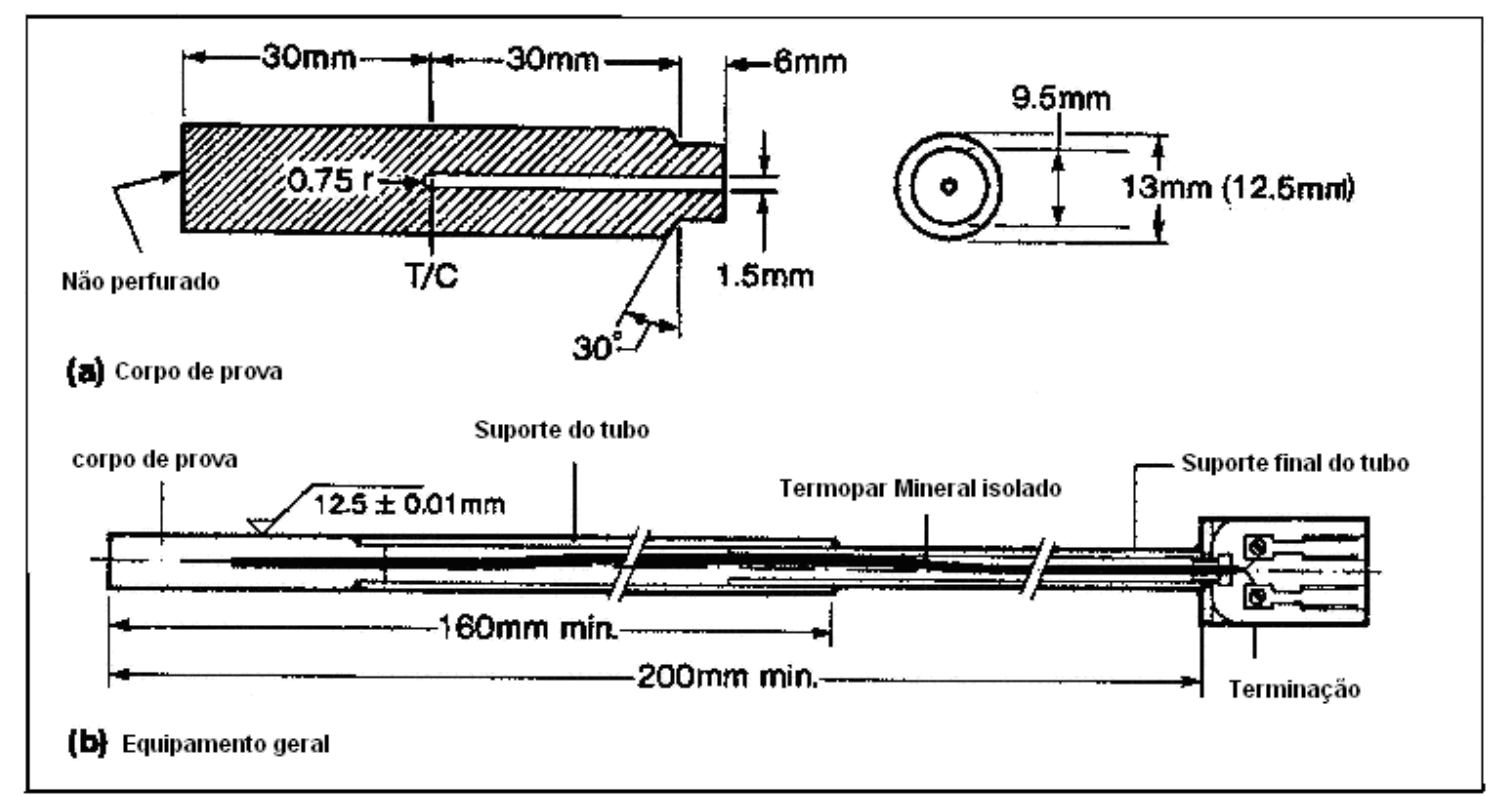

Figura 31 - Esquema do equipamento de curvas de resfriamento (adaptado (22)).

Os dados obtidos são transferidos para um computador, via placa A/D, mostrando em tempo real a curva de resfriamento e processado em seguida a taxa de resfriamento. No monitor do computador é mostrada a taxa máxima obtida pelo fluido ensaiado e também, a temperatura na qual essa taxa máxima ocorre.

A aquisição dessas curvas foi feita sempre a $60^{\circ} \mathrm{C}$ com os óleos de soja e dendê puros e com antioxidantes nos estados não-oxidados e a cada 12 h de 
envelhecimento acelerado totalizando no final $48 \mathrm{~h}$ para as amostras de óleo de soja e $60 \mathrm{~h}$ para as de dendê, possibilitando assim analisar o comportamento das misturas em diferentes tempos de uso.

\subsubsection{Testes Metalográficos}

Utilizaram-se duas ligas metálicas: AISI 1045 e AISI 4140. Para a liga 1045 foram utilizadas amostras de diâmetro de $1 / 2$ " e 1 " de espessura. Para a liga 4140 as amostram tinham 1 " e $2 \frac{1}{2}$ " de diâmetro e 1 " de espessura. Essas dimensões foram escolhidas pois o aço AISI 1045 tem menor temperabilidade do que o AISI 4140. A Tabela 4 que apresenta o cálculo de DI das ligas utilizadas. O cálculo do DI foi feito segundo Rajan et. al., 1992 (19), admitindo tamanho de grão ASTM-8. Podese notar pela Tabela 4 que a temperabilidade varia sobre uma larga escala.

Tabela 4 - Composição e valores teóricos de DI, para as ligas AISI 1045 e AISI 4140.

\begin{tabular}{lccccccc}
\hline Liga & $\% \mathrm{C}$ & $\% \mathrm{Si}$ & $\% \mathrm{Mn}$ & $\% \mathrm{Cr}$ & $\% \mathrm{Mo}$ & $\mathrm{DI} \mathrm{I}_{\text {mín }}$ & $\mathrm{DI}_{\text {máx }}$ \\
\hline AISI & $0,37-0,44$ & $0,1-0,2$ & $0,6-0,9$ & --- & --- & 0,5 “ & 1,0 “ \\
1045 & & & & & & & \\
AISI & $0,38-0,43$ & $0,2-0,35$ & $0,75-1,0$ & $0,8-1,1$ & $0,15-0,25$ & 2,5 “ & 6,0 “ \\
4140 & 0,4
\end{tabular}

Essas amostras foram autenitizadas a $880{ }^{\circ} \mathrm{C}$ até total homogeneização da temperatura e resfriadas nos óleos vegetais e minerais aquecidos a $60{ }^{\circ} \mathrm{C}$, sem agitação. Os óleos usados como fluidos de resfriamento foram:

- Soja + $5 \%$ de Irganox L109,

- Dendê + $2 \%$ Galato de Propila,

- Mineral 1 (convencional), e

- Mineral 2 (rápido).

A preparação metalográfica das amostras foi feita de acordo com técnicas convencionais. 
As micrografias das peças metálicas foram feitas em um microscópio óptico Olympus BX60M e capturadas por uma câmera fotográfica Sony cybershot DSC-N2, acoplada ao mesmo.

\subsubsection{Ensaio de Dureza}

As durezas das peças metálicas foram medidas automaticamente em uma máquina Leco RT - 240 Hardness tester, mostrada na Figura 32. A escala utilizada foi a Rockwell C com $150 \mathrm{Kg}$, de acordo com a norma ASTM E 140-07 (75). Foram feitas três medidas no centro e na superfície de cada peça para se obter uma média.

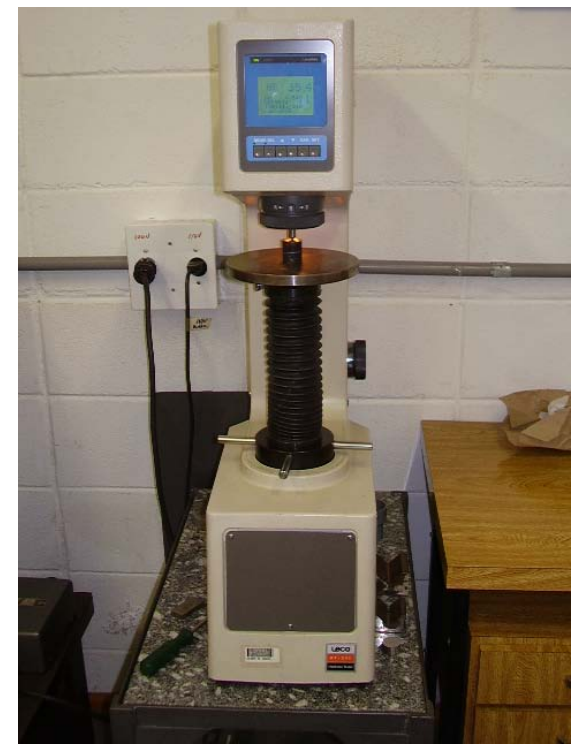

Figura 32 - Equipamento para medida de dureza na escala Rockwell C. 


\section{RESULTADOS E DISCUSSÃO}

$\mathrm{Na}$ primeira parte desse trabalho foi feita a caracterização de algumas propriedades dos óleos de soja e dendê em estado novo e sem adição de antioxidantes. Os resultados encontrados estão apresentados a seguir.

\subsection{Análise Físico-Química dos Óleos Vegetais Novos e Puros}

Os espectros e os dados obtidos a partir da Ressonância Magnética Nuclear $(R M N), H^{1}$, para os óleos de soja e dendê sem oxidação e sem adição de antioxidantes são mostrados na Figura 33 e Tabela 5, respectivamente.

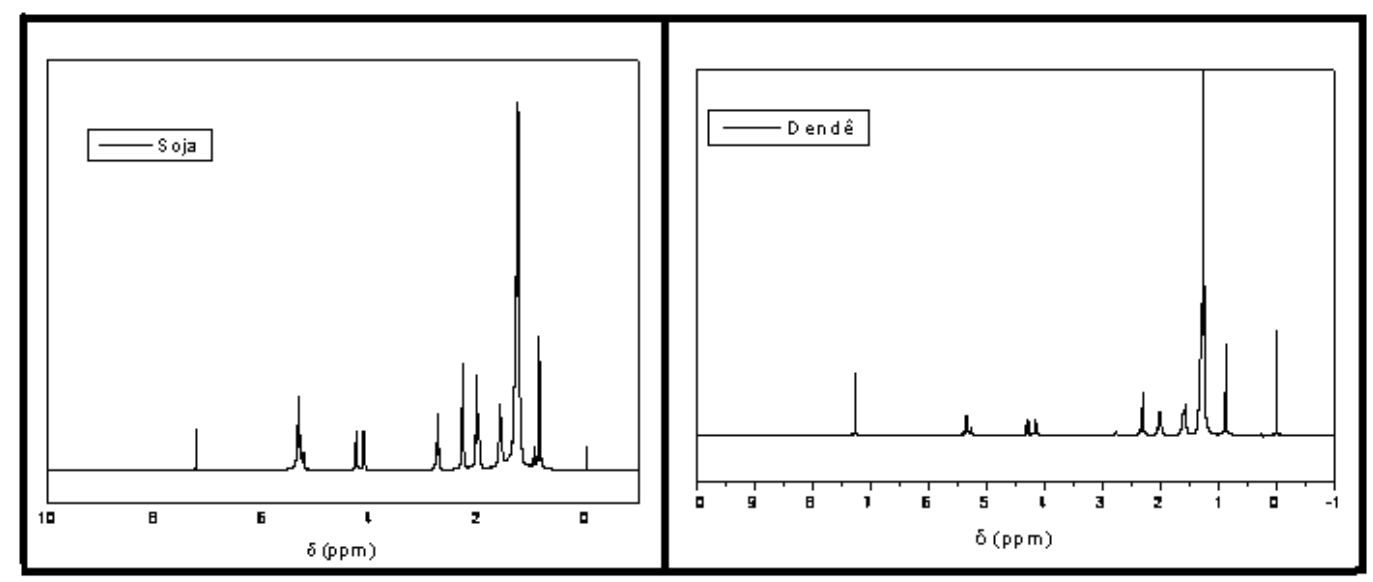

Figura 33 - Espectros de RMN $\mathrm{H}^{1}$ dos óleos de soja e dendê novos e sem aditivos.

Tabela 5 - RMN de $\mathrm{H}^{1}$ dos óleos vegetais novos e puros.

\begin{tabular}{lccccc}
\hline $\begin{array}{l}\text { Óleo } \\
\text { vegetal }\end{array}$ & $\begin{array}{c}\% \\
\text { Olefinicos }\end{array}$ & $\begin{array}{c}\% \mathrm{Bis} \\
\text { alílico } \mathrm{CH}_{2}\end{array}$ & $\begin{array}{c}\% \alpha \mathrm{CH}_{2} \\
\text { para C=O }\end{array}$ & $\begin{array}{c}\% \text { Alílico } \\
\mathrm{CH} 2\end{array}$ & $\begin{array}{c}\% \mathrm{CH}_{2} \\
\text { carbonos } \\
\text { saturados }\end{array}$ \\
\hline Soja & 7,51 & 6,41 & 9,87 & 9,13 & 49,86 \\
Dendê & 2,93 & 5,79 & 5,79 & 10,27 & 61,77 \\
\hline
\end{tabular}

Diferentes parâmetros estruturais participam na reação nos diversos estágios de oxidação. Alguns parâmetros têm significante efeito no processo de oxidação, tais como os grupos dos prótons bis-alílicos e $\alpha-\mathrm{CH}_{2}$ para $\mathrm{C}=\mathrm{O}$ (38). Observando 
tais grupos na Tabela 5, pode-se verificar que o óleo de soja apresenta maior tendência à oxidação.

Os espectros e os dados obtidos a partir da Ressonância Magnética Nuclear $(R M N), C^{13}$, para os óleos de soja e dendê sem oxidação e sem adição de antioxidantes são mostrados na Figura 34 e Tabela 6, respectivamente.

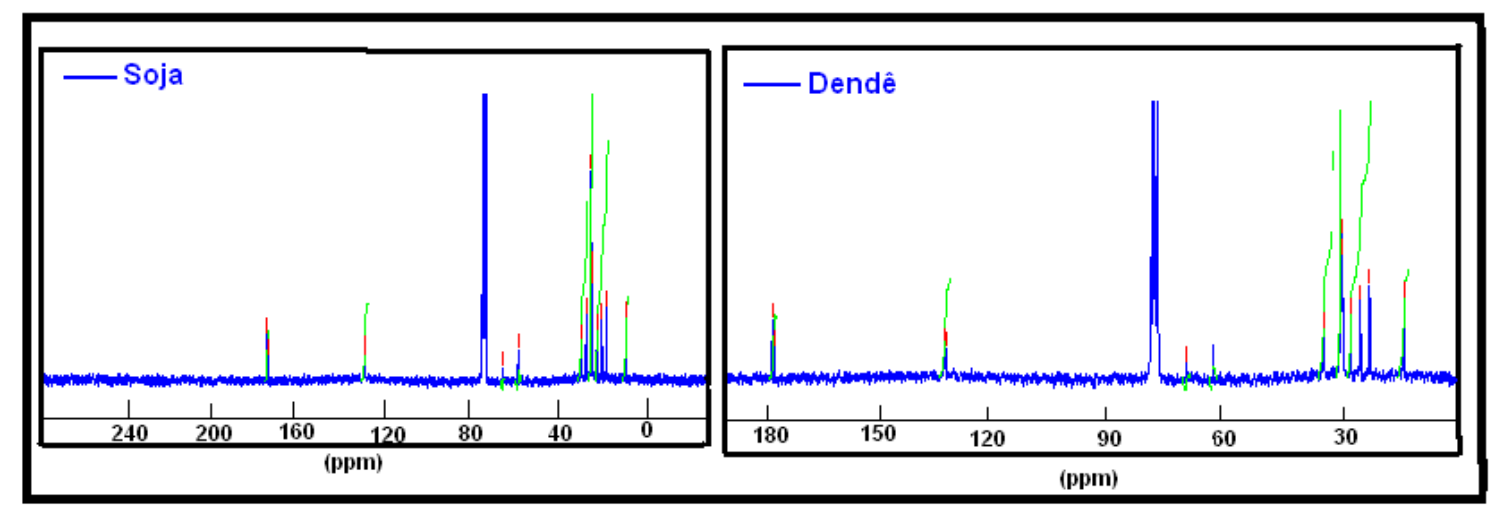

Figura 34 - Espectros de RMN $C^{13}$ dos óleos de soja e dendê novos e sem aditivos.

Tabela 6 - RMN de $\mathrm{C}^{13}$ dos óleos vegetais novos e puros.

\begin{tabular}{lccccc}
\hline $\begin{array}{l}\text { Óleo } \\
\text { vegetal }\end{array}$ & $\begin{array}{c}\% \\
\text { olefínicos }\end{array}$ & $\begin{array}{c}\% \mathrm{CH}_{2} \\
\text { saturados }\end{array}$ & $\begin{array}{c}\% \text { bis alílicos } \\
\mathrm{CH}_{2}\end{array}$ & $\begin{array}{c}\% \omega-2 \text { em C saturados em } \\
\text { ácidos mono e } \mathrm{n}-6 \text { em } \\
\text { polinsaturados }\end{array}$ & $\begin{array}{c}\% \\
3 \text { terminal } \\
\text { metil }\end{array}$ \\
\hline Soja & 15,57 & 36,59 & 8,74 & 5,31 & 4,86 \\
Dendê & 8,12 & 55,70 & 5,33 & 6,73 & 6,69 \\
\hline
\end{tabular}

Observando na Tabela 6 os grupos bis-alílicos e olefínicos confirmamos o que foi obtido no espectro de $\mathrm{H}^{1}$, ou seja, o óleo de soja apresenta maior tendência à oxidação. Nota-se também que os óleos vegetais possuem diferentes parâmetros estruturais. Estes resultados são consistentes com os encontrados por Adhvaryu, et al., 2000 (38).

A Tabela 7 apresenta os índices de acidez, iodo e saponificação para os óleos de soja e dendê.

Tabela 7 - Índices de iodo, acidez e saponificação dos óleos vegetais.

\begin{tabular}{lcc}
\hline Óleo vegetal & Soja & Dendê \\
\hline Índice de Acidez $(\mathrm{mgNaOH} / \mathrm{g})$ & 0,89 & 0,38 \\
Índice de lodo $\left(\mathrm{Cgl}_{2} / \mathrm{g}\right)$ & 11,15 & 4,49 \\
Índice de saponificação $(\mathrm{mgKOH} / \mathrm{g})$ & 196,68 & 201,27 \\
\hline
\end{tabular}


Pode-se observar que o índice de iodo é maior para o óleo de soja, indicando também uma maior tendência à oxidação, pois quanto maior é o índice de iodo, maior é o número de insaturações sendo, portanto, maior a probabilidade da ocorrência de processos oxidativos (59).

A acidez também é uma indicação do nível de oxidação do óleo e mais uma vez o óleo de soja apresentou maior tendência à oxidação.

O índice de saponificação é a medida da presença de ésteres ou componentes gordurosos no óleo. A oxidação do óleo causa um aumento no número de saponificação (26), esse foi o único indicativo onde o dendê mostrou-se mais propenso à oxidação.

A Tabela 8 apresenta os valores da viscosidade para os óleos novos e puros. Realizou-se o ensaio de viscosidade apenas a $40{ }^{\circ} \mathrm{C}$, pois a $100{ }^{\circ} \mathrm{C}$ os óleos envelhecidos se encontram num estado avançado de oxidação. Desse modo, os resultados de viscosidade em elevadas temperaturas são imprecisos. Assim a medida também não foi feita para os óleos novos por não ter parâmetros de comparação.

Tabela 8 - Viscosidade dos óleos vegetais novos e puros a $40^{\circ} \mathrm{C}$.

\begin{tabular}{lc}
\hline Óleo vegetal & Vicosidade (cSt) \\
\hline Soja & 31,6 \\
Dendê & 61,5 \\
\hline
\end{tabular}

Percebe-se com esses valores que a viscosidade do óleo de dendê é superior a do óleo de soja. Conforme já comentado, nos óleos vegetais, a viscosidade decresce com o aumento da temperatura. Isto se dá devido ao maior movimento térmico das moléculas, além da redução da força de ligação intermolecular, que faz com que o fluxo entre as ligações seja mais fácil, reduzindo a viscosidade (48). Portanto é de se esperar que esses valores sejam diferentes durante o banho a $60^{\circ} \mathrm{C}$.

As Tabelas 9 e 10 apresentam os resultados de OOT e OOt da análise de PDSC. 
Tabela 9 - Temperatura de OOT para os óleos de soja e dendê, novos e puros, taxa de aquecimento $10^{\circ} \mathrm{C} / \mathrm{min}$ até $220^{\circ} \mathrm{C}$.

\begin{tabular}{lcc}
\hline & Soja puro & Dendê puro \\
\hline Ensaio 1 $\left({ }^{\circ} \mathrm{C}\right)$ & 169,49 & 171,57 \\
Ensaio 2 $\left({ }^{\circ} \mathrm{C}\right)$ & 168,95 & 176,65 \\
Média $\left({ }^{\circ} \mathrm{C}\right)$ & 169,22 & 174,11 \\
$\begin{array}{l}\text { Quant. de } \\
\text { ensaios }\end{array}$ & 2 & 2 \\
$\begin{array}{l}\text { Desvio padrão } \\
\text { \% de desvio }\end{array}$ & 0,27 & 2,54 \\
padrão & 0,16 & 1,46 \\
\hline
\end{tabular}

Tabela 10 - Tempo de OOt para os óleos de soja e dendê, novos e puros, taxa de aquecimento $10^{\circ} \mathrm{C} / \mathrm{min}$ até $220^{\circ} \mathrm{C}$.

\begin{tabular}{lcc}
\hline & Soja puro & Dendê puro \\
\hline Ensaio 1 (min) & 10,26 & 10,58 \\
Ensaio 2 (min) & 10,34 & 11,01 \\
Média (min) & 10,30 & 10,80 \\
$\begin{array}{l}\text { Quant. de } \\
\text { ensaios }\end{array}$ & 2 & 2 \\
$\begin{array}{l}\text { Desvio padrão } \\
\text { \% de desvio }\end{array}$ & 0,40 & 0,22 \\
padrão & 3,88 & 2,04 \\
\hline
\end{tabular}

Percebe-se que o óleo de dendê apresenta 2,8 \% mais resistência à oxidação que o óleo de soja, pela análise de OOT e pela análise de OOt o valor é 4,9\% superior.

As curvas de resfriamento, relacionando temperatura por tempo para os óleos de soja e dendê, novos e puros, a $60^{\circ} \mathrm{C}$ estão mostradas na Figura 35. A Tabela 11 compara alguns valores destas curvas. 


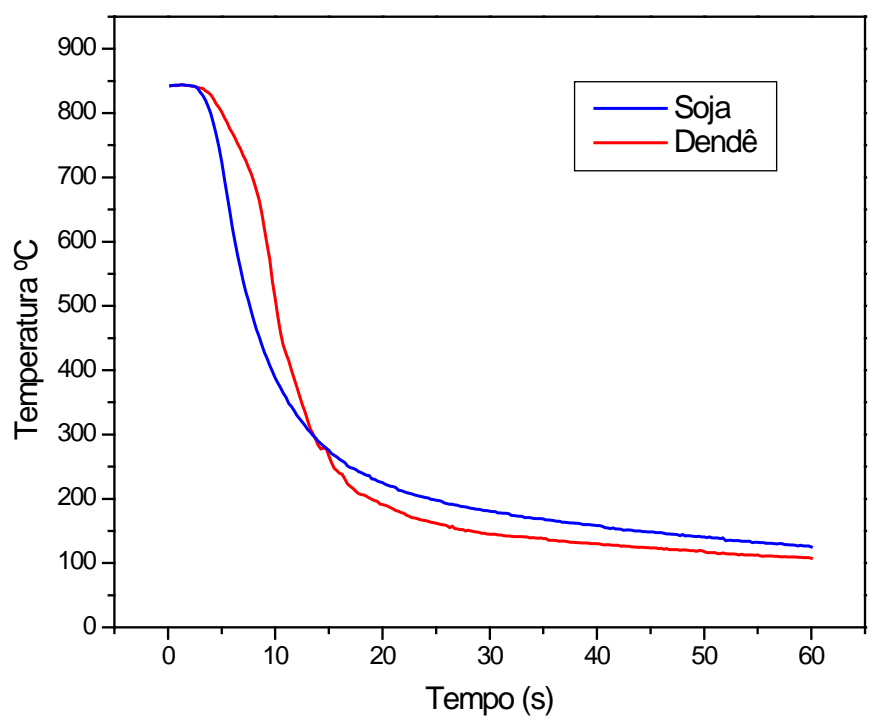

Figura 35 - Curvas de resfriamento, a $60^{\circ} \mathrm{C}$, relacionando temperatura por tempo para os óleos de soja e dendê, novos e puros.

Tabela 11 - Comparação entre o tempo de resfriamento dos óleos de soja e dendê, novos e puros.

\begin{tabular}{lccc}
\hline Óleo vegetal & $\begin{array}{c}\text { Tempo para } \\
\text { alcançar } 700^{\circ} \mathrm{C}\end{array}$ & $\begin{array}{c}\text { Tempo para } \\
\text { alcançar } 300^{\circ} \mathrm{C}\end{array}$ & $\begin{array}{c}\text { Tempo para } \\
\text { alcançar } 200^{\circ} \mathrm{C}\end{array}$ \\
\hline Soja & $5 \mathrm{~s}$ & $13 \mathrm{~s}$ & $24 \mathrm{~s}$ \\
Dendê & $7 \mathrm{~s}$ & $14 \mathrm{~s}$ & $19 \mathrm{~s}$ \\
\hline
\end{tabular}

Observa-se que, como é característico, ambos os óleos não apresentam em suas curvas o primeiro estágio de resfriamento (estágio de vapor). O óleo de dendê é mais rápido no terceiro estágio, pois alcança a temperatura de $200{ }^{\circ} \mathrm{C}$ em $19 \mathrm{~s}$ enquanto o de soja demora $24 \mathrm{~s}$.

A análise de cromatografia gasosa realizada com o óleo de dendê novo e puro é apresentada na Figura 36, e a Tabela 12 apresenta a porcentagem dos ácidos graxos contidos no óleo. A cromatografia gasosa para o óleo de soja foi feita em estudos anteriores (72). 


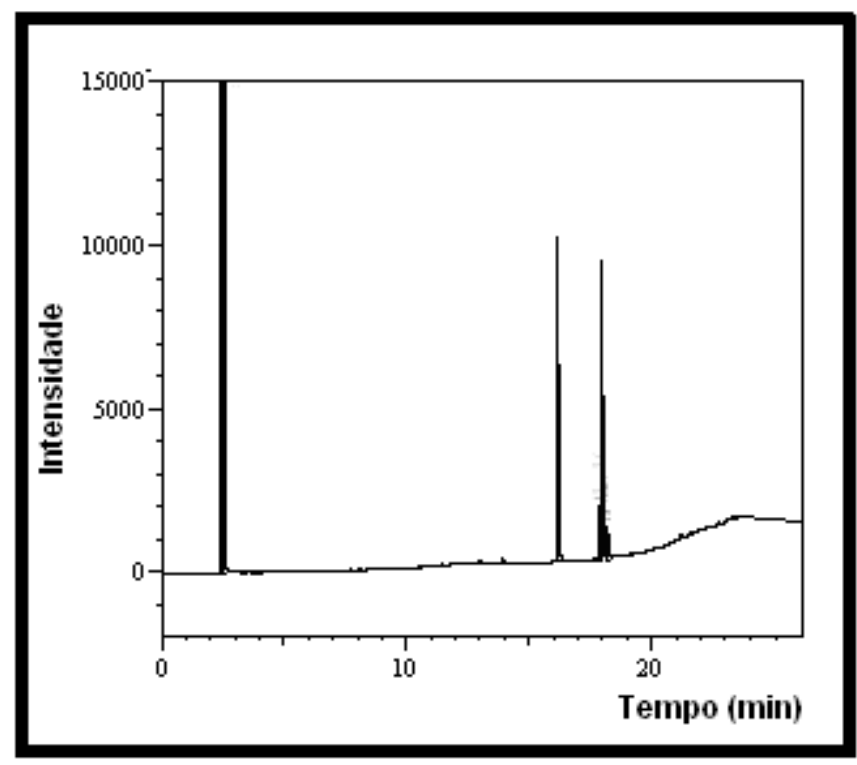

Figura 36 - Análise de cromatografia gasosa do óleo de dendê.

Tabela 12 - Porcentagem de ácidos graxos contidos no óleo de dendê.

\begin{tabular}{lcc}
\hline Ácidos graxos & $\begin{array}{c}\text { Calculado a partir } \\
\text { da Figura 36 }\end{array}$ & Literatura (76) \\
\hline Palmítico & $45,3 \%$ & $43,9 \%$ \\
Linoleico & $7,1 \%$ & $9,5 \%$ \\
Oléico & $40,5 \%$ & $39 \%$ \\
Esteárico & $5,9 \%$ & $4,9 \%$ \\
Linolenico & -- & $0,3 \%$ \\
\hline
\end{tabular}

Observa-se que os resultados obtidos são muito próximos daquele encontrados por (76), as diferenças obtidas são variações que podem ser provenientes da própria região de cultivo do grão, com diferenças de solo, umidade e insolação da região plantada. O óleo de dendê apresenta grande quantidade de ácido oléico, que possui poucas duplas ligações, o que é um indicativo de maior resistência à oxidação.

\subsection{Análise Físico-Química dos Óleos Vegetais Aditivados com Antioxidantes}

As viscosidades dos óleos de soja e dendê foram calculadas a $40{ }^{\circ} \mathrm{C}$, para todas as amostras aditivadas com antioxidantes em todos os tempos de 
envelhecimento. O óleo de soja foi testado com três antioxidantes a mais que o de dendê, PANA, Bisfenol A e Difenilamina, todos na concentração de 1\% em massa. A razão desses testes foi observar o comportamento desses antioxidantes para propor trabalhos futuros com o que apresentar melhor desempenho.

As Figuras 37 e 38 mostram o comportamento da viscosidade de todas as amostras de óleo de soja e dendê, respectivamente.

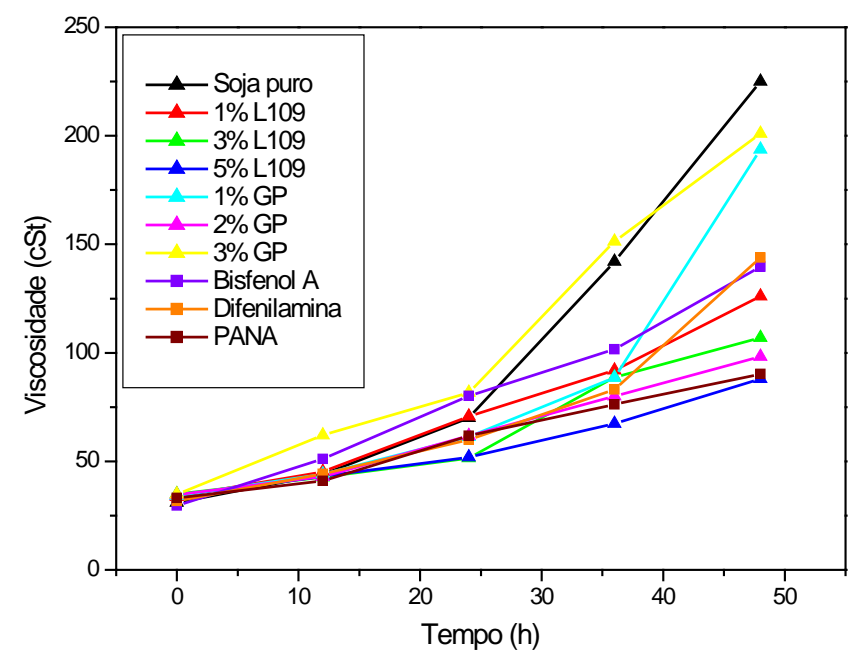

Figura 37 - Viscosidade, a $40^{\circ} \mathrm{C}$, do óleo de soja aditivado com antioxidantes e envelhecido.

Analisando o gráfico da viscosidade do óleo de soja, pode-se notar que o melhor antioxidante foi o Irganox L109 na concentração de $5 \%$, pois obteve o menor valor de viscosidade em todos os tempos de envelhecimento, seguido bem de perto pela PANA na concentração de $1 \%$, o que sugere que esse último antioxidante pode ser mais estudado em trabalhos futuros, em diferentes concentrações e em diferentes óleos. Nota-se também que os valores de viscosidade para os óleos aditivados com o Irganox apresentam uma regularidade maior quando comparados aos que continham Galato de Propila. Os antioxidantes Difenilamina e Bisfenol A apresentaram comportamento intermediário comparados aos aditivos utilizados, mas também podem ser testados em outras concentrações e em diferentes óleos, para um estudo mais completo de seus comportamentos. 


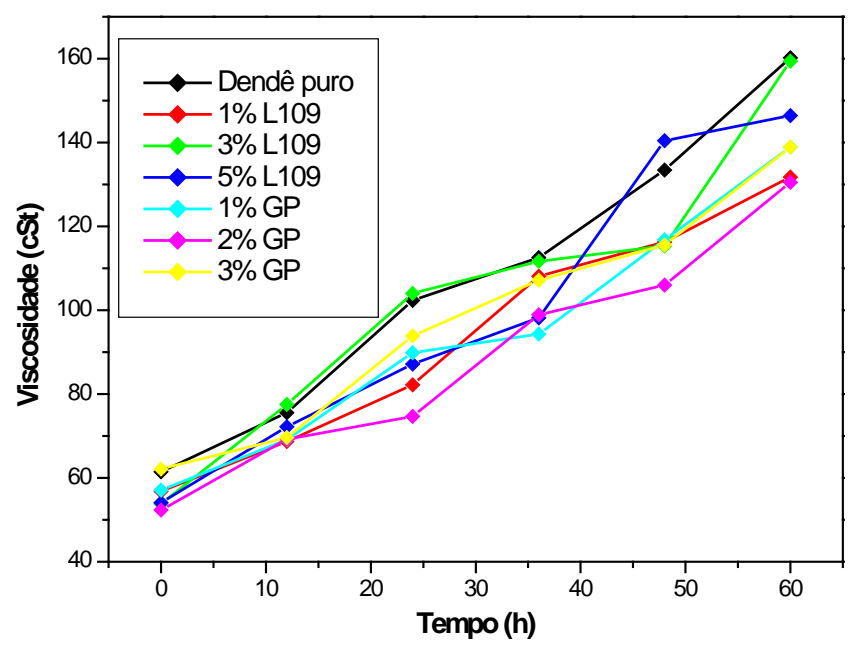

Figura 38 - Viscosidade, a $40^{\circ} \mathrm{C}$, do óleo de dendê aditivado com antioxidantes e envelhecido.

Analisando o gráfico da viscosidade do óleo de dendê, pode-se notar que, diferentemente do óleo de soja, o melhor antioxidante foi o Galato de Propila na concentração de $2 \%$, pois obteve o menor valor de viscosidade na maior parte dos tempos de envelhecimento. Entretanto as outras concentrações do Galato de Propila 1 e 3 \% não mostraram resultados muito distantes, o que indica que a solubilidade desse composto no óleo de dendê deve estar entre 1 e $2 \%$.

As Tabelas de 13 a 16 apresentam os resultados de OOT e OOt obtidos na Calorimetria Exploratória Diferencial com Pressão para óleos de soja e dendê aditivados com o antioxidante Irganox L109. Todas as amostras apresentaram solubilidade total do antioxidante nos óleos.

Tabela 13 - Temperatura de ООт para os óleos de soja aditivados com Irganox L109, sem oxidação, taxa de aquecimento $10^{\circ} \mathrm{C} / \mathrm{min}$ até $220^{\circ} \mathrm{C}$.

\begin{tabular}{lccc}
\hline \% em massa de L109 & $1 \%$ & $3 \%$ & $5 \%$ \\
\hline Ensaio 1 $\left({ }^{\circ} \mathrm{C}\right)$ & 185,63 & 188,36 & 192,86 \\
Ensaio 2 $\left({ }^{\circ} \mathrm{C}\right)$ & 185,63 & 188,48 & 191,56 \\
Média $\left({ }^{\circ} \mathrm{C}\right)$ & 185,63 & 188,42 & 192,21 \\
Quant. de ensaios & 2 & 2 & 2 \\
Desvio padrão & 0,00 & 0,60 & 0,65 \\
\% de desvio padrão & 0,00 & 0,32 & 0,34 \\
\hline
\end{tabular}


Tabela 14 - Tempo de OOt para os óleos de soja aditivados com Irganox L109, sem oxidação, taxa de aquecimento $10^{\circ} \mathrm{C} / \mathrm{min}$ até $220^{\circ} \mathrm{C}$.

\begin{tabular}{lccc}
\hline \% em massa de L109 & $1 \%$ & $3 \%$ & $5 \%$ \\
\hline Ensaio 1 (min) & 11,85 & 12,51 & 12,56 \\
Ensaio 2 (min) & 11,84 & 12,16 & 12,46 \\
Média (min) & 11,85 & 12,34 & 12,51 \\
Quant. de ensaios & 2 & 2 & 2 \\
Desvio padrão & 0,01 & 0,18 & 0,50 \\
\% de desvio padrão & 0,08 & 1,46 & 3,99 \\
\hline
\end{tabular}

Tabela 15 - Temperatura de OOT para os óleos de dendê aditivados com Irganox L109, sem oxidação, taxa de aquecimento $10^{\circ} \mathrm{C} / \mathrm{min}$ até $220^{\circ} \mathrm{C}$.

\begin{tabular}{lccc}
\hline \% em massa de L109 & $1 \%$ & $3 \%$ & $5 \%$ \\
\hline Ensaio 1 $\left({ }^{\circ} \mathrm{C}\right)$ & 185,30 & 189,41 & 190,33 \\
Ensaio 2 $\left({ }^{\circ} \mathrm{C}\right)$ & 185,44 & 188,90 & 191,47 \\
Média $\left({ }^{\circ} \mathrm{C}\right)$ & 185,37 & 189,16 & 190,90 \\
Quant. de ensaios & 2 & 2 & 2 \\
Desvio padrão & 0,70 & 0,26 & 1,02 \\
\% de desvio padrão & 0,38 & 0,14 & 0,53 \\
\hline
\end{tabular}

Tabela 16 - Tempo de OOt para os óleos de dendê aditivados com Irganox L109, sem oxidação, taxa de aquecimento $10^{\circ} \mathrm{C} / \mathrm{min}$ até $220^{\circ} \mathrm{C}$.

\begin{tabular}{lccc}
\hline \% em massa de L109 & $1 \%$ & $3 \%$ & $5 \%$ \\
\hline Ensaio 1 (min) & 11,87 & 12,30 & 12,34 \\
Ensaio 2 (min) & 11,92 & 12,25 & 12,47 \\
Média (min) & 11,90 & 12,28 & 12,41 \\
Quant. de ensaios & 2 & 2 & 2 \\
Desvio padrão & 0,25 & 0,25 & 0,65 \\
\% de desvio padrão & 2,10 & 2,04 & 5,24 \\
\hline
\end{tabular}

Observando os resultados de OOT obitdos para os óleos vegetais nota-se na Tabela 13 para o óleo de soja que, com o aumento de aditivo (Irganox L109) de 1 \% para $5 \%$, ouve uma melhora de 3,5\% na resistência à oxidação. Para o óleo de dendê (Tabela 15) o mesmo aumento de aditivo provocou melhora de $3 \%$. Comparando-se o desempenho dos óleos de soja e dendê percebe-se que na aditivação com $5 \%$, o óleo de soja é $0,7 \%$ melhor que o óleo de dendê. Com aditivação de $3 \%$ o dendê mostra-se 0,4 \% superior à formulação com a soja. No caso da adição de $1 \%$, o óleo de soja ficou 0,1 \% acima do de dendê em relação à resistência à oxidação. 
Considerações semelhantes poderiam ser feitas com os resultados de OOt. Entretanto dado o alto valor de desvio padrão das amostras aditivadas com $5 \%$ L109, optou-se por não fazê-lo.

Na preparação das amostras aditivadas com Galato de Propila notou-se que nenhuma delas apresentou solubilidade total do antioxidante nas concentrações acima de 1\%. A solubilização só foi possível quando as amostras foram levemente aquecidas em banho-maria, por aproximadamente $10 \mathrm{~min}$, á $40{ }^{\circ} \mathrm{C}$.

As Tabelas de 17 a 20 apresentam os resultados de OOT e OOt obtidos na Calorimetria Exploratória Difrencial com Pressão para óleos aditivados com 0 antioxidante Irganox L109.

Tabela 17 - Temperatura de ОOT para os óleos de soja aditivados com Galato de Propila, sem oxidação, taxa de aquecimento $10^{\circ} \mathrm{C} / \mathrm{min}$ até $220^{\circ} \mathrm{C}$.

\begin{tabular}{lccc}
\hline \% em massa de GP & $1 \%$ & $2 \%$ & $3 \%$ \\
\hline Ensaio 1 $\left({ }^{\circ} \mathrm{C}\right)$ & 188,72 & 189,28 & 189,45 \\
Ensaio 2 $\left({ }^{\circ} \mathrm{C}\right)$ & 184,56 & 180,77 & 189,85 \\
Média $\left({ }^{\circ} \mathrm{C}\right)$ & 186,64 & 185,03 & 189,65 \\
Quant. de ensaios & 2 & 2 & 2 \\
Desvio padrão & 2,08 & 4,26 & 0,20 \\
\% de desvio padrão & 1,11 & 2,30 & 0,11 \\
\hline
\end{tabular}

Tabela 18 - Tempo de OOt para os óleos de soja aditivados com Galato de Propila, sem oxidação, taxa de aquecimento $10^{\circ} \mathrm{C} / \mathrm{min}$ até $220^{\circ} \mathrm{C}$.

\begin{tabular}{lccc}
\hline \% em massa de GP & $1 \%$ & $2 \%$ & $3 \%$ \\
\hline Ensaio 1 (min) & 13,16 & 13,26 & 13,23 \\
Ensaio 2 (min) & 12,79 & 12,40 & 13,27 \\
Média (min) & 12,98 & 12,83 & 13,25 \\
Quant. de ensaios & 2 & 2 & 2 \\
Desvio padrão & 0,18 & 0,43 & 0,02 \\
\% de desvio padrão & 1,43 & 3,35 & 0,15 \\
\hline
\end{tabular}

Tabela 19 - Temperatura de OOT para os óleos de dendê aditivados com Galato de Propila, sem oxidação, taxa de aquecimento $10^{\circ} \mathrm{C} / \mathrm{min}$ até $220^{\circ} \mathrm{C}$.

\begin{tabular}{lrrr}
\hline \% em massa de GP & \multicolumn{1}{c}{$1 \%$} & \multicolumn{1}{c}{$2 \%$} & \multicolumn{1}{c}{$3 \%$} \\
\hline Ensaio 1 $\left({ }^{\circ} \mathrm{C}\right)$ & 194,17 & 198,69 & 201,76 \\
Ensaio 2 $\left({ }^{\circ} \mathrm{C}\right)$ & 193,69 & 199,06 & 199,04 \\
Média $\left({ }^{\circ} \mathrm{C}\right)$ & 193,93 & 198,88 & 200,40 \\
Quant. de ensaios & 2 & 2 & 2 \\
Desvio padrão & 0,24 & 0,19 & 1,36 \\
\% de desvio padrão & 0,12 & 0,09 & 0,68 \\
\hline
\end{tabular}


Tabela 20 - Tempo de OOt para os óleos de dendê aditivados com Galato de Propila, sem oxidação, taxa de aquecimento $10^{\circ} \mathrm{C} / \mathrm{min}$ até $220^{\circ} \mathrm{C}$.

\begin{tabular}{lccc}
\hline \% em massa de GP & $1 \%$ & $2 \%$ & $3 \%$ \\
\hline Ensaio 1 (MIN) & 13,67 & 14,11 & 14,42 \\
Ensaio 2 (MIN) & 13,66 & 14,11 & 14,17 \\
Média (MIN) & 13,67 & 14,11 & 14,30 \\
Quant. de ensaios & 2 & 2 & 2 \\
Desvio padrão & 0,00 & 0,00 & 0,12 \\
\% de desvio padrão & 0,04 & 0,00 & 0,87 \\
\hline
\end{tabular}

É possível observar que os resultados obtidos foram muito semelhantes, tanto em tempo como em temperatura, isso indica que o limite de solubilidade gira em torne de $1 \%$, nos dois óleos utilizados, portanto, esse "1\%" também estaria dissolvido nas outras amostras e, em alguns casos, uma pequena fração a mais também estaria solubilizada. Portanto é difícil saber qual concentração de Galato de Propila é a melhor em cada óleo, mas pode-se perceber que todas as amostras de óleo de dendê apresentaram maior estabilidade oxidativa comparadas às de óleo de soja.

Observando os resultados de OOT obitdos para o óleo de soja nota-se na Tabela 17 que com o aumento de aditivo (GP) de $1 \%$ para $3 \%$, ouve uma melhora de 1,6 \% na resistência à oxidação. Portanto constata-se que o antioxidante Irganox L109 age melhor no óleo de soja do que o Galato de Propila, aumentando sua capacidade de resistência à oxidação.

Para o óleo de dendê (Tabela 19) o mesmo aumento de aditivo provocou melhora de $3,3 \%$, o que indica que para o óleo de dendê, diferentemente do de soja, o melhor antioxidante é o Galato de Propila.

Comparando-se o desempenho dos óleos de soja e dendê percebe-se que na aditivação de $3 \%$, o óleo de dendê é 5,7 \% melhor. Com $2 \%$ GP o dendê apresenta $7,5 \%$ mais resistência à oxidação e com 1\% GP 3,9\%.

Para os resultados de OOt (Tabelas 18 e 20) percebe-se que o desempenho do óleo de dendê foi superior ao de soja em todas as formulações: 5,3 \% com 1\% GP; $10 \%$ com $2 \%$ GP e $8 \%$ com $3 \%$ GP.

A Figura 39 mostra as curvas de resfriamento do óleo de soja puro e com todas as formulações, sem oxidação. A Tabela 21 compara alguns valores entre elas. 


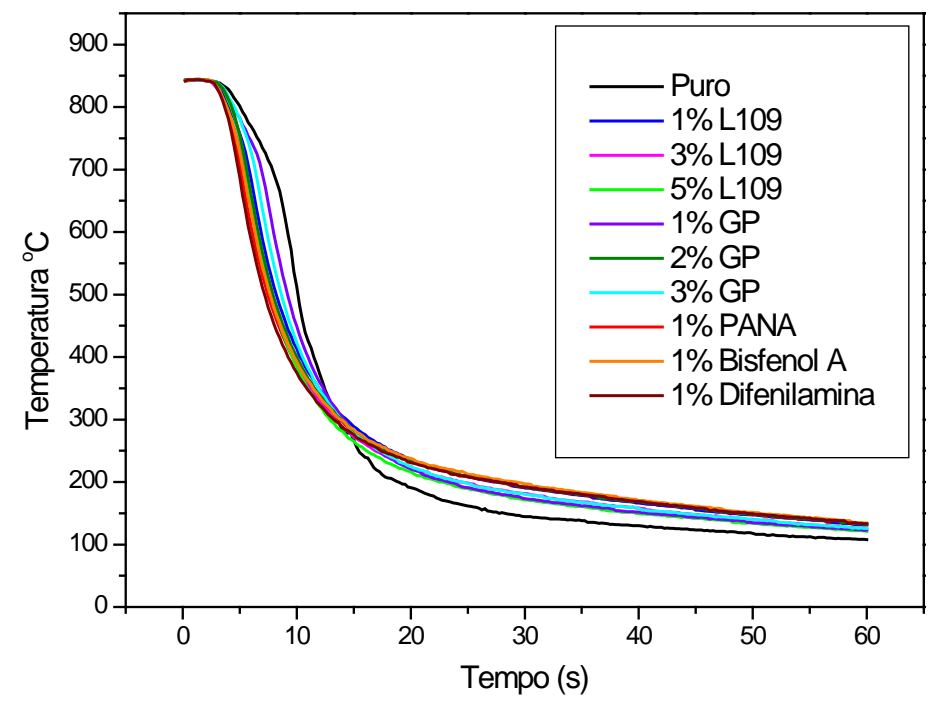

Figura 39 - Curvas de resfriamento, a $60^{\circ} \mathrm{C}$, relacionando temperatura por tempo para óleo de soja no estado não oxidado, para todas as formulações.

Tabela 21 - Comparação entre o tempo de resfriamento dos óleos de soja puro e com todas as formulações, sem oxidação.

\begin{tabular}{lccc}
\hline \% Antioxidante & $\begin{array}{c}\text { Tempo para } \\
\text { alcançar } 700{ }^{\circ} \mathrm{C}\end{array}$ & $\begin{array}{c}\text { Tempo para } \\
\text { alcançar } 300{ }^{\circ} \mathrm{C}\end{array}$ & $\begin{array}{c}\text { Tempo para } \\
\text { alcançar } 200{ }^{\circ} \mathrm{C}\end{array}$ \\
\hline Puro & $5 \mathrm{~s}$ & $13 \mathrm{~s}$ & $24 \mathrm{~s}$ \\
$1 \%$ L109 & $5 \mathrm{~s}$ & $14 \mathrm{~s}$ & $27 \mathrm{~s}$ \\
$3 \%$ L109 & $6 \mathrm{~s}$ & $12 \mathrm{~s}$ & $18 \mathrm{~s}$ \\
$5 \%$ L109 & $5 \mathrm{~s}$ & $13 \mathrm{~s}$ & $25 \mathrm{~s}$ \\
$1 \%$ GP & $6 \mathrm{~s}$ & $13 \mathrm{~s}$ & $23 \mathrm{~s}$ \\
$2 \%$ GP & $6 \mathrm{~s}$ & $14 \mathrm{~s}$ & $25 \mathrm{~s}$ \\
$3 \%$ GP & $7 \mathrm{~s}$ & $14 \mathrm{~s}$ & $23 \mathrm{~s}$ \\
$1 \%$ PANA & $6 \mathrm{~s}$ & $14 \mathrm{~s}$ & $28 \mathrm{~s}$ \\
$1 \%$ Bisfenol A & $5 \mathrm{~s}$ & $14 \mathrm{~s}$ & $29 \mathrm{~s}$ \\
1\% Difenilamina & $5 \mathrm{~s}$ & $13 \mathrm{~s}$ & $28 \mathrm{~s}$ \\
\hline
\end{tabular}

Observa-se que a aditivação do óleo não altera o fato de o primeiro estágio não se formar. Nota-se também que as velocidades de resfriamento das formulações variam quando comparadas à do óleo de soja puro. A formulação de 3\% L109 apresentou-se a mais rápida enquanto que a de 1\% Bisfenol $A$ foi a mais lenta, medidas pelo tempo necessário para se alcançar $200^{\circ} \mathrm{C}$ (temperatura em que normalmente se inicia a transformação martensítica). 
A Figura 40 mostra as curvas de resfriamento do óleo de dendê puro e com todas as formulações, sem oxidação. A Tabela 22 compara alguns valores entre elas.

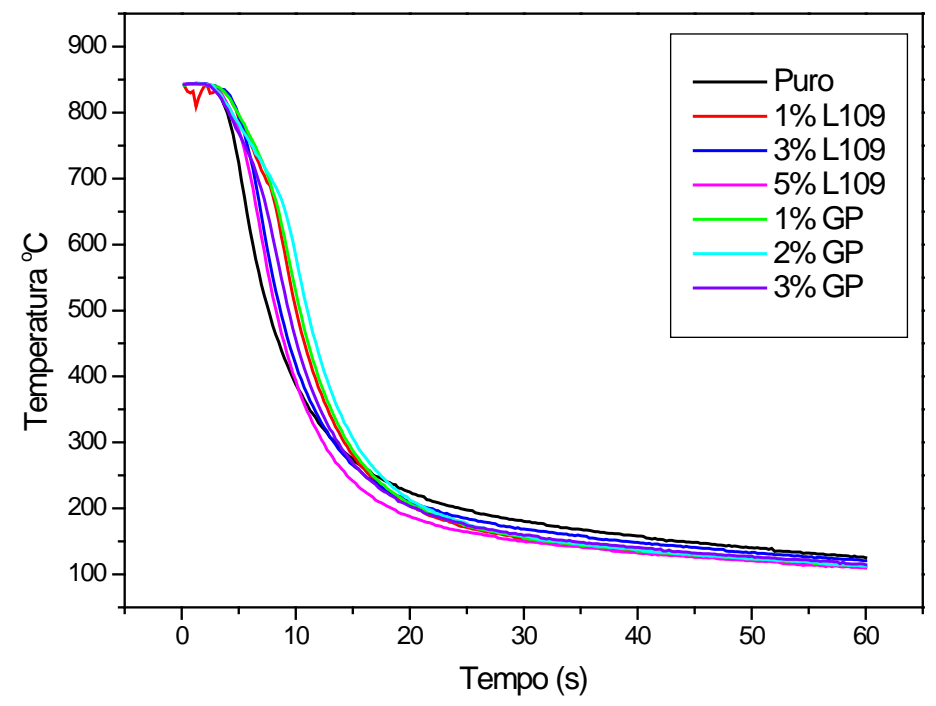

Figura 40 - Curvas de resfriamento, a $60^{\circ} \mathrm{C}$, relacionando temperatura por tempo para óleo de dendê no estado não oxidado, para todas as formulações.

Tabela 22 - Comparação entre o tempo de resfriamento dos óleos de dendê puro e com todas as formulações, sem oxidação.

\begin{tabular}{lccc}
\hline$\%$ Antioxidante & $\begin{array}{c}\text { Tempo para } \\
\text { alcançar } 700{ }^{\circ} \mathrm{C}\end{array}$ & $\begin{array}{c}\text { Tempo para } \\
\text { alcançar } 300{ }^{\circ} \mathrm{C}\end{array}$ & $\begin{array}{c}\text { Tempo para } \\
\text { alcançar } 200{ }^{\circ} \mathrm{C}\end{array}$ \\
\hline Puro & $5 \mathrm{~s}$ & $13 \mathrm{~s}$ & $24 \mathrm{~s}$ \\
$1 \%$ L109 & $7 \mathrm{~s}$ & $14 \mathrm{~s}$ & $20 \mathrm{~s}$ \\
$3 \%$ L109 & $6 \mathrm{~s}$ & $13 \mathrm{~s}$ & $22 \mathrm{~s}$ \\
$5 \%$ L109 & $6 \mathrm{~s}$ & $12 \mathrm{~s}$ & $18 \mathrm{~s}$ \\
$1 \%$ GP & $7 \mathrm{~s}$ & $14 \mathrm{~s}$ & $21 \mathrm{~s}$ \\
$2 \%$ GP & $8 \mathrm{~s}$ & $15 \mathrm{~s}$ & $21 \mathrm{~s}$ \\
$3 \%$ GP & $7 \mathrm{~s}$ & $14 \mathrm{~s}$ & $21 \mathrm{~s}$ \\
\hline
\end{tabular}

Observa-se que para o óleo de dendê a característica de não apresentar o primeiro estágio foi mantida, e todas as formulações foram mais rápidas quando comparadas ao óleo puro, sendo que a mais rápida foi a de 5\% L109.

As Figuras de 41 a 49 mostram as curvas de resfriamento do óleo de soja para todas as formulações e em todos os tempos de envelhecimento. As Tabelas de 23 a 31 comparam alguns valores entre as curvas de cada formulação. 


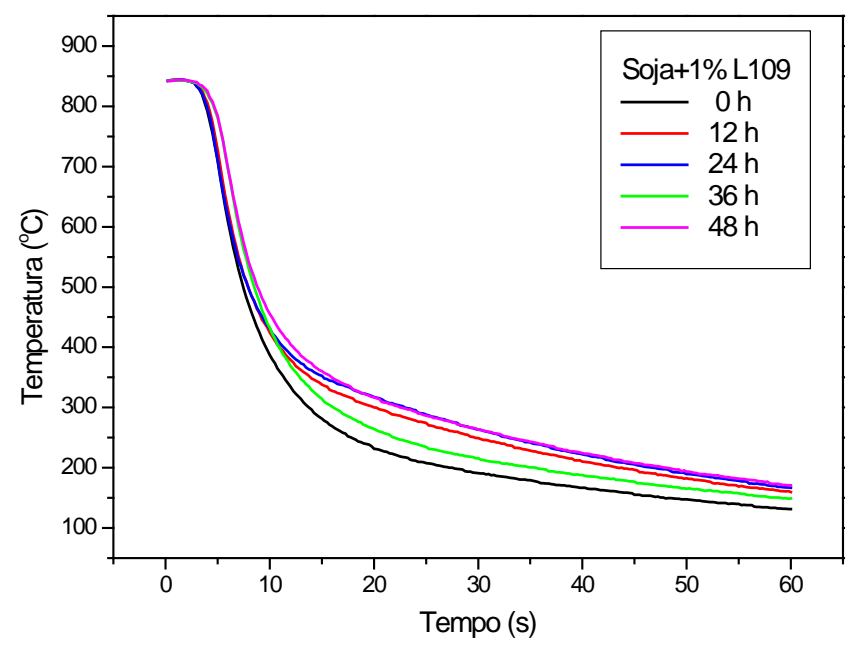

Figura 41 - Curvas de resfriamento, a $60^{\circ} \mathrm{C}$, relacionando temperatura por tempo para o óleo de soja com adição de 1 \% de Irganox L109.

Tabela 23 - Comparação entre o tempo de resfriamento dos óleos de soja aditivados com $1 \%$ L109 em todos os tempos de envelhecimento.

\begin{tabular}{lccc}
\hline $\begin{array}{l}\text { Tempo de } \\
\text { oxidação }\end{array}$ & $\begin{array}{c}\text { Tempo para } \\
\text { alcançar } 700{ }^{\circ} \mathrm{C}\end{array}$ & $\begin{array}{c}\text { Tempo para } \\
\text { alcançar } 300{ }^{\circ} \mathrm{C}\end{array}$ & $\begin{array}{c}\text { Tempo para } \\
\text { alcançar } 200{ }^{\circ} \mathrm{C}\end{array}$ \\
\hline $0 \mathrm{~h}$ & $5 \mathrm{~s}$ & $14 \mathrm{~s}$ & $27 \mathrm{~s}$ \\
$12 \mathrm{~h}$ & $5 \mathrm{~s}$ & $20 \mathrm{~s}$ & $43 \mathrm{~s}$ \\
$24 \mathrm{~h}$ & $5 \mathrm{~s}$ & $23 \mathrm{~s}$ & $47 \mathrm{~s}$ \\
$36 \mathrm{~h}$ & $6 \mathrm{~s}$ & $16 \mathrm{~s}$ & $35 \mathrm{~s}$ \\
$48 \mathrm{~h}$ & $6 \mathrm{~s}$ & $23 \mathrm{~s}$ & $48 \mathrm{~s}$ \\
\hline
\end{tabular}

Em todos os tempos de envelhecimento o tempo necessário para atingir 200 ${ }^{\circ} \mathrm{C}$ aumentou, indicando um retardo na capacidade de resfriamento. Situação semelhante foi observada para as porcentagens de 3 e $5 \%$ L109, conforme verificado nas Figuras 42 e 43 e Tabelas 24 e 25 a seguir. 


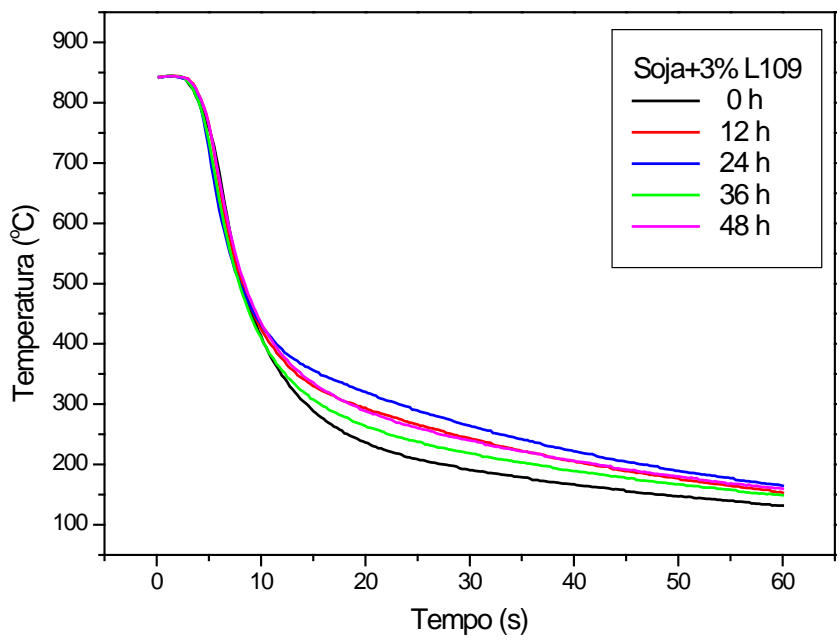

Figura 42 - Curvas de resfriamento, a $60^{\circ} \mathrm{C}$, relacionando temperatura por tempo para o óleo de soja com adição de 3 \% de Irganox L109.

Tabela 24 - Comparação entre o tempo de resfriamento dos óleos de soja aditivados com $3 \%$ L109 em todos os tempos de envelhecimento.

\begin{tabular}{lccc}
\hline $\begin{array}{l}\text { Tempo de } \\
\text { oxidação }\end{array}$ & $\begin{array}{c}\text { Tempo para } \\
\text { alcançar } 700{ }^{\circ} \mathrm{C}\end{array}$ & $\begin{array}{c}\text { Tempo para } \\
\text { alcançar } 300{ }^{\circ} \mathrm{C}\end{array}$ & $\begin{array}{c}\text { Tempo para } \\
\text { alcançar } 200{ }^{\circ} \mathrm{C}\end{array}$ \\
\hline $0 \mathrm{~h}$ & $6 \mathrm{~s}$ & $14 \mathrm{~s}$ & $28 \mathrm{~s}$ \\
$12 \mathrm{~h}$ & $6 \mathrm{~s}$ & $19 \mathrm{~s}$ & $42 \mathrm{~s}$ \\
$24 \mathrm{~h}$ & $6 \mathrm{~s}$ & $23 \mathrm{~s}$ & $46 \mathrm{~s}$ \\
$36 \mathrm{~h}$ & $6 \mathrm{~s}$ & $15 \mathrm{~s}$ & $36 \mathrm{~s}$ \\
$48 \mathrm{~h}$ & $6 \mathrm{~s}$ & $19 \mathrm{~s}$ & $42 \mathrm{~s}$ \\
\hline
\end{tabular}

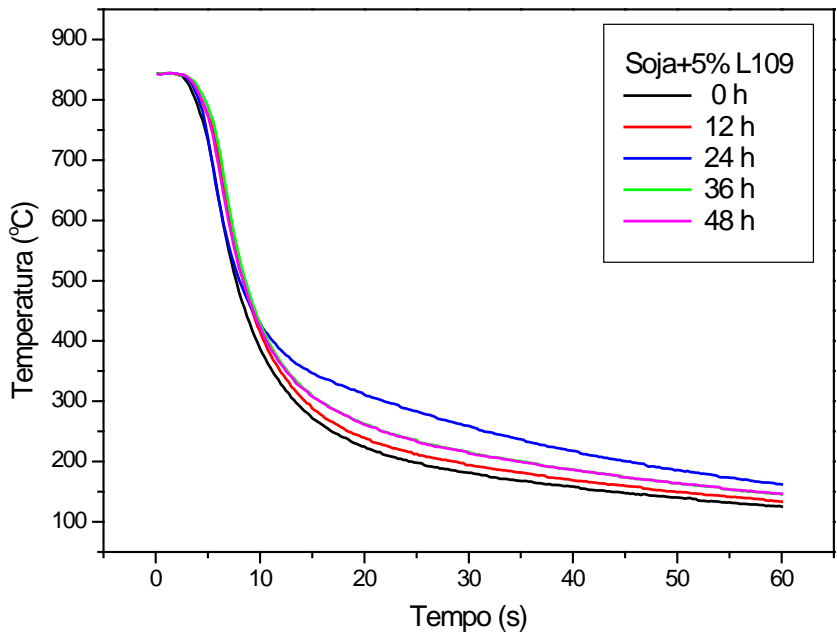

Figura 43 - Curvas de resfriamento, a $60^{\circ} \mathrm{C}$, relacionando temperatura por tempo para o óleo de soja com adição de 5 \% de Irganox L109. 
Tabela 25 - Comparação entre o tempo de resfriamento dos óleos de soja aditivados com $5 \%$ L109 em todos os tempos de envelhecimento.

\begin{tabular}{lccc}
\hline $\begin{array}{l}\text { Tempo de } \\
\text { oxidação }\end{array}$ & $\begin{array}{c}\text { Tempo para } \\
\text { alcançar } 700{ }^{\circ} \mathrm{C}\end{array}$ & $\begin{array}{c}\text { Tempo para } \\
\text { alcançar } 300{ }^{\circ} \mathrm{C}\end{array}$ & $\begin{array}{c}\text { Tempo para } \\
\text { alcançar } 200{ }^{\circ} \mathrm{C}\end{array}$ \\
\hline $0 \mathrm{~h}$ & $6 \mathrm{~s}$ & $13 \mathrm{~s}$ & $24 \mathrm{~s}$ \\
$12 \mathrm{~h}$ & $6 \mathrm{~s}$ & $14 \mathrm{~s}$ & $29 \mathrm{~s}$ \\
$24 \mathrm{~h}$ & $5 \mathrm{~s}$ & $27 \mathrm{~s}$ & $45 \mathrm{~s}$ \\
$36 \mathrm{~h}$ & $6 \mathrm{~s}$ & $16 \mathrm{~s}$ & $35 \mathrm{~s}$ \\
$48 \mathrm{~h}$ & $6 \mathrm{~s}$ & $16 \mathrm{~s}$ & $35 \mathrm{~s}$ \\
\hline
\end{tabular}

No caso das formulações de óleo de soja com Galato de Propila, o atraso no resfriamento medido pelo tempo gasto para atingir $200{ }^{\circ} \mathrm{C}$ foi menor, conforme valores obtidos nas Tabelas de 26 a 28 a seguir.

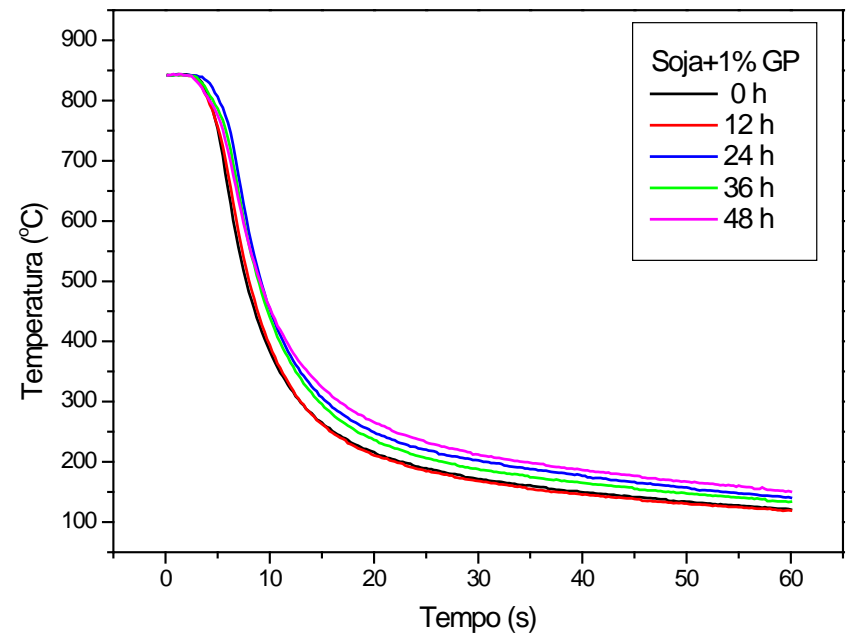

Figura 44 - Curvas de resfriamento, a $60^{\circ} \mathrm{C}$, relacionando temperatura por tempo para o óleo de soja com adição de 1 \% de Galato de Propila.

Tabela 26 - Comparação entre o tempo de resfriamento dos óleos de soja aditivados com $1 \%$ GP em todos os tempos de envelhecimento.

\begin{tabular}{lccc}
\hline $\begin{array}{l}\text { Tempo de } \\
\text { oxidação }\end{array}$ & $\begin{array}{c}\text { Tempo para } \\
\text { alcançar } 700{ }^{\circ} \mathrm{C}\end{array}$ & $\begin{array}{c}\text { Tempo para } \\
\text { alcançar } 300{ }^{\circ} \mathrm{C}\end{array}$ & $\begin{array}{c}\text { Tempo para } \\
\text { alcançar } 200{ }^{\circ} \mathrm{C}\end{array}$ \\
\hline $0 \mathrm{~h}$ & $6 \mathrm{~s}$ & $13 \mathrm{~s}$ & $23 \mathrm{~s}$ \\
$12 \mathrm{~h}$ & $6 \mathrm{~s}$ & $13 \mathrm{~s}$ & $22 \mathrm{~s}$ \\
$24 \mathrm{~h}$ & $7 \mathrm{~s}$ & $16 \mathrm{~s}$ & $31 \mathrm{~s}$ \\
$36 \mathrm{~h}$ & $7 \mathrm{~s}$ & $15 \mathrm{~s}$ & $27 \mathrm{~s}$ \\
$48 \mathrm{~h}$ & $6 \mathrm{~s}$ & $17 \mathrm{~s}$ & $35 \mathrm{~s}$ \\
\hline
\end{tabular}




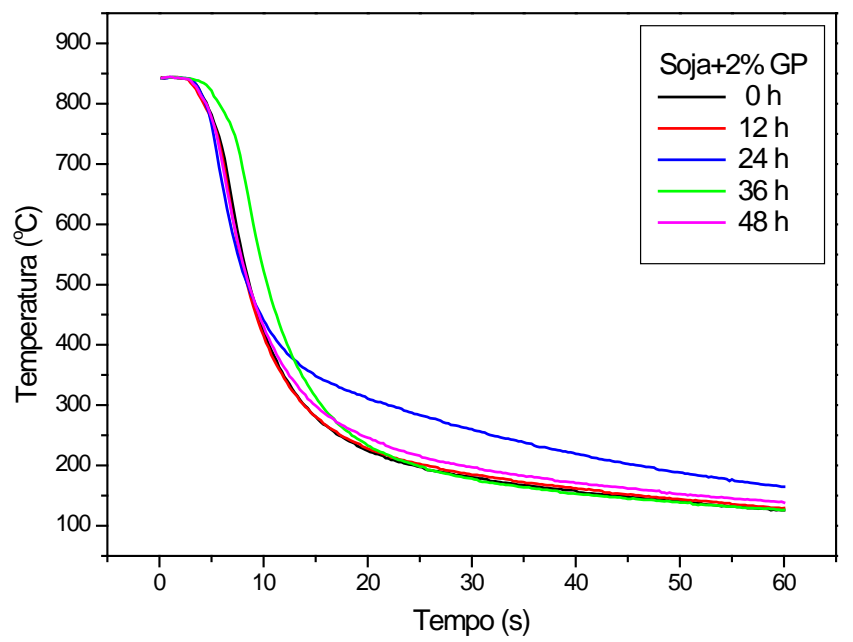

Figura 45 - Curvas de resfriamento, a $60^{\circ} \mathrm{C}$, relacionando temperatura por tempo para o óleo de soja com adição de $2 \%$ de Galato de Propila.

Tabela 27 - Comparação entre o tempo de resfriamento dos óleos de soja aditivados com $2 \%$ GP em todos os tempos de envelhecimento.

\begin{tabular}{lccc}
\hline $\begin{array}{l}\text { Tempo de } \\
\text { oxidação }\end{array}$ & $\begin{array}{c}\text { Tempo para } \\
\text { alcançar } 700{ }^{\circ} \mathrm{C}\end{array}$ & $\begin{array}{c}\text { Tempo para } \\
\text { alcançar } 300{ }^{\circ} \mathrm{C}\end{array}$ & $\begin{array}{c}\text { Tempo para } \\
\text { alcançar } 200{ }^{\circ} \mathrm{C}\end{array}$ \\
\hline $0 \mathrm{~h}$ & $6 \mathrm{~s}$ & $14 \mathrm{~s}$ & $25 \mathrm{~s}$ \\
$12 \mathrm{~h}$ & $6 \mathrm{~s}$ & $14 \mathrm{~s}$ & $26 \mathrm{~s}$ \\
$24 \mathrm{~h}$ & $6 \mathrm{~s}$ & $21 \mathrm{~s}$ & $46 \mathrm{~s}$ \\
$36 \mathrm{~h}$ & $8 \mathrm{~s}$ & $16 \mathrm{~s}$ & $25 \mathrm{~s}$ \\
$48 \mathrm{~h}$ & $6 \mathrm{~s}$ & $15 \mathrm{~s}$ & $29 \mathrm{~s}$ \\
\hline
\end{tabular}

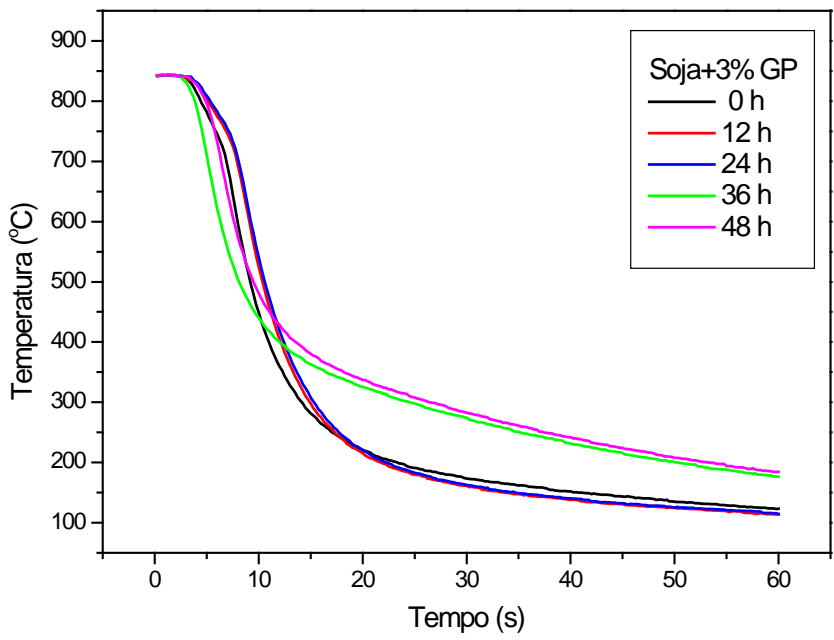

Figura 46 - Curvas de resfriamento, a $60^{\circ} \mathrm{C}$, relacionando temperatura por tempo para o óleo de soja com adição de $3 \%$ de Galato de Propila. 
Tabela 28 - Comparação entre o tempo de resfriamento dos óleos de soja aditivados com $3 \%$ GP em todos os tempos de envelhecimento.

\begin{tabular}{lccc}
\hline $\begin{array}{l}\text { Tempo de } \\
\text { oxidação }\end{array}$ & $\begin{array}{c}\text { Tempo para } \\
\text { alcançar } 700^{\circ} \mathrm{C}\end{array}$ & $\begin{array}{c}\text { Tempo para } \\
\text { alcançar } 300^{\circ} \mathrm{C}\end{array}$ & $\begin{array}{c}\text { Tempo para } \\
\text { alcançar } 200^{\circ} \mathrm{C}\end{array}$ \\
\hline $0 \mathrm{~h}$ & $7 \mathrm{~s}$ & $14 \mathrm{~s}$ & $23 \mathrm{~s}$ \\
$12 \mathrm{~h}$ & $8 \mathrm{~s}$ & $15 \mathrm{~s}$ & $22 \mathrm{~s}$ \\
$24 \mathrm{~h}$ & $8 \mathrm{~S}$ & $15 \mathrm{~s}$ & $23 \mathrm{~s}$ \\
$36 \mathrm{~h}$ & $6 \mathrm{~s}$ & $25 \mathrm{~s}$ & $50 \mathrm{~s}$ \\
$48 \mathrm{~h}$ & $7 \mathrm{~s}$ & $26 \mathrm{~s}$ & $53 \mathrm{~s}$ \\
\hline
\end{tabular}

Conforme já comentado anteriormente, houve certa dificuldade em dissolver maiores porcentagens de Galato de Propila nos óleos. Esse fato provocou uma não homogeneidade da solução, o que por sua vez pode ter interferido nas curvas de resfriamento, gerando variações nos valores das Tabelas de 26 a 28.

A Figura 47 e a Tabela 29 mostram que no caso da PANA as variações mais significativas ocorreram nos tempos de envelhecimento iguais a 12 e $24 \mathrm{~h}$, retornando às suas características originais a partir de $36 \mathrm{~h}$ de envelhecimento.

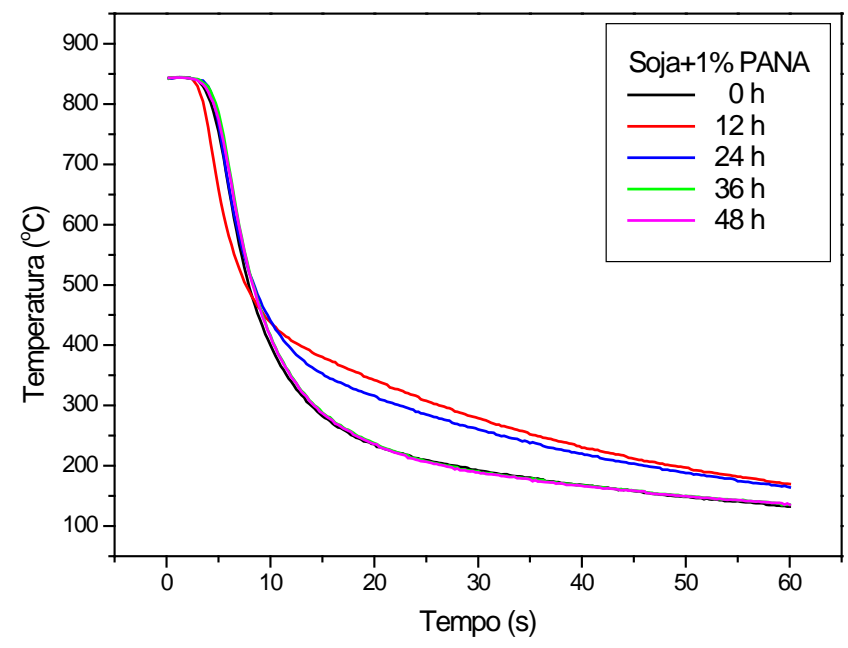

Figura 47 - Curvas de resfriamento, a $60^{\circ} \mathrm{C}$, relacionando temperatura por tempo para o óleo de soja com adição de $1 \%$ de PANA. 
Tabela 29 - Comparação entre o tempo de resfriamento dos óleos de soja aditivados com $1 \%$ PANA em todos os tempos de envelhecimento.

\begin{tabular}{lccc}
\hline $\begin{array}{l}\text { Tempo de } \\
\text { oxidação }\end{array}$ & $\begin{array}{c}\text { Tempo para } \\
\text { alcançar } 700^{\circ} \mathrm{C}\end{array}$ & $\begin{array}{c}\text { Tempo para } \\
\text { alcançar } 300^{\circ} \mathrm{C}\end{array}$ & $\begin{array}{c}\text { Tempo para } \\
\text { alcançar } 200{ }^{\circ} \mathrm{C}\end{array}$ \\
\hline $0 \mathrm{~h}$ & $6 \mathrm{~s}$ & $14 \mathrm{~s}$ & $28 \mathrm{~s}$ \\
$12 \mathrm{~h}$ & $5 \mathrm{~s}$ & $26 \mathrm{~s}$ & $48 \mathrm{~s}$ \\
$24 \mathrm{~h}$ & $6 \mathrm{~s}$ & $22 \mathrm{~s}$ & $46 \mathrm{~s}$ \\
$36 \mathrm{~h}$ & $6 \mathrm{~s}$ & $14 \mathrm{~s}$ & $27 \mathrm{~s}$ \\
$48 \mathrm{~h}$ & $6 \mathrm{~s}$ & $14 \mathrm{~s}$ & $27 \mathrm{~s}$ \\
\hline
\end{tabular}

No caso do Bisfenol A, praticamente não houve mudança nas curvas de resfriamento com o aumento do tempo de envelhecimento, como verificado na Figura 48 e Tabela 30.

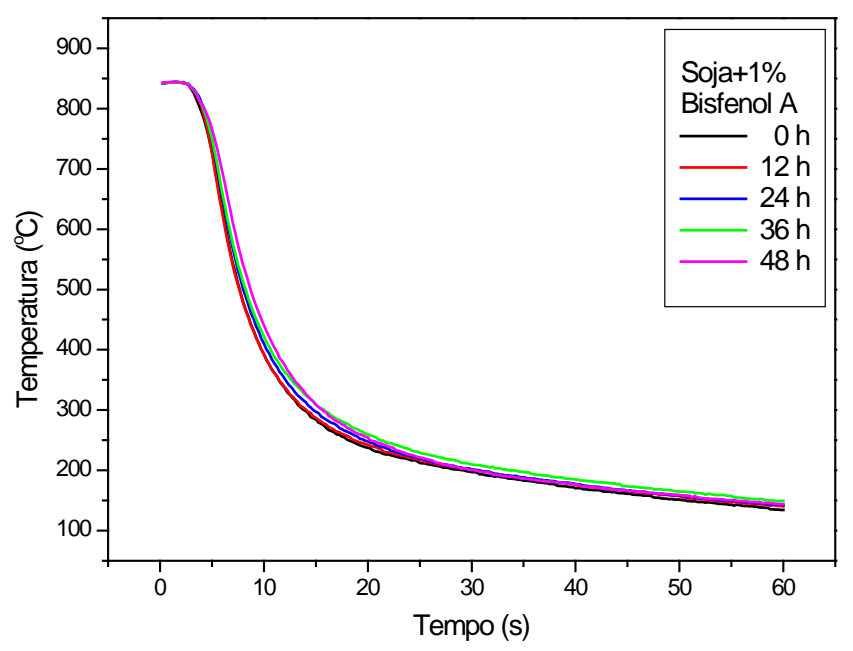

Figura 48 - Curvas de resfriamento, a $60^{\circ} \mathrm{C}$, relacionando temperatura por tempo para o óleo de soja com adição de $1 \%$ de Bisfenol A.

Tabela 30 - Comparação entre o tempo de resfriamento dos óleos de soja aditivados com $1 \%$ Bisfenol A em todos os tempos de envelhecimento.

\begin{tabular}{lccc}
\hline $\begin{array}{l}\text { Tempo de } \\
\text { oxidação }\end{array}$ & $\begin{array}{c}\text { Tempo para } \\
\text { alcançar } 700{ }^{\circ} \mathrm{C}\end{array}$ & $\begin{array}{c}\text { Tempo para } \\
\text { alcançar } 300{ }^{\circ} \mathrm{C}\end{array}$ & $\begin{array}{c}\text { Tempo para } \\
\text { alcançar } 200{ }^{\circ} \mathrm{C}\end{array}$ \\
\hline $0 \mathrm{~h}$ & $5 \mathrm{~s}$ & $14 \mathrm{~s}$ & $29 \mathrm{~s}$ \\
$12 \mathrm{~h}$ & $5 \mathrm{~s}$ & $14 \mathrm{~s}$ & $30 \mathrm{~s}$ \\
$24 \mathrm{~h}$ & $6 \mathrm{~s}$ & $15 \mathrm{~s}$ & $31 \mathrm{~s}$ \\
$36 \mathrm{~h}$ & $6 \mathrm{~s}$ & $16 \mathrm{~s}$ & $34 \mathrm{~s}$ \\
$48 \mathrm{~h}$ & $6 \mathrm{~s}$ & $16 \mathrm{~s}$ & $31 \mathrm{~s}$ \\
\hline
\end{tabular}

Observações similares não podem ser tecidas para o aditivo Difenilamina, como mostrado na Figura 49. Neste caso, a partir de $24 \mathrm{~h}$ de envelhecimento o fluido se torna mais lento, conforme Tabela 31. 


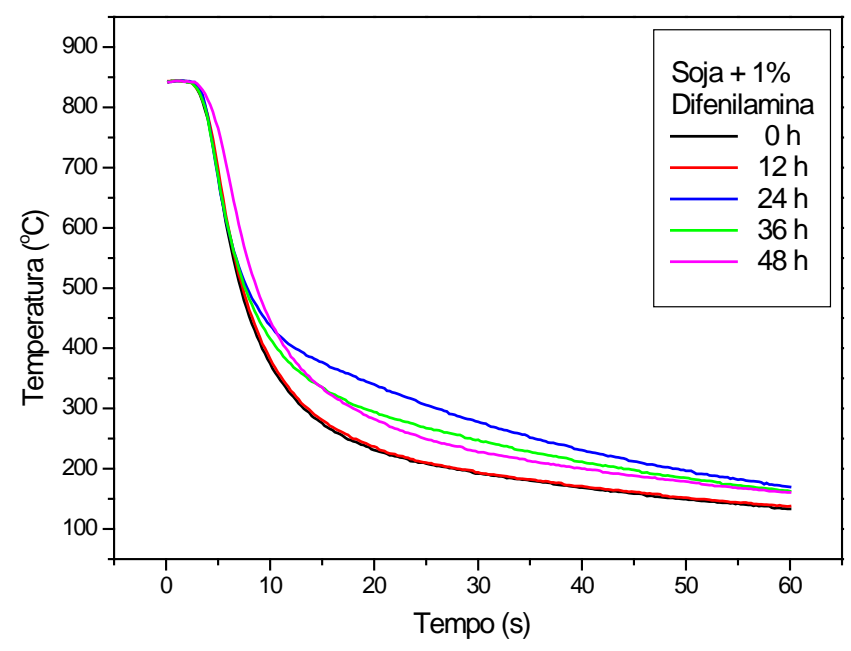

Figura 49 - Curvas de resfriamento, a $60^{\circ} \mathrm{C}$, relacionando temperatura por tempo para o óleo de soja com adição de $1 \%$ de Difenilamina.

Tabela 31 - Comparação entre o tempo de resfriamento dos óleos de soja aditivados com 1\% Difenilamina em todos os tempos de envelhecimento.

\begin{tabular}{lccc}
\hline $\begin{array}{l}\text { Tempo de } \\
\text { oxidação }\end{array}$ & $\begin{array}{c}\text { Tempo para } \\
\text { alcançar } 700{ }^{\circ} \mathrm{C}\end{array}$ & $\begin{array}{c}\text { Tempo para } \\
\text { alcançar } 300{ }^{\circ} \mathrm{C}\end{array}$ & $\begin{array}{c}\text { Tempo para } \\
\text { alcançar } 200{ }^{\circ} \mathrm{C}\end{array}$ \\
\hline $0 \mathrm{~h}$ & $5 \mathrm{~s}$ & $13 \mathrm{~s}$ & $28 \mathrm{~s}$ \\
$12 \mathrm{~h}$ & $5 \mathrm{~s}$ & $13 \mathrm{~s}$ & $28 \mathrm{~s}$ \\
$24 \mathrm{~h}$ & $5 \mathrm{~s}$ & $26 \mathrm{~s}$ & $49 \mathrm{~s}$ \\
$36 \mathrm{~h}$ & $5 \mathrm{~s}$ & $19 \mathrm{~s}$ & $44 \mathrm{~s}$ \\
$48 \mathrm{~h}$ & $6 \mathrm{~s}$ & $18 \mathrm{~s}$ & $40 \mathrm{~s}$ \\
\hline
\end{tabular}

Nas formulações com os antioxidantes PANA, Bisfenol A e Difenilamina a que apresentou melhor desempenho foi a $1 \%$ PANA, sendo a segunda melhor entre todas, ficando atrás somente da $5 \%$ L109. Esse é mais um indicativo que a PANA é um bom antioxidante para o óleo de soja e deve ser estudado em outras concentrações. O Bisfenol $A$ apesar de não se apresentar muito rápido teve o comportamento mais estável quanto ao tempo de envelhecimento e estabilidade oxidativa.

As diferenças mais significativas nas curvas aparecem a partir de $400{ }^{\circ} \mathrm{C}$, ou seja, próximas ao início do terceiro estágio, a exceção das concentrações acima de $1 \%$ de GP, que apresentaram diferenças no comportamento em todos os estágios da curva. Em todas as situações a ausência do primeiro estágio foi notada.

De uma maneira geral quanto mais oxidados os óleos se encontram, mais lentos eles se mostram. 
As Figuras de 50 a 55 mostram as curvas de resfriamento do óleo de dendê em todas as formulações e em todos os tempos de envelhecimento. As Tabelas de 32 a 37 comparam alguns valores entre as curvas de cada formulação.

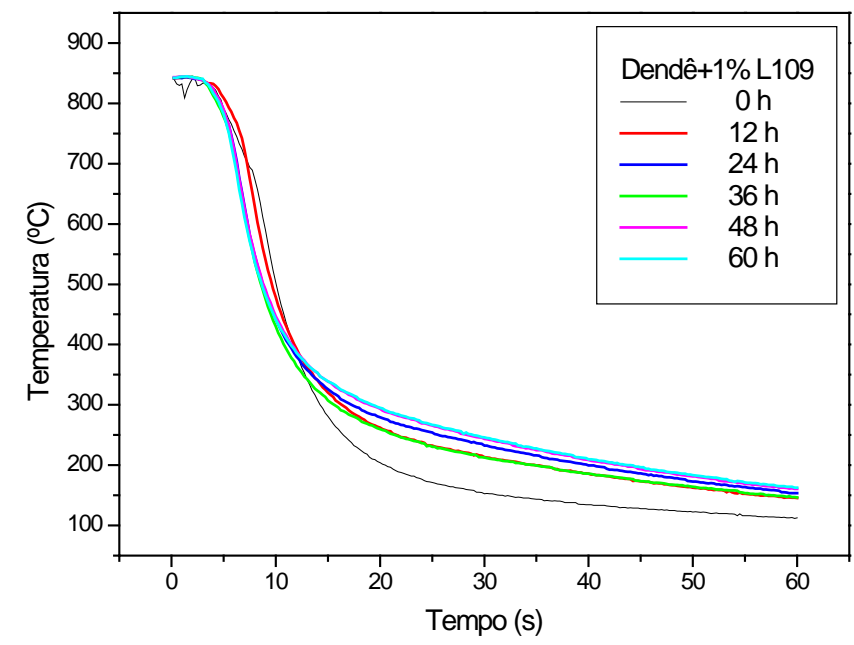

Figura 50 - Curvas de resfriamento, a $60^{\circ} \mathrm{C}$, relacionando temperatura por tempo para o óleo de dendê com adição de 1 \% de Irganox L109.

Tabela 32 - Comparação entre o tempo de resfriamento dos óleos de dendê aditivados com 1\% L109 em todos os tempos de envelhecimento.

\begin{tabular}{lccc}
\hline $\begin{array}{l}\text { Tempo de } \\
\text { oxidação }\end{array}$ & $\begin{array}{c}\text { Tempo para } \\
\text { alcançar } 700{ }^{\circ} \mathrm{C}\end{array}$ & $\begin{array}{c}\text { Tempo para } \\
\text { alcançar } 300{ }^{\circ} \mathrm{C}\end{array}$ & $\begin{array}{c}\text { Tempo para } \\
\text { alcançar } 200{ }^{\circ} \mathrm{C}\end{array}$ \\
\hline $0 \mathrm{~h}$ & $7 \mathrm{~s}$ & $14 \mathrm{~s}$ & $20 \mathrm{~s}$ \\
$12 \mathrm{~h}$ & $7 \mathrm{~s}$ & $16 \mathrm{~s}$ & $34 \mathrm{~s}$ \\
$24 \mathrm{~h}$ & $6 \mathrm{~s}$ & $17 \mathrm{~s}$ & $40 \mathrm{~s}$ \\
$36 \mathrm{~h}$ & $6 \mathrm{~s}$ & $16 \mathrm{~s}$ & $35 \mathrm{~s}$ \\
$48 \mathrm{~h}$ & $6 \mathrm{~s}$ & $19 \mathrm{~s}$ & $43 \mathrm{~s}$ \\
$60 \mathrm{~h}$ & $6 \mathrm{~s}$ & $19 \mathrm{~s}$ & $44 \mathrm{~s}$ \\
\hline
\end{tabular}

Situação semelhante às formulações do óleo de soja com aditivo Irganox L109 pode ser vista com o óleo de dendê com o mesmo aditivo. Para todas as concentrações estudadas o envelhecimento provocou uma diminuição na capacidade de resfriamento. 


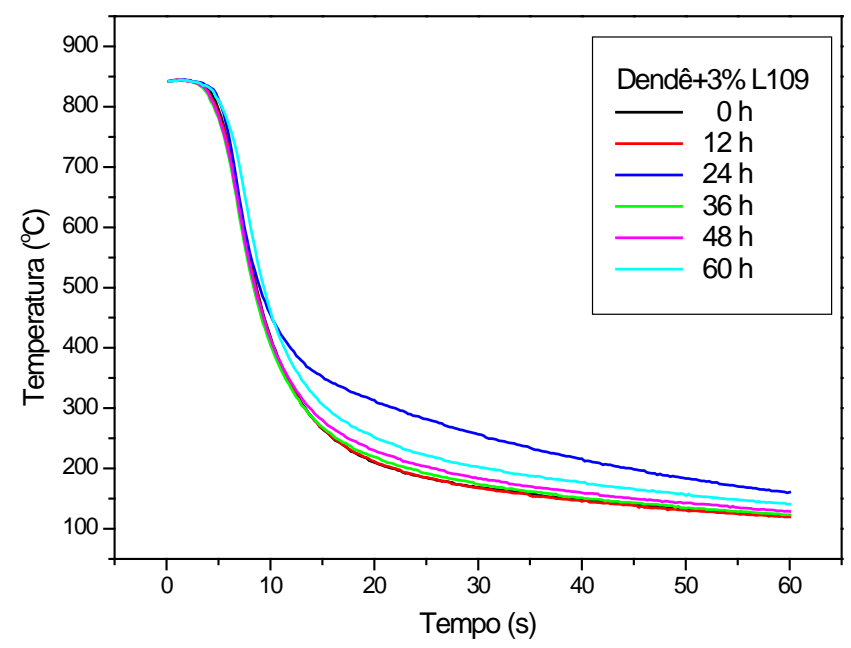

Figura 51 - Curvas de resfriamento, a $60^{\circ} \mathrm{C}$, relacionando temperatura por tempo para o óleo de dendê com adição de $3 \%$ de Irganox L109.

Tabela 33 - Comparação entre o tempo de resfriamento dos óleos de dendê aditivados com $3 \%$ L109 em todos os tempos de envelhecimento.

\begin{tabular}{lccc}
\hline $\begin{array}{l}\text { Tempo de } \\
\text { oxidação }\end{array}$ & $\begin{array}{c}\text { Tempo para } \\
\text { alcançar } 700{ }^{\circ} \mathrm{C}\end{array}$ & $\begin{array}{c}\text { Tempo para } \\
\text { alcançar } 300{ }^{\circ} \mathrm{C}\end{array}$ & $\begin{array}{c}\text { Tempo para } \\
\text { alcançar } 200{ }^{\circ} \mathrm{C}\end{array}$ \\
\hline O h & $6 \mathrm{~s}$ & $13 \mathrm{~s}$ & $22 \mathrm{~s}$ \\
$12 \mathrm{~h}$ & $6 \mathrm{~s}$ & $13 \mathrm{~s}$ & $22 \mathrm{~s}$ \\
$24 \mathrm{~h}$ & $7 \mathrm{~s}$ & $22 \mathrm{~s}$ & $44 \mathrm{~s}$ \\
$36 \mathrm{~h}$ & $6 \mathrm{~s}$ & $13 \mathrm{~s}$ & $24 \mathrm{~s}$ \\
$48 \mathrm{~h}$ & $6 \mathrm{~s}$ & $14 \mathrm{~s}$ & $26 \mathrm{~s}$ \\
$60 \mathrm{~h}$ & $7 \mathrm{~s}$ & $15 \mathrm{~s}$ & $31 \mathrm{~s}$ \\
\hline
\end{tabular}

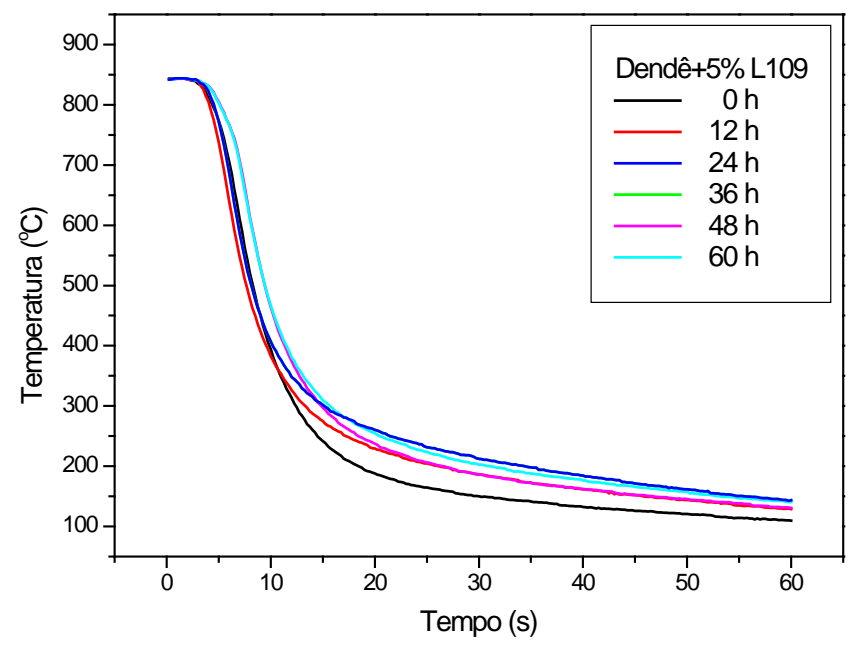

Figura 52 - Curvas de resfriamento, a $60^{\circ} \mathrm{C}$, relacionando temperatura por tempo para o óleo de dendê com adição de $5 \%$ de Irganox L109. 
Tabela 34 - Comparação entre o tempo de resfriamento dos óleos de dendê aditivados com $5 \%$ L109 em todos os tempos de envelhecimento.

\begin{tabular}{lccc}
\hline $\begin{array}{l}\text { Tempo de } \\
\text { oxidação }\end{array}$ & $\begin{array}{c}\text { Tempo para } \\
\text { alcançar } 700{ }^{\circ} \mathrm{C}\end{array}$ & $\begin{array}{c}\text { Tempo para } \\
\text { alcançar } 300{ }^{\circ} \mathrm{C}\end{array}$ & $\begin{array}{c}\text { Tempo para } \\
\text { alcançar } 200{ }^{\circ} \mathrm{C}\end{array}$ \\
\hline $0 \mathrm{~h}$ & $6 \mathrm{~s}$ & $12 \mathrm{~s}$ & $18 \mathrm{~s}$ \\
$12 \mathrm{~h}$ & $6 \mathrm{~s}$ & $13 \mathrm{~s}$ & $26 \mathrm{~s}$ \\
$24 \mathrm{~h}$ & $6 \mathrm{~s}$ & $15 \mathrm{~s}$ & $34 \mathrm{~s}$ \\
$36 \mathrm{~h}$ & $7 \mathrm{~s}$ & $15 \mathrm{~s}$ & $27 \mathrm{~s}$ \\
$48 \mathrm{~h}$ & $7 \mathrm{~s}$ & $16 \mathrm{~s}$ & $31 \mathrm{~s}$ \\
$60 \mathrm{~h}$ & $6 \mathrm{~s}$ & $15 \mathrm{~s}$ & $34 \mathrm{~s}$ \\
\hline
\end{tabular}

No caso das formulações do óleo de dendê com Galato de Propila é observada tendência similar ao óleo de soja com esse antioxidante.

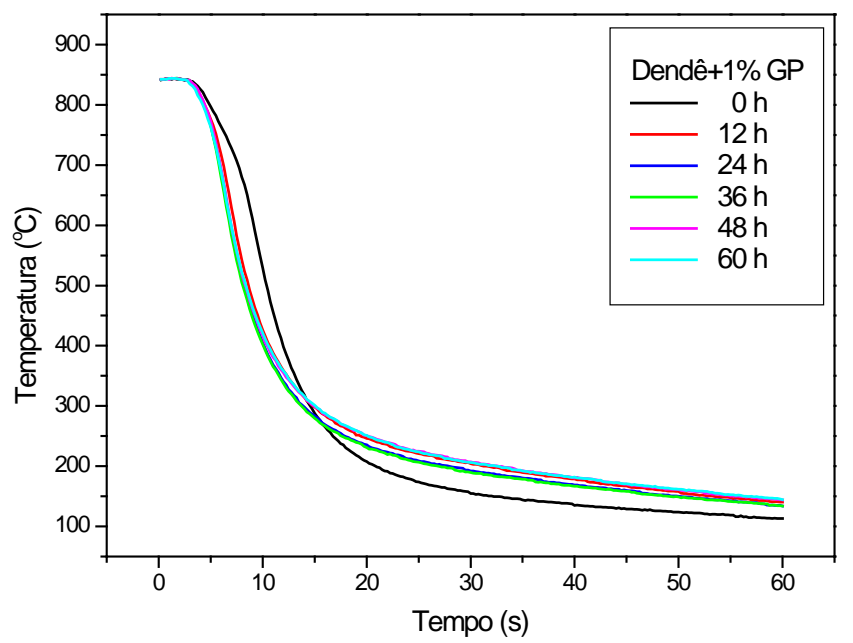

Figura 53 - Curvas de resfriamento, a $60^{\circ} \mathrm{C}$, relacionando temperatura por tempo para o óleo de dendê com adição de $1 \%$ de Galato de Propila.

Tabela 35 - Comparação entre o tempo de resfriamento dos óleos de dendê aditivados com 1\% GP em todos os tempos de envelhecimento.

\begin{tabular}{lccc}
\hline $\begin{array}{l}\text { Tempo de } \\
\text { oxidação }\end{array}$ & $\begin{array}{c}\text { Tempo para } \\
\text { alcançar } 700{ }^{\circ} \mathrm{C}\end{array}$ & $\begin{array}{c}\text { Tempo para } \\
\text { alcançar } 300{ }^{\circ} \mathrm{C}\end{array}$ & $\begin{array}{c}\text { Tempo para } \\
\text { alcançar } 200{ }^{\circ} \mathrm{C}\end{array}$ \\
\hline $0 \mathrm{~h}$ & $7 \mathrm{~s}$ & $14 \mathrm{~s}$ & $21 \mathrm{~s}$ \\
$12 \mathrm{~h}$ & $6 \mathrm{~s}$ & $15 \mathrm{~s}$ & $31 \mathrm{~s}$ \\
$24 \mathrm{~h}$ & $6 \mathrm{~s}$ & $14 \mathrm{~s}$ & $28 \mathrm{~s}$ \\
$36 \mathrm{~h}$ & $6 \mathrm{~s}$ & $14 \mathrm{~s}$ & $27 \mathrm{~s}$ \\
$48 \mathrm{~h}$ & $6 \mathrm{~s}$ & $15 \mathrm{~s}$ & $32 \mathrm{~s}$ \\
$60 \mathrm{~h}$ & $6 \mathrm{~s}$ & $15 \mathrm{~s}$ & $32 \mathrm{~s}$ \\
\hline
\end{tabular}




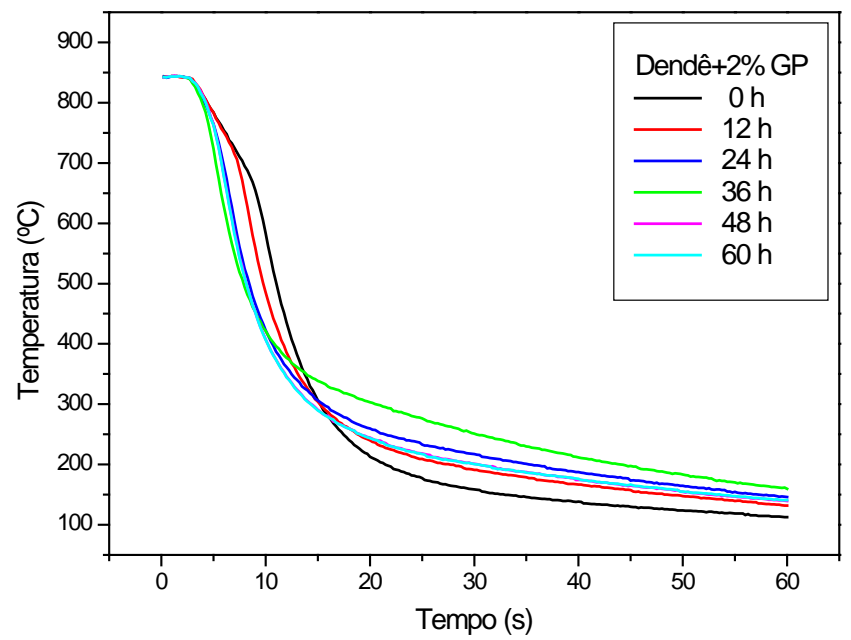

Figura 54 - Curvas de resfriamento, a $60^{\circ} \mathrm{C}$, relacionando temperatura por tempo para o óleo de dendê com adição de $2 \%$ de Galato de Propila.

Tabela 36 - Comparação entre o tempo de resfriamento dos óleos de dendê aditivados com $2 \%$ GP em todos os tempos de envelhecimento.

\begin{tabular}{lccc}
\hline $\begin{array}{l}\text { Tempo de } \\
\text { oxidação }\end{array}$ & $\begin{array}{c}\text { Tempo para } \\
\text { alcançar } 700{ }^{\circ} \mathrm{C}\end{array}$ & $\begin{array}{c}\text { Tempo para } \\
\text { alcançar } 300{ }^{\circ} \mathrm{C}\end{array}$ & $\begin{array}{c}\text { Tempo para } \\
\text { alcançar } 200{ }^{\circ} \mathrm{C}\end{array}$ \\
\hline $0 \mathrm{~h}$ & $8 \mathrm{~s}$ & $15 \mathrm{~s}$ & $21 \mathrm{~s}$ \\
$12 \mathrm{~h}$ & $7 \mathrm{~s}$ & $15 \mathrm{~s}$ & $27 \mathrm{~s}$ \\
$24 \mathrm{~h}$ & $6 \mathrm{~s}$ & $16 \mathrm{~s}$ & $32 \mathrm{~s}$ \\
$36 \mathrm{~h}$ & $5 \mathrm{~s}$ & $20 \mathrm{~s}$ & $44 \mathrm{~s}$ \\
$48 \mathrm{~h}$ & $6 \mathrm{~s}$ & $15 \mathrm{~s}$ & $30 \mathrm{~s}$ \\
$60 \mathrm{~h}$ & $6 \mathrm{~s}$ & $14 \mathrm{~s}$ & $30 \mathrm{~s}$ \\
\hline
\end{tabular}

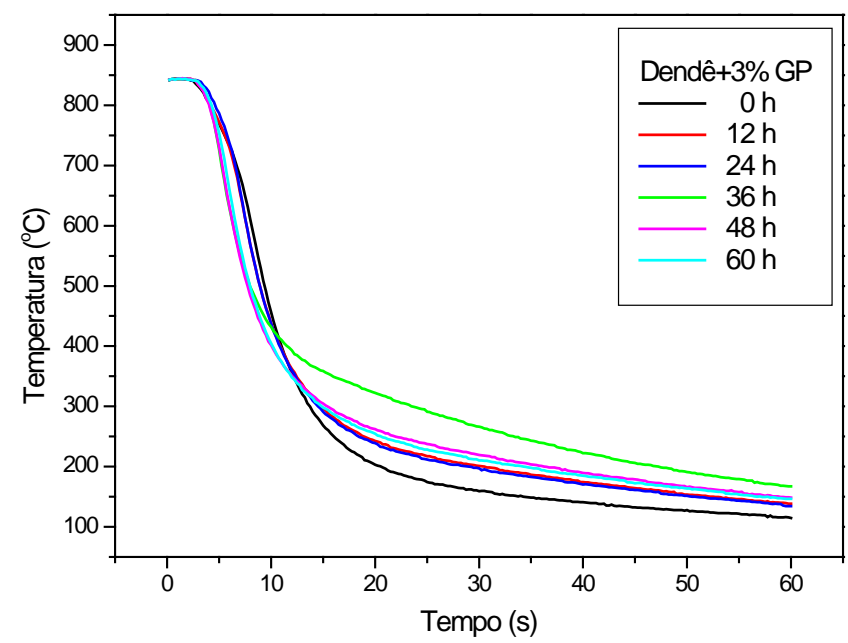

Figura 55 - Curvas de resfriamento, a $60^{\circ} \mathrm{C}$, relacionando temperatura por tempo para o óleo de dendê com adição de $3 \%$ de Galato de Propila. 
Tabela 37 - Comparação entre o tempo de resfriamento dos óleos de dendê aditivados com 3\% GP em todos os tempos de envelhecimento.

\begin{tabular}{lccc}
\hline $\begin{array}{l}\text { Tempo de } \\
\text { oxidação }\end{array}$ & $\begin{array}{c}\text { Tempo para } \\
\text { alcançar } 700{ }^{\circ} \mathrm{C}\end{array}$ & $\begin{array}{c}\text { Tempo para } \\
\text { alcançar } 300^{\circ} \mathrm{C}\end{array}$ & $\begin{array}{c}\text { Tempo para } \\
\text { alcançar } 200^{\circ} \mathrm{C}\end{array}$ \\
\hline $0 \mathrm{~h}$ & $7 \mathrm{~s}$ & $14 \mathrm{~s}$ & $21 \mathrm{~s}$ \\
$12 \mathrm{~h}$ & $6 \mathrm{~s}$ & $15 \mathrm{~s}$ & $30 \mathrm{~s}$ \\
$24 \mathrm{~h}$ & $7 \mathrm{~s}$ & $15 \mathrm{~s}$ & $29 \mathrm{~s}$ \\
$36 \mathrm{~h}$ & $5 \mathrm{~s}$ & $24 \mathrm{~s}$ & $47 \mathrm{~s}$ \\
$48 \mathrm{~h}$ & $5 \mathrm{~s}$ & $16 \mathrm{~s}$ & $36 \mathrm{~s}$ \\
$60 \mathrm{~h}$ & $6 \mathrm{~s}$ & $15 \mathrm{~s}$ & $34 \mathrm{~s}$ \\
\hline
\end{tabular}

Observando-se as Figuras de 53 a 55 verifica-se que para as curvas de resfriamento dos óleos oxidados, a formulação 1\% foi a mais estável, ou seja, apresentou menos alteração no comportamento das curvas. Na formulação com 2 \% um comportamento um pouco diferente foi notado: aparentemente há início da formação do primeiro estágio. Esse comportamento irregular aponta mais uma vez para a solubilidade do GP nos óleos vegetais, que deve estar em torno de $1 \%$.

\subsection{Comparação Entre os Óleos Utilizados na Têmpera}

A Figura 56 apresenta as curvas de resfriamento dos óleos utilizados na têmpera. Foram utilizados dois óleos minerais para comparação com o s óleos vegetais: o óleo mineral 1 corresponde a um óleo convencional e o óleo mineral 2 é um óleo rápido. 


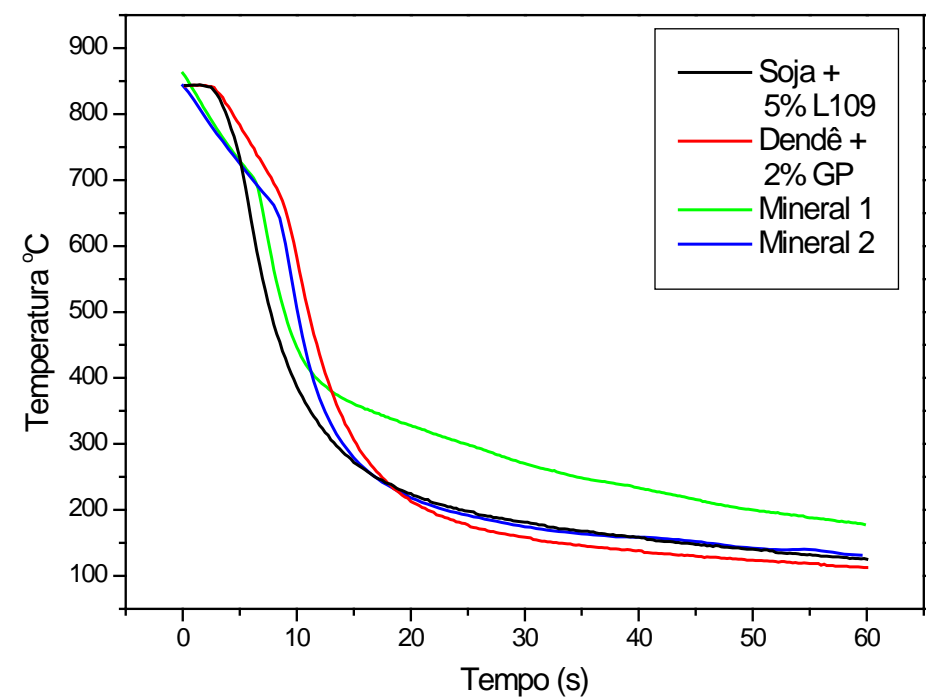

Figura 56 - Curvas de resfriamento, a $60^{\circ} \mathrm{C}$, relacionando temperatura por tempo para os óleos vegetais e minerais utilizados na têmpera.

Tabela 38 - Comparação entre o tempo de resfriamento dos óleos vegetais e minerais* utilizados na têmpera.

\begin{tabular}{lccc}
\hline Óleo & $\begin{array}{c}\text { Tempo para } \\
\text { alcançar } 700{ }^{\circ} \mathrm{C}\end{array}$ & $\begin{array}{c}\text { Tempo para } \\
\text { alcançar } 300{ }^{\circ} \mathrm{C}\end{array}$ & $\begin{array}{c}\text { Tempo para } \\
\text { alcançar 200 }{ }^{\circ} \mathrm{C}\end{array}$ \\
\hline Soja + 5\%L109 & $6 \mathrm{~s}$ & $13 \mathrm{~s}$ & $24 \mathrm{~s}$ \\
Dendê + 2\%GP & $8 \mathrm{~s}$ & $15 \mathrm{~s}$ & $21 \mathrm{~s}$ \\
Mineral 1 & $6 \mathrm{~s}$ & $24 \mathrm{~s}$ & $50 \mathrm{~s}$ \\
Mineral 2 & $6 \mathrm{~s}$ & $14 \mathrm{~s}$ & $23 \mathrm{~s}$ \\
\hline
\end{tabular}

Observando-se a Figura 56 verifica-se que diferentemente dos óleos vegetais, os minerais apresentam primeiro estágio bem definido, sendo menor para o mineral 2 que é um óleo "mais rápido". Pela Tabela 38 nota-se que, particularmente no tempo necessário para atingir $200{ }^{\circ} \mathrm{C}$, os óleos vegetais tem velocidades de resfriamento similares às do óleo Mineral 2.

\footnotetext{
* Óleos minerais 1 e 2 foram gentilmente cedidos pela empresa Quimifort.
} 


\subsection{Análise da Dureza e Estrutura das Peças Metálicas Temperadas}

A dureza Rockwell C dos aços temperados nos diferentes meios de resfriamento estudados é apresentada na Tabela 39.

Tabela 39 - Dureza Rockwell C dos aços temperados com os óleos vegetais e óleos minerais.

\begin{tabular}{lcccc}
\hline Óleo de têmpera & $\begin{array}{c}\text { Aço } \\
\text { AISI }\end{array}$ & $\begin{array}{c}\text { Diâmetro } \\
\text { (") }\end{array}$ & $\begin{array}{c}\text { Média centro } \\
\text { (Rockwell C) }\end{array}$ & $\begin{array}{c}\text { Média Superfície } \\
\text { (Rockwell C) }\end{array}$ \\
\hline Soja + 5\% L109 & 1045 & $1 / 2$ & $40,5 \pm 1,5$ & $50,9 \pm 1,3$ \\
Soja + 5\% L109 & 4140 & 1 & $41,7 \pm 0,6$ & $51,3 \pm 0,3$ \\
Soja + 5\% L109 & 4140 & $21 / 2$ & $41,8 \pm 1,8$ & $45,6 \pm 1,1$ \\
Dendê + 2\% GP & 1045 & $1 / 2$ & $41,1 \pm 1,2$ & $54,1 \pm 1,4$ \\
Dendê + 2\% GP & 4140 & 1 & $48,4 \pm 0,9$ & $63,3 \pm 0,2$ \\
Dendê + 2\% GP & 4140 & $21 / 2$ & $47,2 \pm 1,3$ & $53,8 \pm 0,5$ \\
Dendê + 2\% GP & 1045 & $1 / 2$ & $41,1 \pm 1,2$ & $54,1 \pm 1,4$ \\
Mineral 1 & 1045 & $1 / 2$ & $36,7 \pm 0,6$ & $41,4 \pm 0,1$ \\
Mineral 1 & 4140 & 1 & $35,6 \pm 3,2$ & $42,1 \pm 0,7$ \\
Mineral 1 & 4140 & $21 / 2$ & $32,8 \pm 0,4$ & $40,5 \pm 0,4$ \\
Mineral 2 & 1045 & $1 / 2$ & $38,6 \pm 0,5$ & $47,9 \pm 0,2$ \\
Mineral 2 & 4140 & 1 & $38,9 \pm 1,1$ & $50,4 \pm 0,3$ \\
Mineral 2 & 4140 & $21 / 2$ & $27,7 \pm 0,3$ & $30,3 \pm 0,4$ \\
\hline
\end{tabular}

As Figuras de 57 a 59 mostram os gráficos da dureza das peças metálicas temperadas com os óleos vegetais e minerais; na superfície, no centro e na superfície novamente.

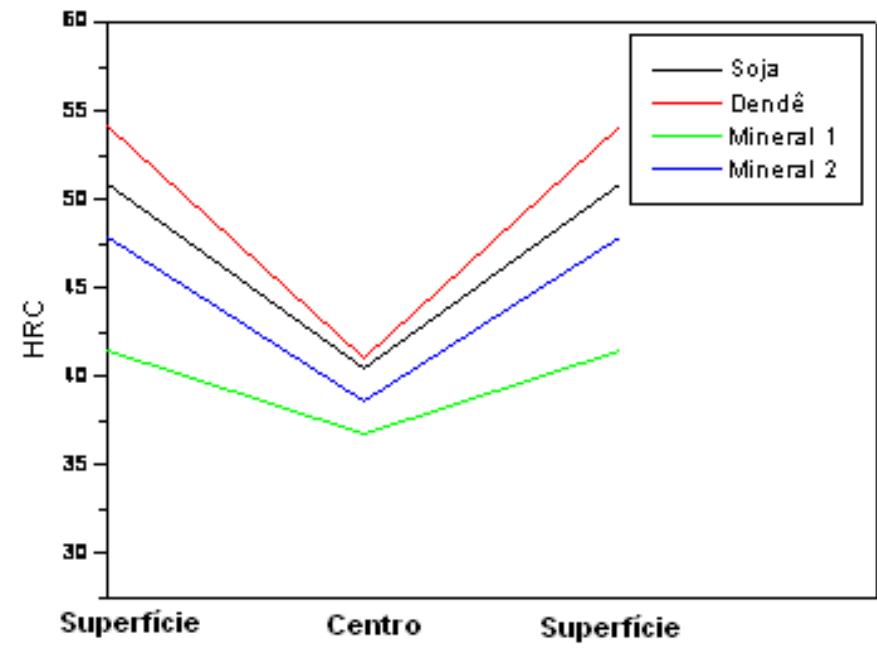

Figura 57 - Dureza Rockwell C, na superfície, centro e superfície, das amostras de aço AISI 1045 com $1 / 2$ " de diâmetro 
Verifica-se para o aço AISI 1045 com $1 \frac{1}{2}$ " de diâmetro a têmpera realizada com o óleo de dendê obteve maior dureza, seguido do óleo de soja e dos óleos minerais 2 e 1 respectivamente. O óleo de soja se apresenta mais lento (em relação ao tempo para alcançar $200{ }^{\circ} \mathrm{C}$ - Tabela 38) do que o óleo mineral 2, portanto esperava-se que a tempera do óleo de soja tivesse uma dureza maior. Entretanto o óleo mineral 2 ,diferentemente do óleo de soja, apresenta primeiro estágio o que explicaria essa diferença encontrada nos resultados.

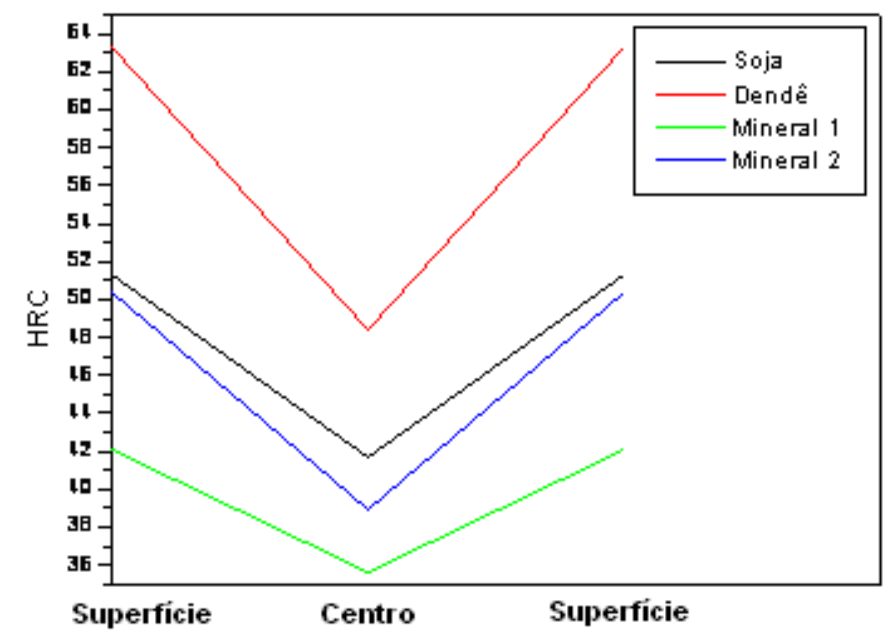

Figura 58 - Dureza Rockwell C, na superfície, centro e superfície, das amostras de aço AISI 4140 com 1 " de diâmetro.

Observando-se a Figura 58, nota-se que para o aço AISI 4140 com 1" de diâmetro foi mantido o que se obteve no aço AISI 1045 e por se tratar de um aço de maior temperabilidade, mas com diâmetro maior, os valores de durezas se distanciaram.

Considerações similares podem ser feitas com o aço AISI com $2 \frac{1 / 2}{\text { " de }}$ diâmetro, como se observa na Figura 59. 


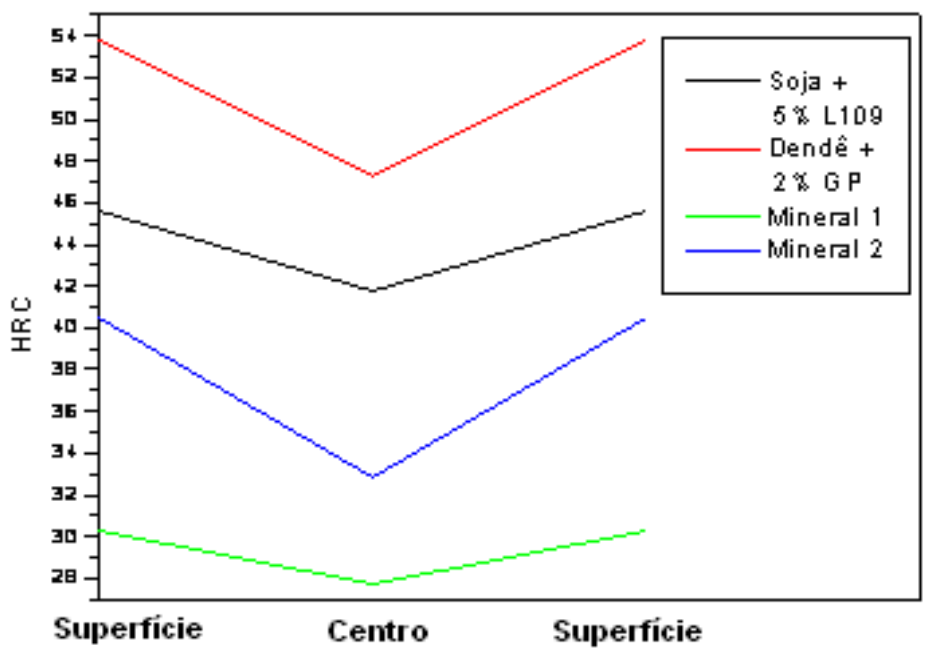

Figura 59 - Dureza Rockwell C, na superfície, centro e superfície, das amostras de aço AISI 4140 com 2 1⁄2" de diâmetro.

Entre os óleos utilizados como meios de têmpera o óleo de dendê + 2 \% GP foi o que mostrou maior capacidade de extração de calor das peças metálicas.

As microestruturas do aço AISI 1045 com $1 / 2$ " de diâmetro estão mostradas nas Figuras 60 e 61 e consistem basicamente de perlita fina e martensita.

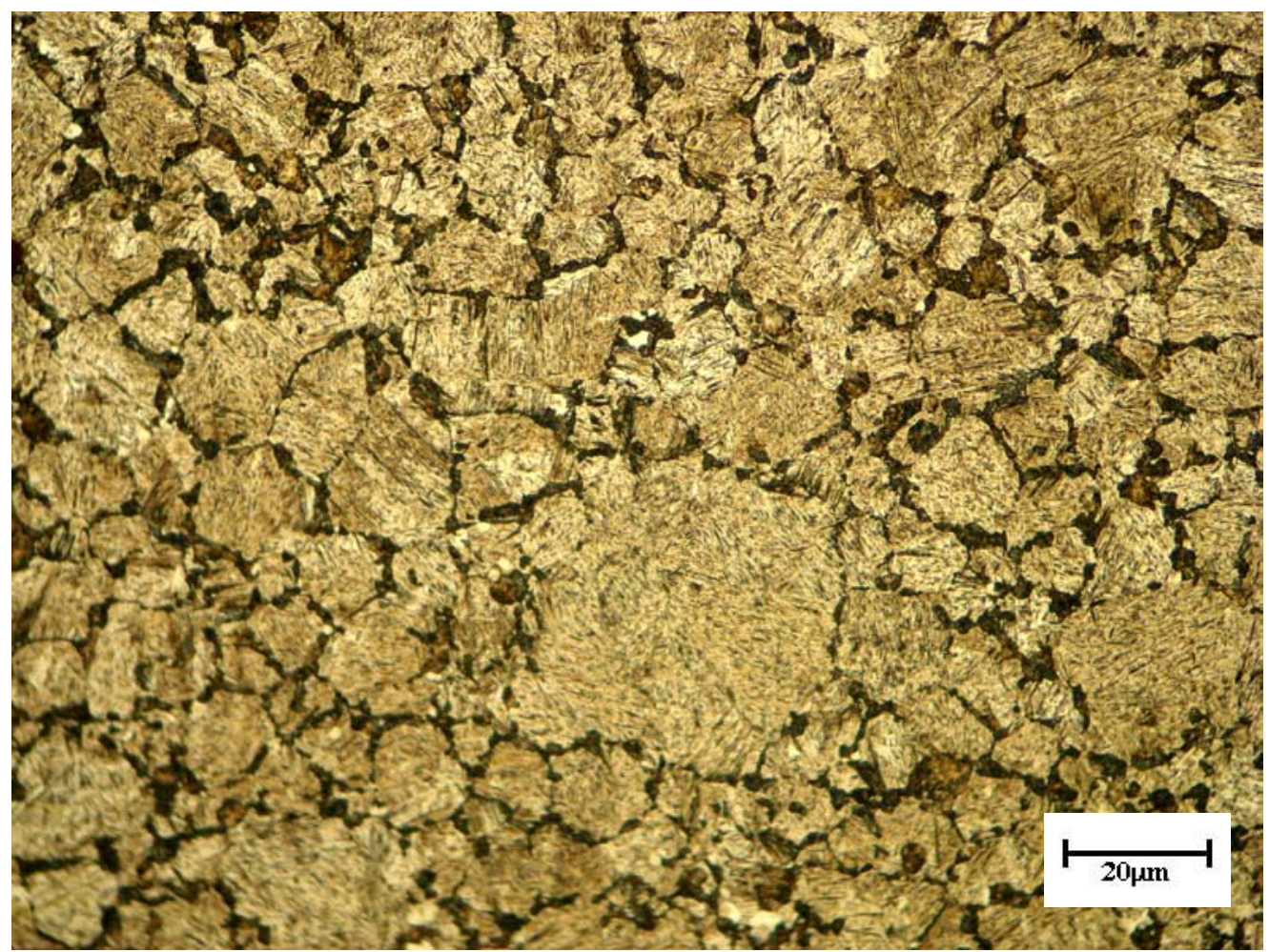

Figura 60 - Micrografia do aço AISI 1045 com $1 \frac{1}{2}$ " de diâmetro, resfriado com óleo de soja + 5\% L109. 


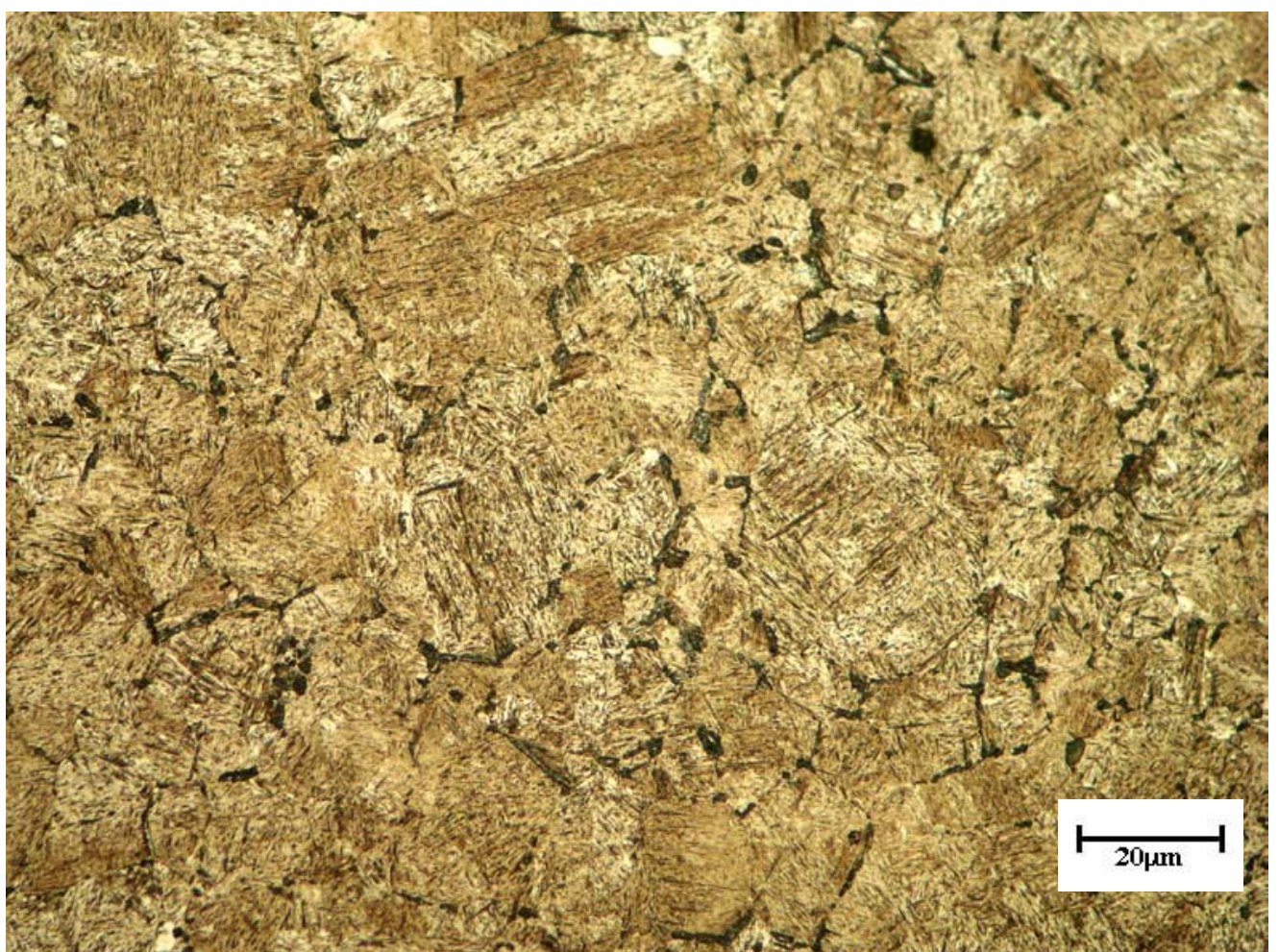

Figura 61 - Micrografia do aço AISI $1045 \mathrm{com} \mathrm{1/2}$ " de diâmetro, resfriado com óleo de dendê + $2 \%$ GP.

A Figura 60 (resfriamento em óleo de soja + 5 \% L109) mostra maior quantidade de perlita fina do que a Figura 61 (resfriamento em óleo de dendê + $2 \%$ GP), condizente com os valores de dureza da Figura 57. As microestruturas relativas aos óleos minerais são condizentes com os valores de dureza observados, ou seja, com quantidade de perlita fina maior que as amostras resfriadas com óleo de dendê e também maior do que as encontradas na têmpera com óleo de soja. O aspecto é semelhante às Figuras 60 e 61 apresentadas.

As Figuras 62 e 63 mostram as microestruturas de perlita fina e martensita correspondente de barras de aço AISI 4140 com 1 " de diâmetro resfriadas em óleo de Dendê + 2 \% GP e óleo Mineral 2. 


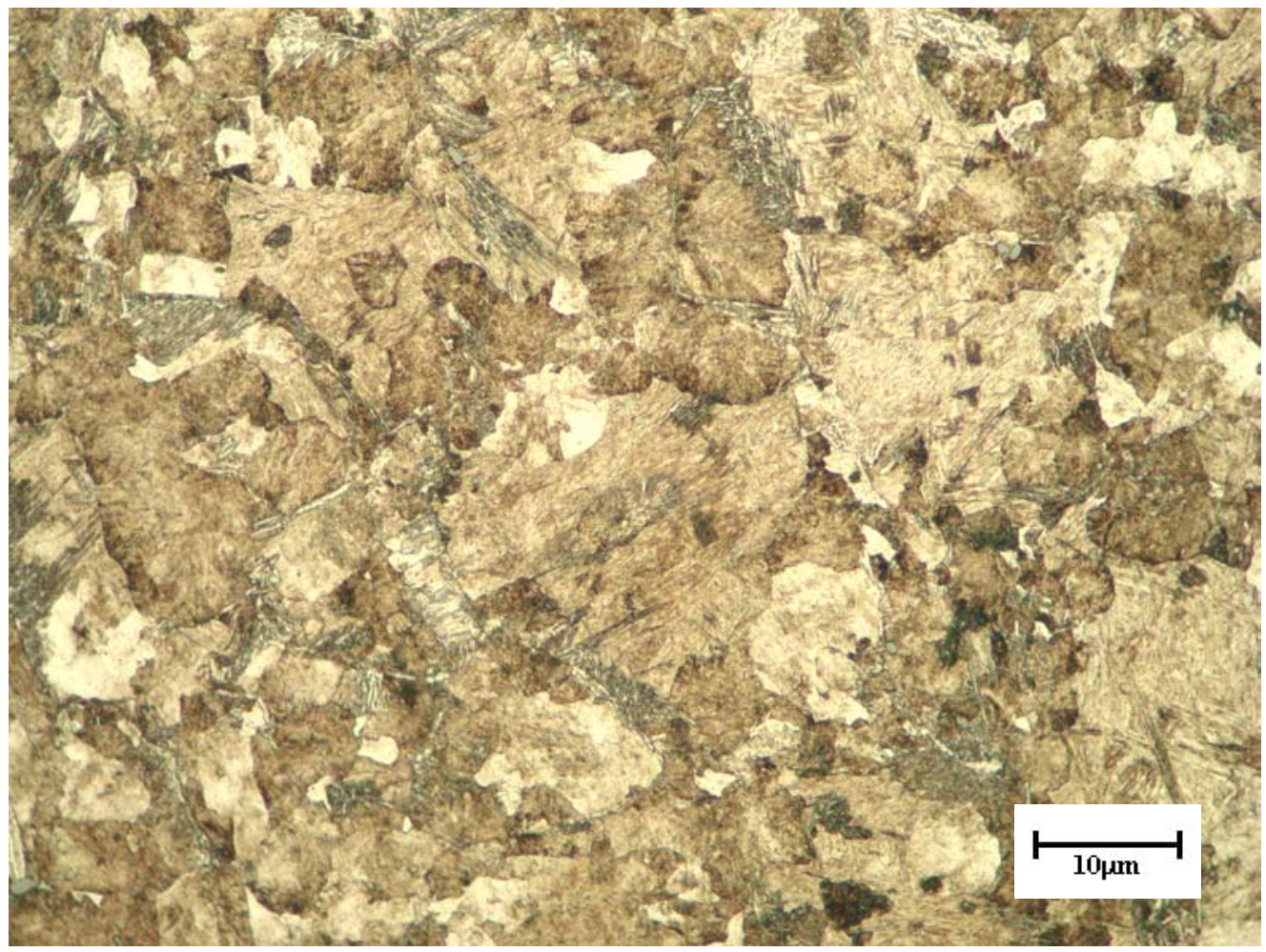

Figura 62 - Micrografia do aço AISI 4140 com 1 " de diâmetro, resfriado com óleo de dendê + $2 \%$ GP.

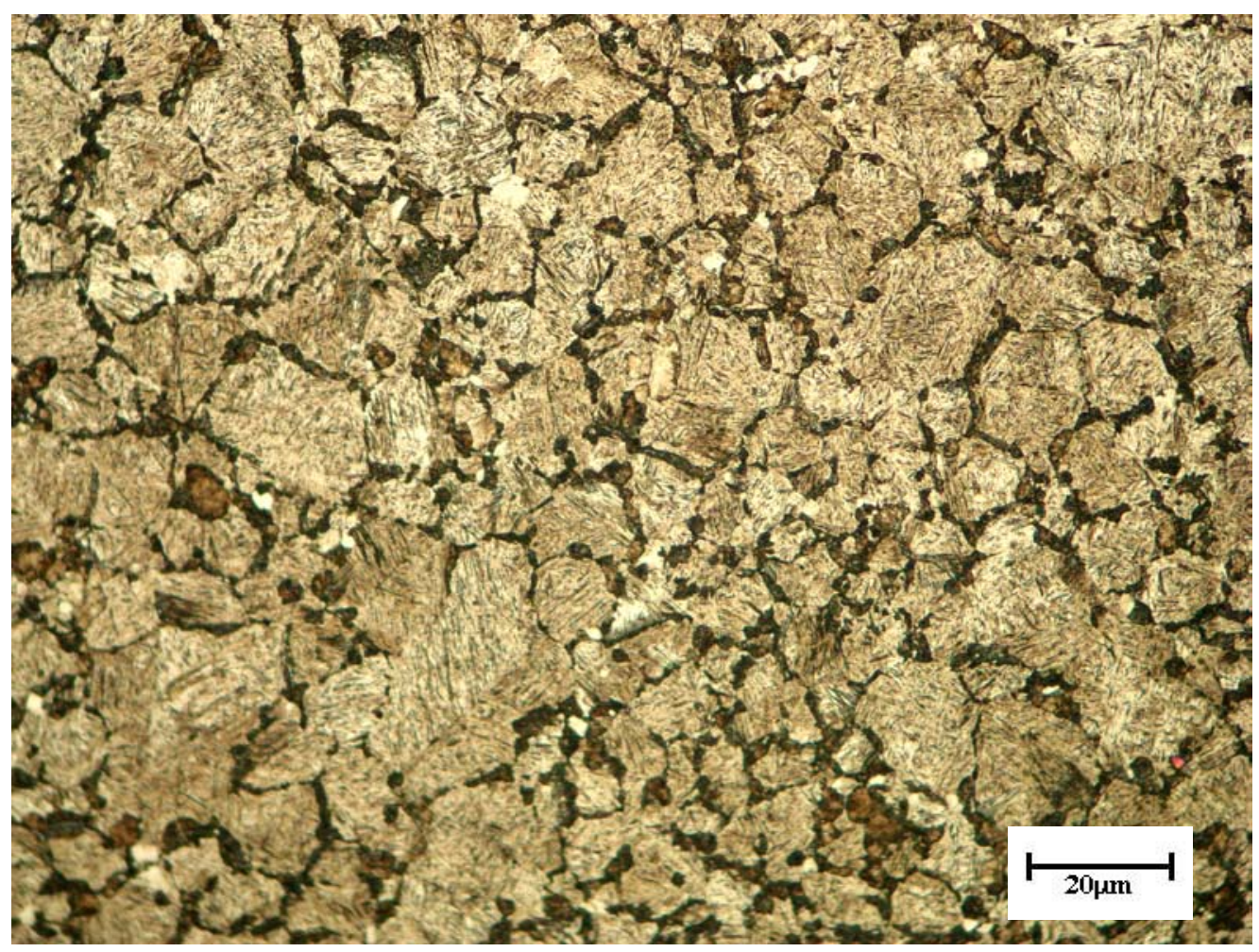

Figura 63 - Micrografia do aço AISI 4140 com 1 " de diâmetro, resfriado com óleo mineral 2. 
A Figura 62 mostra maior quantidade de martensita do que a Figura 63, indicando maior dureza da microestrutura da Figura 62, como relatado na Figura 58. As microestruturas correspondentes aos demais meios de resfriamento são também condizentes com os valores de dureza observados. Os aspectos microestruturais são similares aos aqui apresentados.

As micrografias das Figuras 64 e 65 são referentes às amostras de aço AISI 4140 de 2 1/2 " de diâmetro resfriadas em óleo de soja + 5 \% L109 e dendê + 2 \% $\mathrm{GP}$, respectivamente.

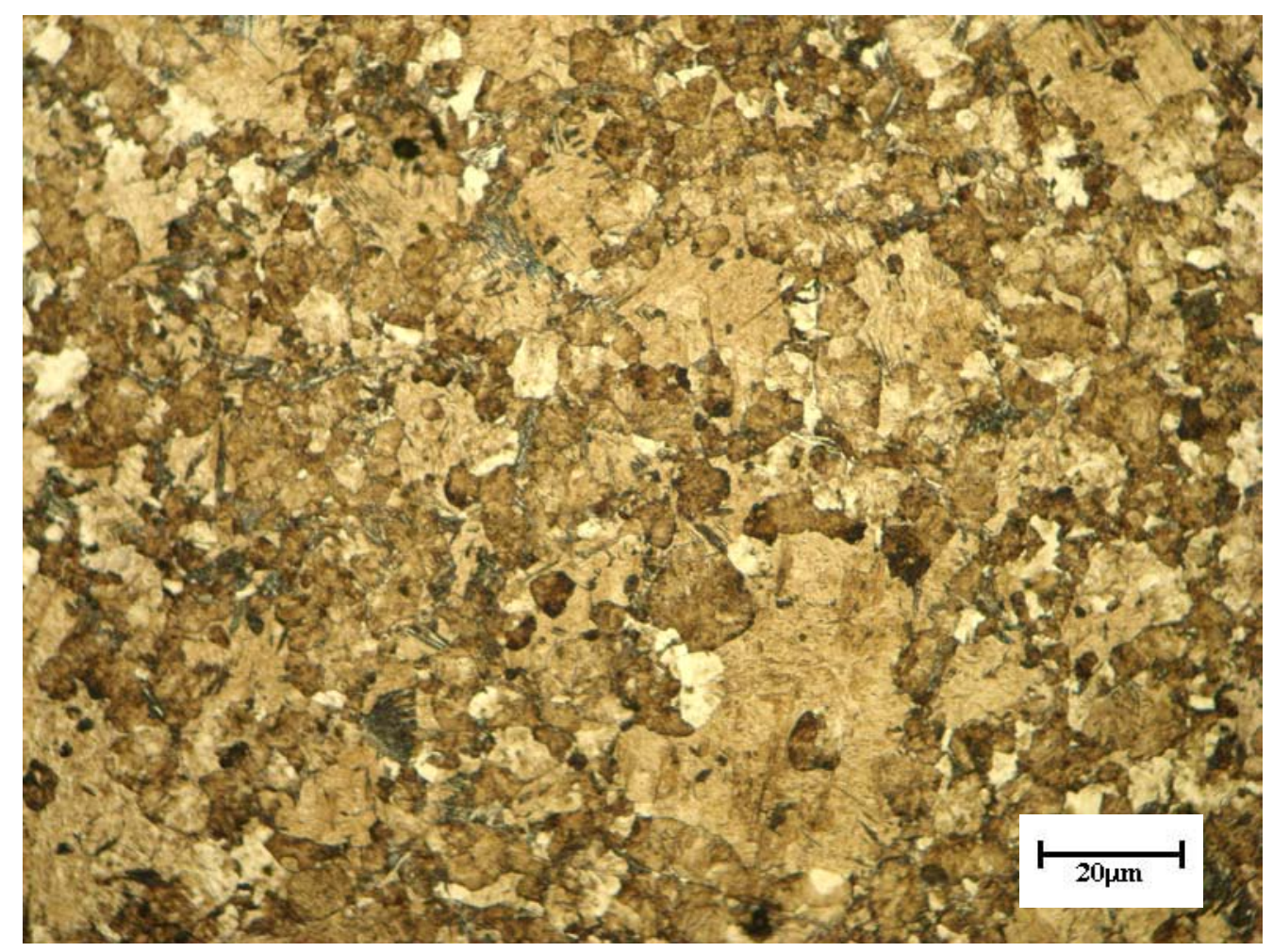

Figura 64 - Micrografia do aço AISI 4140 com $2 \frac{1}{2}$ " de diâmetro, resfriado com óleo de soja 5\% L109. 


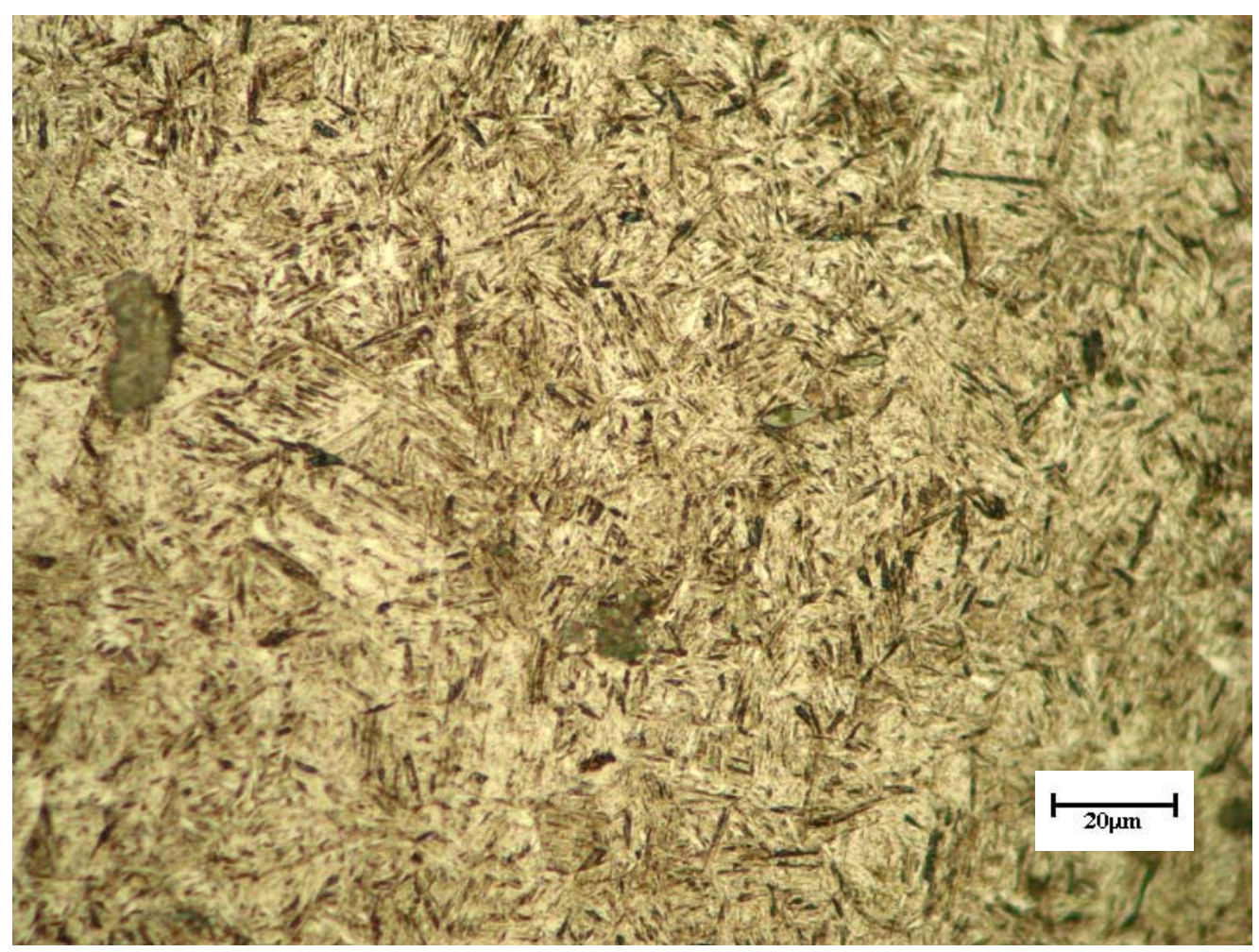

Figura 65 - Micrografia do aço AISI 4140 com $2 \frac{1}{2}$ " de diâmetro, resfriado com óleo de dendê + $2 \%$ GP.

As microestruturas mostram intensa modificação de predominantemente perlita fina (Figura 64) para predominantemente martensítica (Figura 65). Essas microestruturas explicariam as grandes variações de dureza encontradas na Figura 59. No caso dos óleos minerais, o desempenho em resfriamento foi ainda inferior aos óleos vegetais, mostrando valores de dureza bem baixos (Figura 59) correspondentes à estrutura perlítica. 


\section{CONCLUSÕES}

A partir dos ensaios de RMN, PDSC, viscosidade, pode-se dizer que o óleo de dendê apresentou características mais resistentes à oxidação do que o óleo de soja.

O antioxidante Irganox L109 obteve melhor desempenho quando adicionado ao óleo de soja, sendo que a melhor concentração em massa desse aditivo no óleo foi a de $5 \%$.

O antioxidante Galato de Propila apresentou melhor desempenho ao ser adicionado ao óleo de dendê, sendo que a melhor concentração em massa desse aditivo no óleo deve estar entre 1 e $2 \%$, pois acima dessa porcentagem o aditivo se torna insolúvel.

O antioxidante Bisfenol A foi o que apresentou comportamento mais estável em relação às curvas de resfriamento com os diferentes tempos de oxida;áo.

De maneira geral quanto mais oxidado se torna o óleo, menor é sua capacidade de resfriar.

O óleo de dendê + 2 \% GP mostrou maior capacidade de extração de calor das peças de aços nele temperadas do que os demais óleos estudados 


\section{SUGESTÕES PARA TRABALHOS FUTUROS}

Para trabalhos futuros propõem-se os seguintes itens:

Realizar os testes de oxidação a temperaturas mais baixas e tempos mais longos, para que se possam ver melhor as pequenas diferenças entre as composições de óleos e antioxidantes.

Verificar a solubilidade do antioxidante Irganox L109 no óleo de soja e estudar concentrações maiores desse antioxidante nesse óleo.

Verificar a solubilidade do antioxidante Galato de Propila nos óleos utilizados e estudar concentrações menores desse antioxidante nesse óleo.

Estudar outras formulações com os antioxidantes PANA e Bisfenol A em concentrações diferentes de $1 \%$, para o óleo de soja e outros óleos vegetais. 


\section{REFERÊNCIAS}

1 JONES, N. Managing used oil. Lubes 'n' Greases, v.2, n.6, p.20-21, 1996.

2 HENRY,J.A. Composition and toxicity of petroleum products and their additives. Human and Experimental Toxicology, v. 17, n. 2, p.111-123, 1998.

3 EICHENBERGER, H. F. Biodegradable hydraulic lubricant - an overview of current developments in central Europe. USA: SAE, 1991. (Technical Paper Series, n. 941759).

4 ERDMAN, K. D., KLING, G. H., THARP, D. E. High-performance biodegradable fluid requirements for mobile hydraulic systems. USA: SAE, 1998. (Technical Paper Series, n. 981518).

5 ROSE, B., HONARY, L. A report on the field test performance of a soybeanbased hydraulic oil. USA: SAE, 1998. (Technical Paper Series, n. 982005).

6 EMBRAPA, Empresa Brasileira de Pesquisa Agropecuária. Disponível em <http://www.cnpso.embrapa.br/producaosoja/tab/fig_0_3.htm>. Acesso em: 09 nov. 2009.

7 GUTIÉRREZ, L. F.; SÁNCHEZ, O. J.; CARDONA, C. A.; Process integration possibilities for biodiesel from palm oil using ethanol obtained from lignocellulosic residues of oil palm industry. Bioresource Technology, v. 100, p. 1227-1237, 2009.

8 KODALI, D. R. High performance ester lubricants from natural oils. Industrial Lubrication and Tribology, v. 54, n. 4, p.165-170, 2002.

9 TOTTEN, G. E; BATES, C. E; CLINTON, N. A.; Handbook of quenchants and quenching technology. Ohio: ASM International, 1993.

10 TENSI, H. M.; STICH, A.; TOTTEN, G. E. Fundamentals of quenching. Metal Heat Treating, p.20-28, Mar./Apr., 1995.

11 TOTTEN, G. E.; WEBSTER, G. M.; BLACKWOOD, R. R.; JARVIS, L. M.; NARUMI, T. Chute quench recommendations for continuous furnace applications with aqueous polymer quenchant. Heat Treatment of Metals, v.2, n.2, p. 36-39, 1996. 
12 TOTTEN, G. E.; ORSZAK, K. B.; JARVIS, L. M.; BLACKWOOD, R. R. How to effectively use polymer quenchants. Industrial Heating, v. 58, n. 10, p. 37-41, 1991.

13 BATES, C. E. Selecting quenchants to maximize tensile properties and minimize distortion in aluminum parts. Journal of Heat Treating, v. 5, n.1, p. 27-40, 1987.

14 TOTTEN, G. E.; LALLY, K. S. Proper agitation dictates quench success. Heat Treatment, v. 24, n. 9, p. 12-17, 1992.

15 TKACHUK, T. I.; SHEREMETA, B. K.; ORAZOVA, M. R. The state and prospects of devising quenching petroleum oils. Metal Science and Heat Treatment, v. 32, n. 6, p. 400-402, 1990.

16 HILDER, N. The behavior of polymer quenchants. 1988. Thesis (PhD) Department of Mechanical and Production Engineering, Aston University, Birmingham, 1988.

17 CALLISTER , W. D. JR., Ciência e engenharia de materiais: uma introdução, 7a ed. Utah: John Wiley \& Sons, 2008.

18 TOTTEN, G. E.; WESTBROOK, S. R.; SHAH, R. J. Fuels and lubricants handbook: technology, properties, performance, and testing. Ohio: ASTM International, 2003.

19 RAJAN, T.V.; SHARMA, A.; SHARMA C.P. Heat treatment, principles and techiniques. New Delhi: PHI, 1992. p.140 - 141.

20 CHANDLER, H. Heat treater's guide: practices and procedures for irons and steels. 2nd ed. Chicago: ASM International, 1995.

21 VONBERGEN, R.T. The effects of quenchant media selection and control on the distortion of engineered steel parts. Materials Science Forum, v. 163-165, p. 139150, 1994.

22 FARAH, A. F.; Caracterização de óleos vegetais como alternativa para meios de resfriamento utilizados no tratamento térmico de têmpera. 2002. Dissertação (Doutorado em Ciência e Engenharia de Materiais) - Escola de Engenharia de São Carlos, Instituto de Física de São Carlos, Instituto de Química de São Carlos, Universidade de São Paulo, São Carlos, 2002. 
23 AMERICAN SOCIETY FOR TESTING AND MATERIALS. ASTM D 6200-01: standard test method for determination of cooling characteristics of quench oils by cooling curve analysis. west Conshohocken. USA: ASTM International, 2007. 6 p.

24 PLACEK, D. G. The use of phosphate ester quench oils for improved antiwear properties and safety considerations. Lubrication Engineering, v. 51, n. 7, p. 611616, 1995.

25 BASHFORD, A.; MILLS, A. J. The development of improved additives for quenching oils using laboratory simulations. Heat Treatment of Metals, v.11, n.1, p.9-14, 1984.

26 BOYER, H. E.; CARY, P. R. Quenching and control of distortion. Ohio: ASM International, 1988. p.289.

27 CANALE, L. C. F. Estudos de sistemas laboratoriais de agitação para fluidos de têmpera. 1999. 63p. Tese (Livre Docência) - Departamento de Engenharia de Materiais, Aeronáutica e Automobilística da Escola de Engenharia de São Carlos, Universidade de São Paulo, 1999.

28 BRENNAN, R. J.; FAULKNER, C. H. A new quenching alternative. In: INTERNATIONAL CONFERENCE ON QUENCHING AND THE CONTROL OF DISTORTION, 2., 1996, Cleveland. Proceedings... Ohio: ASM International, 1996. p. 423-428.

29 TOTTEN, G. E.; KLING, G. H.; REICHEL, J. Biodegradable hydraulic fluids: A review, In: SCANDINAVIAN INTERNATIONAL CONFERENCE ON FLUID POWER, 6., May 25-28,1999, Tampere, Finland. Proceedings... Finland: Tampere Univ. of Tech., 1999.

30 CANALE, L. C. F.; FERNANDES, M. F.; AGUSTINHO, S. C. M.; TOTTEN, G. E.; FARAH, A. F. Oxidation of vegetable oils and its impact on quenching performance. International Journal Materials and Product Technology, v.24, p.101-124, 2005.

31 MOORE, D. Safer liquid quenchants. Heat Treatment Progress, v. 1, p. 29-33, 2001.

32 HONARY, L. A. T. Performance of vegetable oils as a heat treat quenchant. In: INTERNATIONAL CONFERENCE ON QUENCHING AND THE CONTROL OF DISTORTION, 2., 1996, Cleveland. Proceedings... Ohio: ASM International, 1996. p. 595-606. 
33 ASADAUSKAS, S.; PEREZ, J. M.; DUDA, J. L. Oxidative stability and antiwear properties of high oleic vegetable oils. Journal of the Society of Tribologists and Lubrication Engineers, v. 52, n. 12, p. 877-882, 1996.

34 MORETTO, E.; FETT, R.; GONZAGA, L. V. Introdução à ciência de alimentos. Florianópolis: Editora UFsc, 2002 . v.1, 255p.

35 GIESE, J. Fats, oils, and fat replacers. Food Technology - Especial Report, v.50, n.4, p.78-83, April, 1996.

36 MORETTO, E.; FETT, R. Tecnologia de óleos e gorduras vegetais na indústria de alimentos. São Paulo: Varela, 150p, 1998.

37 FARIA, E. A.; LELES, M. I. G.; IONASHIRO, M.; ZUPPA, T. O.; ANTONIOSI F., N. R. Estudo da estabilidade térmica de óleos e gorduras vegetais por TG/DTG e DTA, Eclética Química, São Paulo, v. 27, p.111-119, 2002.

38 ADHVARYU, A.; ERHAN, S. Z.; LIU, Z. S.; PEREZ, J. M. Oxidation kinetic studies of oils derived from unmodified and genetically modified vegetables using pressurized differential scanning calorimetry and nuclear magnetic resonance spectroscopy. Thermochimica Acta, n.364, p.87-97, 2000.

39 ADAMCZEWUSKA, J. Z.; WILSON, D. Development of ecologically responsive lubricants. Journal Synthetics Lubricants, v. 14, n. 2, p. 129-142, 1996.

40 DOMINGUES, R. F.; BIDOIA, E. D. Avaliação da biodegradação e do descarte de óleo lubrificante automotivo. Disponível em: <www.biologico.sp.gov.br/biologico/v68_supl_raib/318.PDF>. Acesso em: 3 mar. 2007.

41 HAROLD, S. Biodegradability: review of the current situation. Freedom CA: Lubrizol Corporation, 1993.

42 HELLíN, L. C.; CLAUSELL, M. P. R. Incidencia de la fritura en la composición de la fracción lipídica de diversos aperitivos de consumo generalizado en nuestro pais, Analises Bromatológicas, v.36, n.1, p.5-31, 1984.

43 SOUZA, A. G.; SANTOS, J. C. O., CONCEIÇÃO, M. M.; SILVA, M. C. D.; PRASAD, S. A Thermoanalytic and kinetic study of sunflower oil. Brazilian Journal of Chemical Engineering, v.21, n.2, p.265-273, April - June, 2004. 
44 MEASURING rancidity in fats and oils. N.PAL - Analytical Laboratories. Disponível em:

<http://www.ralstonanalytical.com/\%5CFileUploads\%5CInformation\%5CQuality\%20

of\%20Fats\%20and\%20Oils\%2002.pdf>. Acesso em: 20 jun. 2007.

45 GATTO, V. J.; MOEHLE, W. E.; COBB, T. W.; SCHNELLER, E. R. Oxidation fundamentals and its application to turbine oil testing. Journal of ASTM International, v.3, n.4, April, 2006.doi:10.1520/JAl13498.

46 BARROS, A. M. C. Rancidez oxidativa e antioxidantes. Disponível em:

<http://www.socil.com.br/coelhos/salatecnica_antioxidantes>. Acesso em: 6 nov. 2009.

47 CHASAN, D. E. Oxidative stabilization of natural oils: technical development manager additives for lubricants. Ardsley, NY: Ciba Additives, 1994.

48 SANTOS, J. C.; SANTOS, I. M. G.; CONCEIÇÃO, M. M.; PORTO, S. L.; TRINDADE, M. F. S.; SOUZA, A. G.; PRASAD, S.; FERNANDES JUNIOR., V. J.; ARAÚJO, A.S. Thermoanalytical, kinetic and rheological parameters of commercial edible vegetable oils. Journal of Thermal Analysis and Calorimetry, v.75, p.419428, 2004.

49 AZEREDO, H. M. C.; FARIA, J. A. F.; SILVA, M. A. A. P. Minimization of peroxide formation rate in soybean oil by antioxidant combinations. Food Research International, v.37, p.689-694, 2004.

50 SILVA, F. A. M.; BORGES, M. F. M; FERREIRA, M. A. Métodos para avaliação do grau de oxidação lipídica e da capacidade antioxidante. Química Nova, São Paulo, v.22, n.1, jan. /fev., 1999.

51 LEMAR, R. L. Effects of thermal degradation on the lubrication properties of fluids. USA: American Society of Lubrication Engineers, 1967. Preprint Number 67AM 7B-2.

52 WIKIPÉDIA, a enciclopédia livre. Disponível em: <http://pt.wikipedia.org/wiki/antioxidantes>. Acesso em: 9 nov. 2009.

53 GLANCEY, J. L.; KNOWLTON, S.; BENSON, E. R. Development of a high oleic soybean oil-based hydraulic fluid. Milwaukee: SAE, September, 1998. Technical Paper Series, number 981999. 
54 HONARY, L.; BOECKENSTEDT, R. Making a case for soy-based lubricants. Lubrication Engineering, v.54, n.7, p.18-20, 1998.

55 OHKAWA, S. et al. Oxidation and corrosion characteristics of vegetable-base biodegradable hydraulic oils. Detroid: SAE, April, 1995. Technical Paper Series, number 951038.

56 GRUPP, V. H. Biologisch abbaubare schmierstoffe: Eine kritische durchsicht der literatur und betreibserfahrungen. VGB Kraftwerkstechnik, v.77, n.1, p.56-60, 1997.

57 REMMELMANN, A.; MURRENHOFF, H. Environmentally acceptable hydraulic pressure media: new changes for mobile hydraulics. Detroid: SAE, April 1998. Technical Paper Series, number 981515.

58 TUMBRICK, M. B. Fluid care as a tool to improve the life time of biodegradable fluids in mobile hydraulic vehicles. Peoria: SAE, April 1998. Technical Paper Series, number 981499.

59 REDA, S. Y. Estudo comparativo de óleos vegetais submetidos a estresse térmico. 2004. Dissertação (Mestrado em Ciência e Tecnologia de Alimentos) Universidade Estadual de Ponta Grossa, Ponta Grossa, 2004.

60 MANNINA, L.; SOBOLEV, A. P.; SEGRE, A. Olive oil as seen by NMR and chemometrics. Spectrocopy Europe, v. 15, n.3, p.6-14, 2003.

61 HASSEL, R.L. Thermal analisys: an alternative method of measuring oil stability. Journal American oil chemistry society, v. 53, p. 179-181,1976.

62 DUNN, R. O. Analisys of oxidative stability of methil soyate by pressurized differential scanning calorimetry. Transactions of the ASAE, v. 43, n 5, p. 12031208., 2000.

63 KAUFMAN, R. E. e RHINE, W.E. Development of a reimaning useful life of a lubricant evaluation techinique. Part 1: differential scanning calorimetry techiniques. Lubrication Engineering, v. 44, n 2, p. 154-161,1976..

64 ZEMAN, A.; SPRENGEL, A.; NIEDERMEIER, D.; SPÄTH, M. Biodegradable lubricants - studies on thermo - oxidation of metal - working and hidraulics fluids by differential scanning calorimetry (DSC). Thermochimica Acta, v. 268, p. 9-15.,1995. 
65 BLAINE, R.L.; RIGA, A.T. Recertification of the polyethylene oxidation induction time reference material. Thermochimica Acta, v. 399, n .1, p. 209-212, 2003.

66 LANÇAS,F.M. Cromatografia em fase gasosa. São Carlos: Acta Eventos, 1993.

67 LEE, C.S.; OOI, T.L.; CHUAN, C.H.; AHMAD, S. Systhesis of palm oil-based diethanolamides. Jounal of American Oil Chemistry Society, v.84, p. 945-952, 2007.

68 TOTTEN, G. E.; WEBSTER, G. M.; ULISSES, C. Chemistry of quenching. In: CONGRESSO INTERNATIONAL DE TECNOLOGIA METALURGICA E DE MATERIAIS, 49, 1994, São Carlos. Anais... São Paulo: Associação brasileira de metais. 1994. p.242-253.

69 TENSI, H. M.; STICH, A. Characterization of polymer quenchants. Heat Treating Technology, v.25, n.5, p.25-29, May, 1993.

70 CANALE, L. C. F.; CRNKOVIC, O. R. Característica de resfriamento de soluções de polímero para tempera. Heat Treatment Technology, v.52, n.455, p.411-415, 1996.

71 IGWE, I. O. The effects of temperature on the viscosity of vegetable oils in solution. Industrial Crops and Products, n.19, p.185-190, 2004.

72 SOUZA, E.C. Estudo da oxidação do óleo de soja com diferentes concentrações de aditivos anti-oxidantes, para uso em tratamentos térmicos de têmpera. 2007. 160p. Dissertação (Mestrado em Ciência e Engenharia de Materiais) - Instituto de química de São Carlos, Instituto de física de São Carlos, Escola de engenharia de São Carlos, Universidade de São Paulo, São Carlos, 2007.

73 ASSOCIAÇÃO BRASILEIRA DE NORMAS TÉCNICAS. NBR 10441 - 10/02. Produtos de petróleo - Líquidos transparentes e opacos - Determinação da viscosidade cinemática e cálculo da viscosidade dinâmica. Rio de Janeiro: 2002.

74 BODIN, J.; SEGERBERG, S. Measurement and evaluation of the power of quenching media for hardening. Heat Treatment of Metals, v.20, n.1, p.15-23, 1993. 
75 AMERICAN SOCIETY FOR TESTING AND MATERIALS. E 140 - 07: standard hardness conversion tables for metals relationship among brinell hardness, vickers hardness, rockwell hardness, superficial hardness, knoop hardness, and scleroscope hardness. USA: ASTM International, 2007.

76 BRISCOE, B. J.; LUCKHAM, P.F.; REN, S.R. An assessment of a rolling-ball viscometer for studying non-Newtonian fluids. Colloids and Surfaces, v.62, p.153162, 1992. 